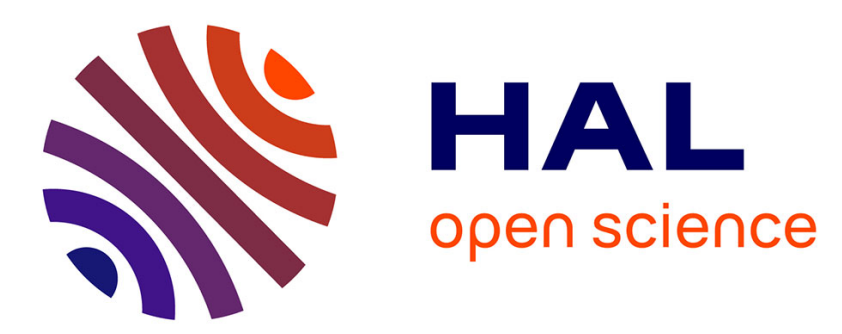

\title{
Recent advances on naphthalic anhydrides and 1,8-naphthalimide-based photoinitiators of polymerization
}

Guillaume Noirbent, Frederic Dumur

\section{- To cite this version:}

Guillaume Noirbent, Frederic Dumur. Recent advances on naphthalic anhydrides and 1,8naphthalimide-based photoinitiators of polymerization. European Polymer Journal, 2020, 132, pp.109702. 10.1016/j.eurpolymj.2020.109702 . hal-02866904

\section{HAL Id: hal-02866904 https://hal.science/hal-02866904}

Submitted on 1 Jul 2020

HAL is a multi-disciplinary open access archive for the deposit and dissemination of scientific research documents, whether they are published or not. The documents may come from teaching and research institutions in France or abroad, or from public or private research centers.
L'archive ouverte pluridisciplinaire HAL, est destinée au dépôt et à la diffusion de documents scientifiques de niveau recherche, publiés ou non, émanant des établissements d'enseignement et de recherche français ou étrangers, des laboratoires publics ou privés. 


\section{Journal Pre-proofs}

Recent Advances on Naphthalic Anhydrides and 1,8-Naphthalimide-Based Photoinitiators of Polymerization

Guillaume Noirbent, Frédéric Dumur

PII:

S0014-3057(20)30783-7

DOI: https://doi.org/10.1016/j.eurpolymj.2020.109702

Reference: EPJ 109702

To appear in:

European Polymer Journal

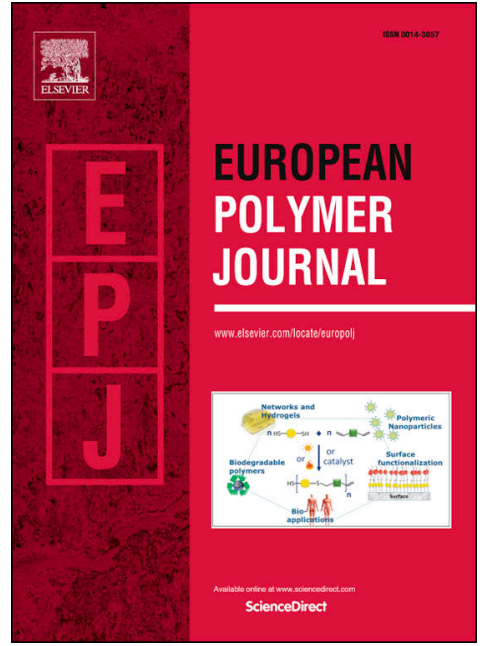

Received Date: $\quad 28$ March 2020

Revised Date: $\quad 14$ April 2020

Accepted Date: $\quad 16$ April 2020

Please cite this article as: Noirbent, G., Dumur, F., Recent Advances on Naphthalic Anhydrides and 1,8Naphthalimide-Based Photoinitiators of Polymerization, European Polymer Journal (2020), doi: https://doi.org/ 10.1016/j.eurpolymj.2020.109702

This is a PDF file of an article that has undergone enhancements after acceptance, such as the addition of a cover page and metadata, and formatting for readability, but it is not yet the definitive version of record. This version will undergo additional copyediting, typesetting and review before it is published in its final form, but we are providing this version to give early visibility of the article. Please note that, during the production process, errors may be discovered which could affect the content, and all legal disclaimers that apply to the journal pertain.

(c) 2020 Elsevier Ltd. All rights reserved. 


\title{
Recent Advances on Naphthalic Anhydrides and 1,8-Naphthalimide-Based Photoinitiators of Polymerization
}

\author{
Guillaume Noirbent,* Frédéric Dumur* \\ Aix Marseille Univ, CNRS, ICR, UMR 7273, F-13397 Marseille - France \\ Guillaume.noirbent@univ-amu.fr, Frederic.dumur@univ-amu.fr
}

\begin{abstract}
The design of photoinitiators of polymerization is an active research field and the development of initiators activable in the visible range and under low light intensity have been the focus of numerous research efforts from both the academic and industrial communities. Recently, two families of polyaromatic compounds, i.e. 1,8-naphthalic anhydride and naphthalimides, have been extensively studied by different research groups due to their easiness of synthesis and the possibility to easily tune the photophysical properties. Especially, panchromatic, crosslinkable or water-soluble photoinitiators could be easily developed starting from the benchmark and cheap 1,8-naphthalic anhydride. In this review, an overview of the different photoinitiators based on naphthalic anhydride or the naphthalimide scaffold is presented. Based on the diversity of structures reported in the literature, a structureperformance relationship could be established in this review.
\end{abstract}

\section{Keywords}

Photoinitiator; naphthalimide; naphthalic anhydride, photopolymerization; LED; visible light; low light intensity; panchromatic; water-soluble

\section{Introduction}

Photopolymerization which consists in converting a liquid resin into a solid polymer film upon exposure to a light source offers many striking advantages compared to the traditional thermal polymerization. Among the most interesting features, an efficient spatial and temporal control can be obtained, enabling to elaborate complex structures.[1-4] No workup following the polymerization process is also necessary. A fast polymerization process can also be obtained, outperforming from this viewpoint the traditional thermal polymerization which requires hours to produce the targeted polymers and a subsequent treatment to isolate the polymers in pure form. (See Figure 1).[5,6] As the last advantage, 
photopolymerization can be carried out in solvent-free conditions drastically limiting the release of volatile organic compounds (VOCs).[7-9] Benefiting from these different advantages, application of photopolymerization which was initially limited to coatings and adhesives[10,11] has recently been extended to emerging research fields such as 3D and 4Dprinting [12-15] and high-tech applications.[16] The access to thick and filled samples is also possible thank to the recent development of new photoinitiating systems operating in the visible range and even in the near infrared region.[3,17-21]

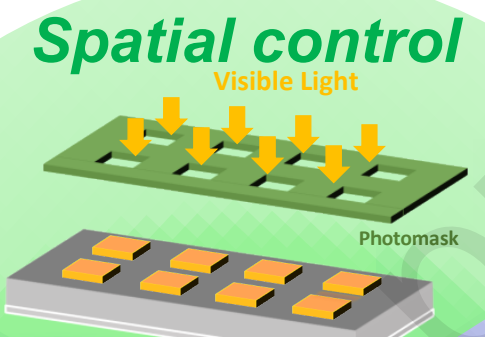

\section{Photopolymerization} Main characteristics

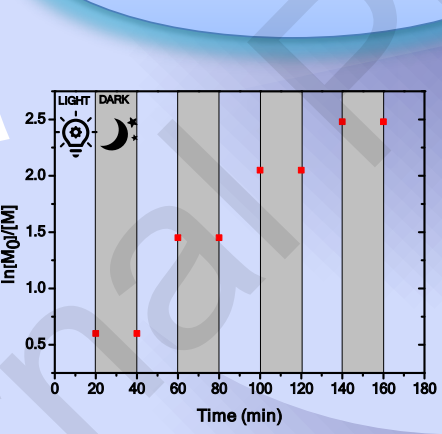

Temporal control

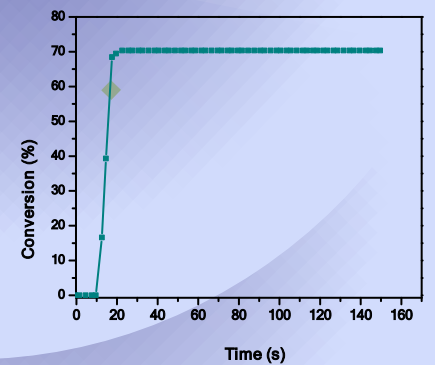

Remarkable kinetics

Figure 1. The different specificities of photopolymerization.

Concerning this last point, light penetration inside the photocurable resin is the keypoint to efficiently initiate a polymerization process. As evidenced in the Figure 2 , if the light penetration is limited to $600 \mu \mathrm{m}$ at $400 \mathrm{~nm}$ in a polystyrene latex, this latter can reach 5 $\mathrm{cm}$ for an irradiation at $800 \mathrm{~nm} .[22]$ 


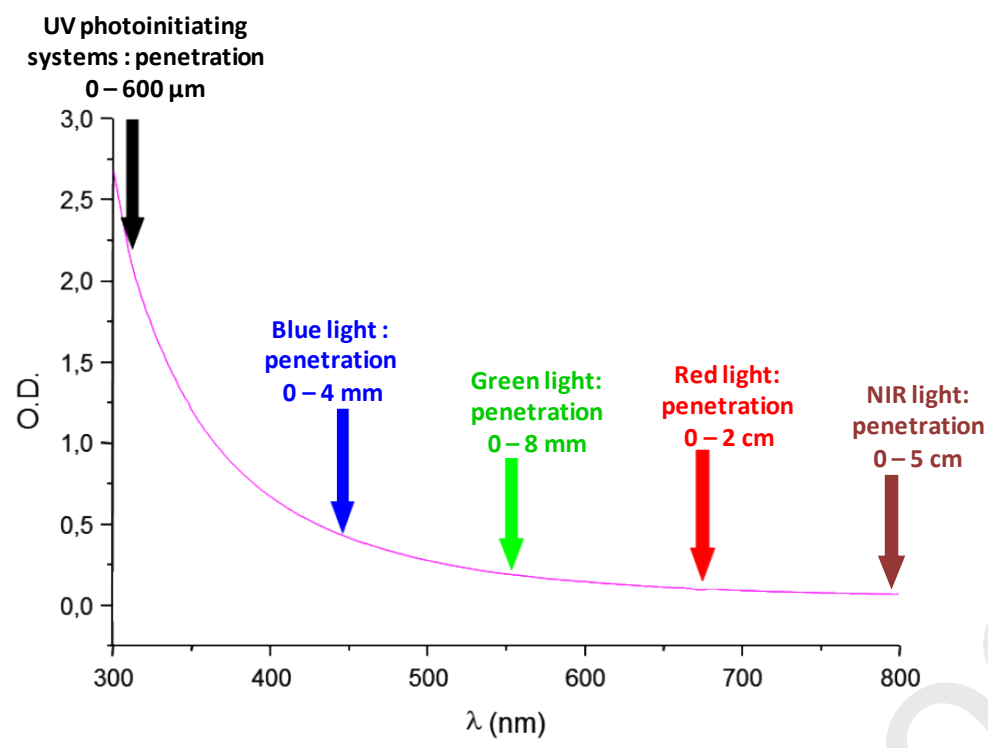

Figure 2. Light penetration inside a polystyrene latex with an average diameter of $112 \mathrm{~nm}$. Reproduced with permission from Bonardi et al. [22]. Copyright 2018 American Chemical Society.

However, it has to be noticed that the light penetration is dependent of the selected resin but also of the overall formulations so that this curve should be determined for each new formulation. Indeed, light penetration inside a resin can be affected by multiple parameters. Thus, the turbidity, the refractive index of the liquid resin, the solubility of the different additives in resins, the molar extinction coefficient of the photosensitizer that can impede light penetration by acting as an internal filter, but also the ability of the different components to induce light scattering (especially if one of the component is partially dissolved) govern the light penetration inside the samples. Besides, if the light penetration can varied from a resin to another one, visible light resins remains appealing candidates for photopolymerization so that a great deal of efforts has been devoted by photopolymerists to develop such photoinitiating systems. In this field, photoinitiators that can be activated under low light intensity and in the visible range remains still scarce and only few families have been studied to date (see Scheme 1). 


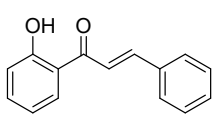

chalcone 1<smiles></smiles>

bodipy 5

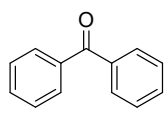

benzophenone 10

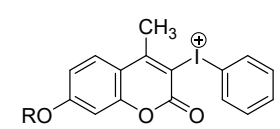

iodonium salts 2

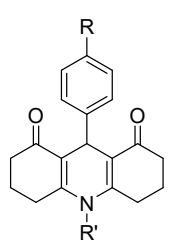

acridine-1,8-dione 3

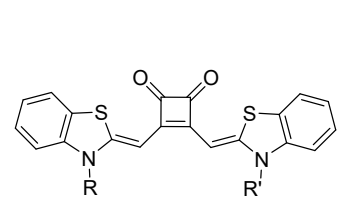

squaraines 4

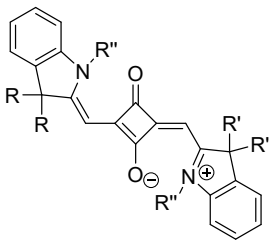

es 4

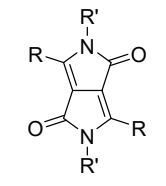

diketopyrrolopyrrole 6

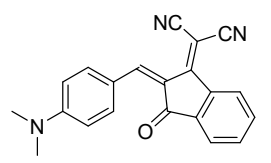

push-pull dyes 11

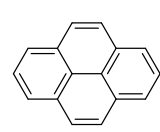

pyrene 7

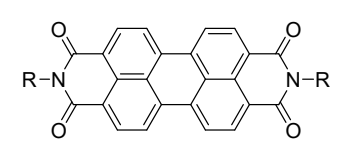

perylene 8

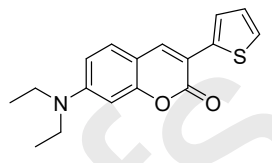

coumarine 9
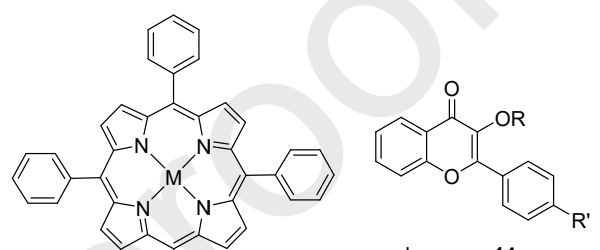

dihydroxyanthraquinone 12

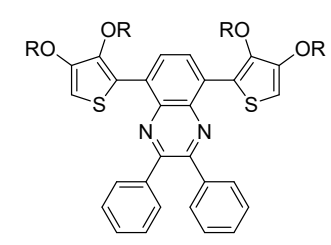

2,3-diphenylquinoxaline derivatives 15

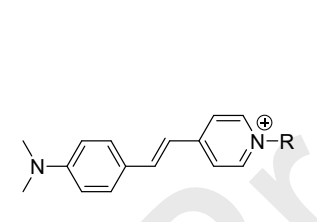

Pyridinium derivatives 16

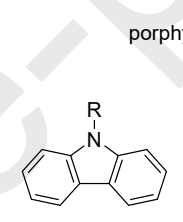

Carbazole 17

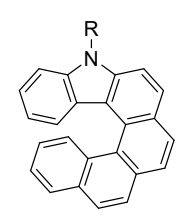

helicenes 18
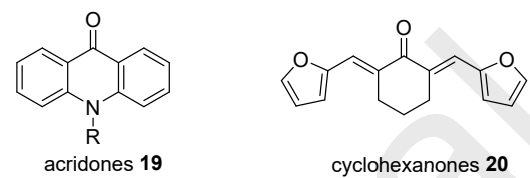

cyclohexanones 20

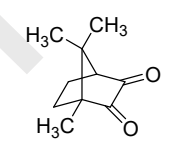

camphorquinones 21

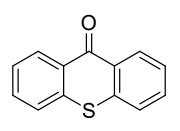

thioxanthones 22
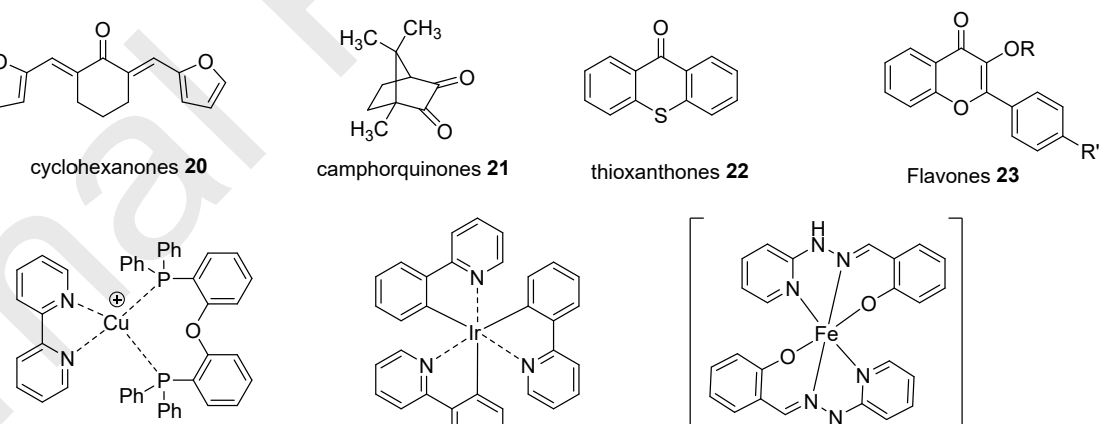

Copper complexes 24

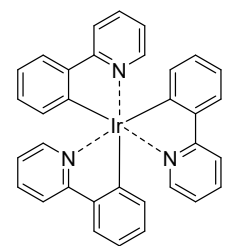

Iridium complexes $\mathbf{2 5}$

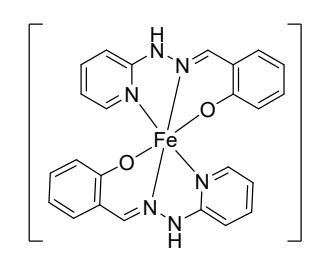

Iron complexes 26

Scheme 1. Examples of twenty-six families of visible light photoinitiators recently reported in the literature.

Among all visible light photoinitiators reported in the literature, chalcones,[23] iodonium salts,[24-26] acridine-1,8-dione,[27,28] squaraines, porphyrins and bodipys,[29,30] push-pull dyes,[31-38] dihydroanthraquinone,[39] chromones,[40,41] 2,3diphenylquinoxaline derivatives,[42] pyridinium salts,[43] carbazoles,[44-49] helicenes,[50,51] acridones,[52,53] cyclohexanones,[54-56] camphorquinones,[57,58] thioxanthones,[61,62] flavones,[63] ferrocenes,[24,64] copper,[32,65-75] iridium [76-81] and 
iron[81-86] complexes can be cited as the most widely studied. Interest for visible light sources over the traditional UV light commonly used in industry is supported by the safety concerns raised by the harmful effects of ultraviolet radiations (skin and eyes damage).[87-90] Considering that the easiness of synthesis, the high reaction yields, the photochemical and thermal stability are crucial parameters considered by industrials, two families of interest i.e. the 1,8-naphthalimides and the naphthalic anhydrides have emerged starting from 2014 as two promising families of molecules for the design of photoinitiators activable under low light intensity and in the visible range. More precisely, the possibility to finely tune the absorption properties of 1,8-naphthalimides and naphthalic anhydrides by various chemical modifications made these structures, versatile candidates for photoinitiation between 400 and $600 \mathrm{~nm}$ (See Figure 3).

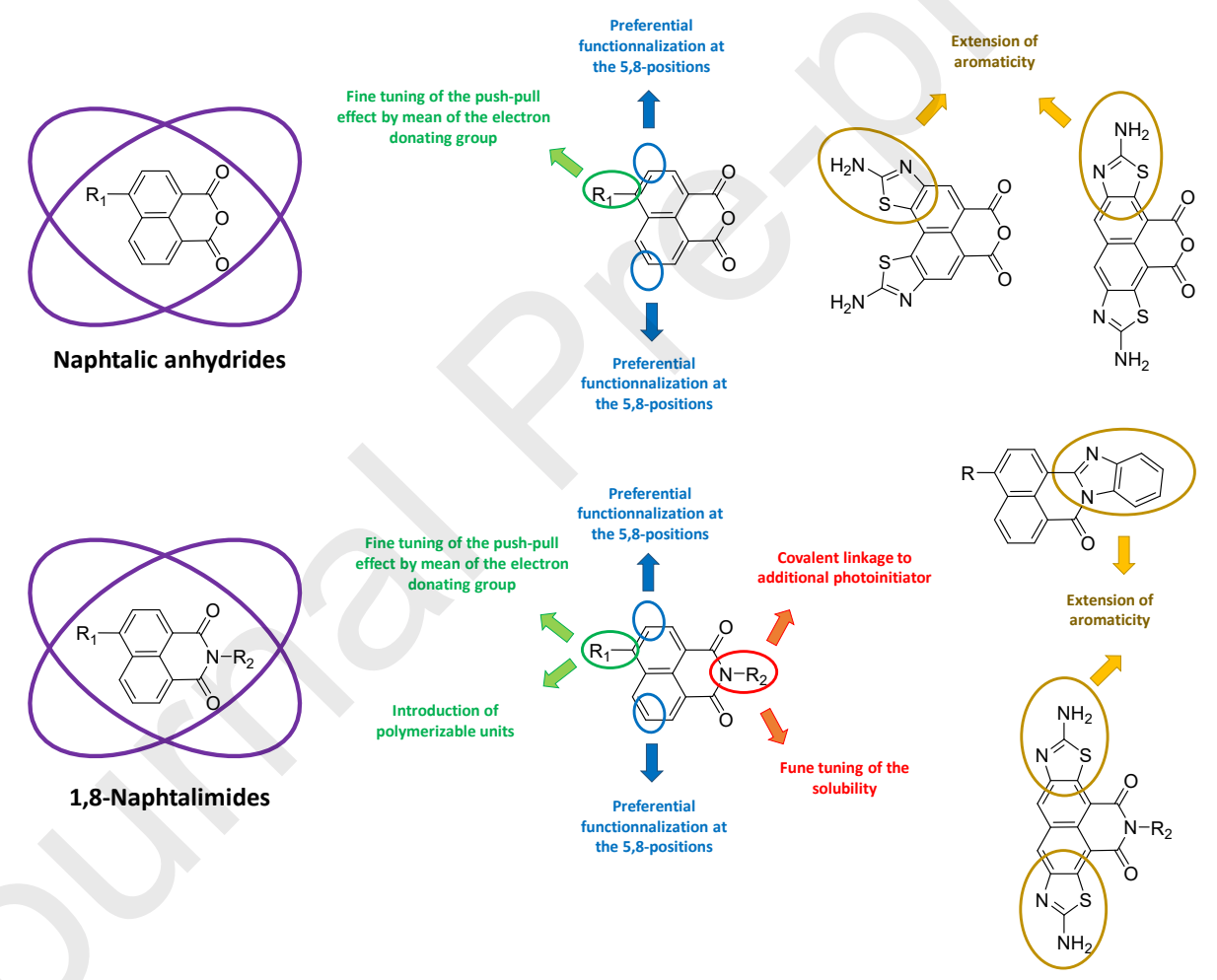

Figure 3. The different chemical modifications enabling to finely tune the optical properties of 1,8-naphthalimides and naphthalic anhydrides.

Notably, by chemical engineering, the solubility, the polyaromaticity or the fine tuning of the photophysical properties by modification of the substitution pattern of the naphthalene core could be carried out. In this review, an overview of the different naphthalimides and naphthalic anhydrides-based photoinitiators reported to date are presented. Based on the diversity of structures described in the literature (around 80 structures), numerous 
naphthalimides and naphthalic anhydride derivatives have been examined as photoinitiators of polymerization over the years, enabling to establish a structure-performance relationship.

\section{Naphthalic anhydrides as photoinitiators of polymerization}

\subsection{Substitution at the 6-position.}

Naphthalic anhydrides are extremely robust structures that have notably been examined for their photophysical properties,[91-93] as singlet emitters from Organic LightEmitting Diodes (OLEDs),[94] as monomers for the elaboration of proton exchange membranes[95] or as fluorescent probes for cells imaging.[96] Concerning photopolymerization, the first use of a naphthalic anhydride derivative as photoinitiator of polymerization was reported in 2014 with NAPHT-1.[97] By introducing a piperidinyl group at the 6-position of the naphthalic anhydride core, an absorption extending from 350 to $550 \mathrm{~nm}$ could be obtained, making NAPHT-1 an excellent candidate for photopolymerization carried out at $405 \mathrm{~nm}$, corresponding presently to the wavelength under use in 3D printers.[98-100] When used in combination with an iodonium salt (lod), $N$-vinylcarbazole (NVK), an amine (MDEA) or a triazine $(\mathrm{R}-\mathrm{Cl})$, the resulting photoinitiating systems could efficiently promote various types of photopolymerizations, including the free radical polymerization (FRP) of (meth)acrylates (TMPTA), the cationic polymerization (CP) or the free radical promoted cationic polymerization (FRPCP) of epoxides (EPOX) and vinylether monomers (DVE-3), the dual cure of acrylate/epoxide (TMPTA/EPOX) blends or the thiol-ene (trithiol/DVE-3) photopolymerization (see Scheme 2).

Considering the broadness of the absorption spectrum, photopolymerization with a halogen lamp (12 mW/cm², emission between 380 and $800 \mathrm{~nm}$ ) or laser diodes emitting at $405 \mathrm{~nm}\left(110 \mathrm{~mW} / \mathrm{cm}^{2}\right), 457 \mathrm{~nm}\left(100 \mathrm{~mW} / \mathrm{cm}^{2}\right)$ and $462 \mathrm{~nm}\left(10 \mathrm{~mW} / \mathrm{m}^{2}\right)$ could be efficiently initiated with regards to the outstanding molar extinction coefficients of NAPHT-1 at these specific wavelengths $\left(9700,4100\right.$ and $3400 \mathrm{M}^{-1} \cdot \mathrm{cm}^{-1}$ at 405,457 and $462 \mathrm{~nm}$ respectively), resulting from an efficient charge transfer between the piperidinyl group and the anhydride moiety. One of the keypoint to create an efficient photoinitiating system is the interaction rate constant between the iodonium salt and the photosensitizer, the iodonium salt being unable to absorb in the visible range. 


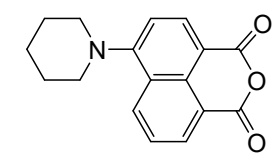

NAPHT-1

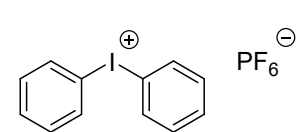

lod

$\mathrm{HO}_{\mathrm{I}} \sim \mathrm{OH}$
MDEA

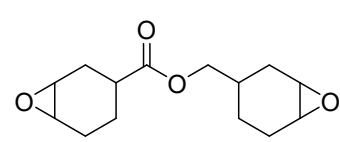

EPOX

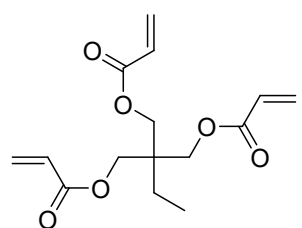

TMPTA<smiles>C=Cn1c2ccccc2c2ccccc21</smiles>

NVK<smiles>C=COCC(C)OC=C</smiles>

DVE-3<smiles>CCC(COC(=O)CCS)(COC(=O)CCS)COC(=O)CCS</smiles>

trithiol

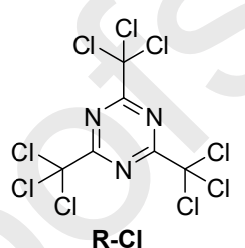

Scheme 2. Chemical structures of NAPHT-1 and the different monomers and additives.

In the case of NAPHT-1, a rate constant of interaction of $5.4 \times 10^{9} \mathrm{M}^{-1} \cdot \mathrm{s}^{-1}$ was determined by fluorescence quenching experiments for the NAPHT-1/lod system, evidencing the electron transfer to be diffusion-controlled. The free energy changes $(\Delta G)$ for the ${ }^{1}$ NAPHT$1 /$ lod electron transfer reactions was highly negative so that the singlet route was determined as being the main route to produce radicals, according to the following equations $r 1-r 3$ :

$$
\begin{gathered}
\text { NAPHT }-\mathbf{1} \rightarrow \mathbf{1}_{\text {NAPHT }-1}(h v) \\
\mathbf{1}_{\text {NAPHT }-1}+P h_{2} I^{+} \rightarrow \text { NAPHT }-\mathbf{1}^{\bullet+}+P h_{2} I^{\bullet} \\
P h_{2} I^{\bullet} \rightarrow P h^{\bullet}+P h-I
\end{gathered}
$$

These results were confirmed by steady state photolysis experiments, a fast decrease of the absorption being observed for the NAPHT-1/lod system upon irradiation with a halogen lamp (12 mW/cm², emission between 380 and $800 \mathrm{~nm}$ ) (See Figure 4). Especially, the presence of an isobestic point also confirmed that no side-reaction occurred during photolysis. The remarkable photoinitiating ability of NAPHT-1 was evidenced during the CP of EPOX, a final monomer conversion of $57 \%$ being obtained for the two-component system NAPHT-1/lod $(0.5 \% / 2 \%, w / w)$ upon irradiation with a halogen lamp. Use of a three-component system 
NAPHT-1/lod/NVK $(0.5 \% / 2 \% / 3 \%, \mathrm{w} / \mathrm{w} / \mathrm{w})$ did not enhance the final monomer conversion, still peaking at $77 \%$ after $800 \mathrm{~s}$ of irradiation, attesting of the high reactivity of NAPHT-1 ${ }^{\bullet+}$.
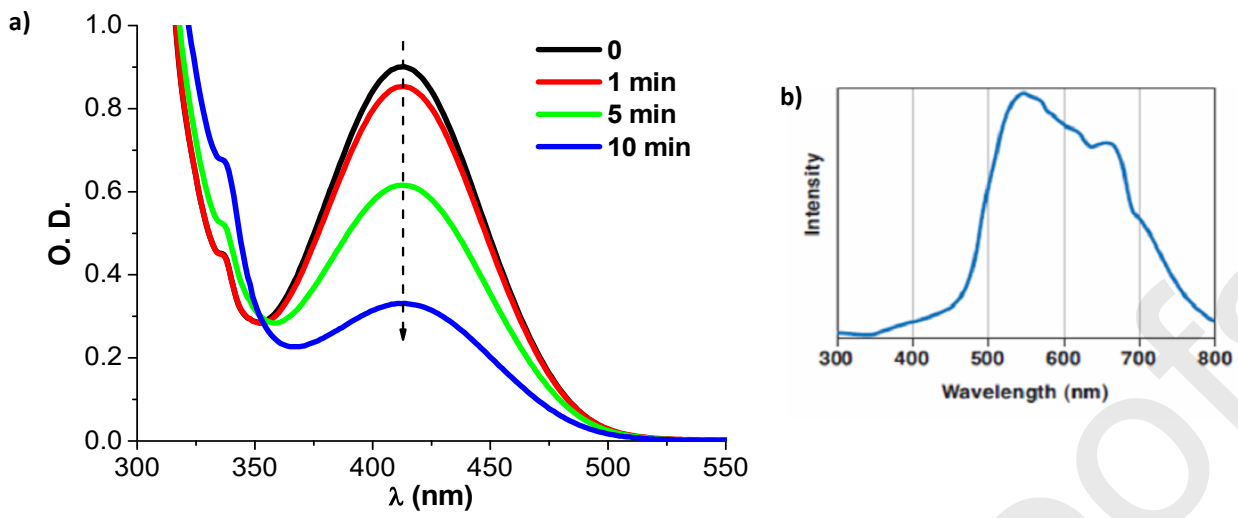

Figure 4. a) Steady state photolysis of NAPHT-1/lod in acetonitrile upon irradiation with a halogen lamp b) emission spectrum of the halogen lamp. Reproduced with permission from Xiao et al. [97]. Copyright 2014 American Chemical Society.

Indeed, generally, an improvement of the final monomer conversion is observed upon addition of NVK, generating the more reactive radical $\mathrm{Ph}-\mathrm{NVK}^{\bullet}$ capable to reduce the oxidized photosensitizer and produce the highly reactive $\mathrm{Ph}-\mathrm{NVK}^{+}$according to the mechanism proposed in the Figure 5.[101]

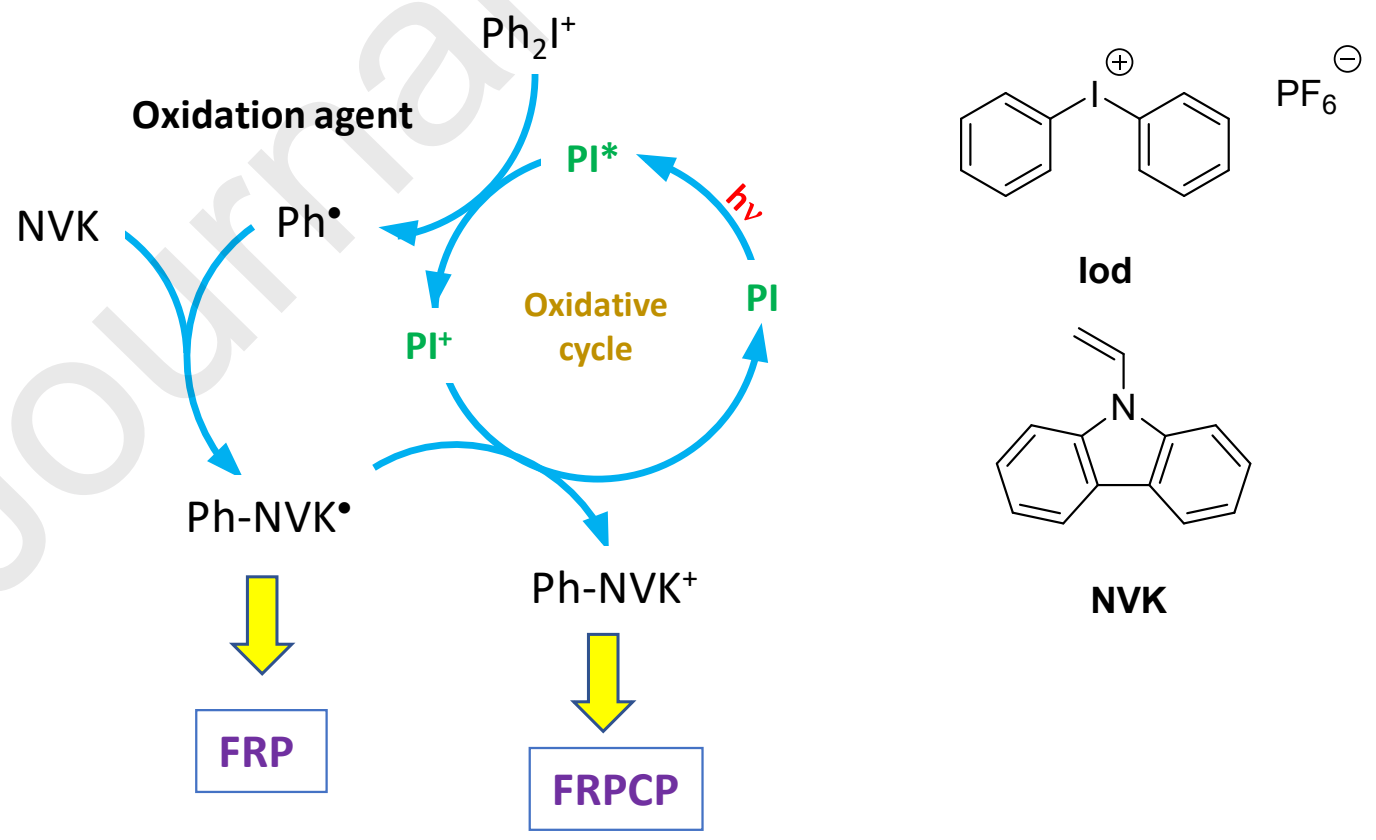

Figure 5. Oxidative catalytic cycle capable to form the highly reactive cationic species $\mathrm{Ph}$ - 
High final monomer conversions of 62 and $73 \%$ were also attained with the threecomponent system NAPHT-1/lod/NVK $(0.5 \% / 2 \% / 3 \%, \mathrm{w} / \mathrm{w} / \mathrm{w})$ upon irradiation with a laser diode emitting at $457 \mathrm{~nm}\left(100 \mathrm{~mW} / \mathrm{cm}^{2}\right)$ and a LED bulb emitting at $462 \mathrm{~nm}\left(10 \mathrm{~mW} / \mathrm{cm}^{2}\right)$ respectively. While examining the performance obtained during the FRP of TMPTA, almost similar results were obtained with the three-component systems NAPHT-1/lod/NVK $(0.5 \% / 2 \% / 3 \%, w / w / w)$ or NAPHT-1/MDEA/R-Cl $(0.5 \% / 2 \% / 1 \%, w / w / w)$, since final monomer conversions of 57 and $51 \%$ were respectively obtained upon irradiation with a laser diode at $457 \mathrm{~nm}$ for $400 \mathrm{~s}$ in laminate. Comparison with reference systems such as camphorquinone (CQ)/lod $(0.5 \% / 2 \%, w / w)$ or camphorquinone (CQ)/MDEA $(0.5 \% / 2 \%, w / w)$ revealed these two photoinitiating systems to provide lower final conversions, peaking respectively at 35 and $46 \%$ in the same conditions. It has to be noticed that comparisons have been established with camphorquinone which is one of the rare benchmark photoinitiators exhibiting an absorption in the visible range.[102-109] The remarkable efficiency of the reductive cycle involved in the three-component system NAPHT-1/MDEA/R-Cl $(0.5 \% / 2 \% / 1 \%, \mathrm{w} / \mathrm{w} / \mathrm{w})$ can be explained on the basis of the equations $r 4-r 8$, producing the two initiating species $\mathrm{R}^{\bullet} \bullet$ and $\operatorname{MDEA}_{(-\mathrm{H})} \bullet$.

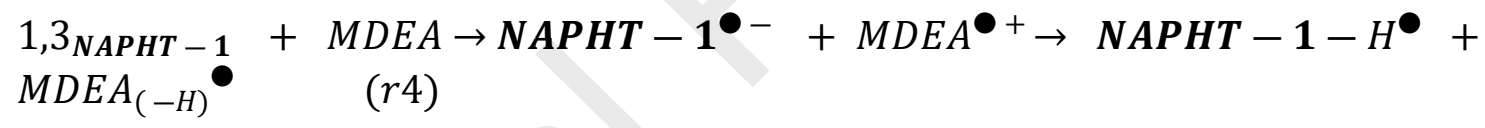

$$
\begin{aligned}
& \text { NAPHT }-\mathbf{1}+R^{\prime}-C l \rightarrow N A P H T-\mathbf{1}^{\bullet+}+\left(R^{\prime}-C l\right)^{\bullet-} \\
& \text { NAPHT }-\mathbf{1}-H^{\bullet}+R^{\prime}-C l \rightarrow \text { NAPHT }-\mathbf{1}+H^{+}+\left(R^{\prime}-C l\right)^{\bullet-}(r 6) \\
& \text { NAPHT }-\mathbf{1}^{\bullet-}+R^{\prime}-C l \rightarrow \mathbf{N A P H T}-\mathbf{1}+\left(R^{\prime}-C l\right)^{\bullet-}(r 7) \\
& \left(R^{\prime}-C l\right)^{\bullet-} \rightarrow R^{\prime \bullet}+C l^{-}(r 8)
\end{aligned}
$$

Possibility to polymerize methacrylates was also examined with a representative resin, namely the bisphenol A-glycidyl methacrylate (BISGMA)/triethylene-glycol-dimethacrylate (TEGDMA) (70\%/30\%) blend which is a resin commonly used in dentistry.[110-112] Final monomer conversions of $40 \%$ was determined after $200 \mathrm{~s}$ of irradiation with a blue LED under air. As shown in the Figure 5, the simultaneous generation of $\mathrm{Ph}-\mathrm{NVK}^{\bullet}$ and $\mathrm{Ph}-\mathrm{NVK}^{+}$allows the concomitant polymerization of an epoxide and an acrylate and the formation of interpenetrated polymer network (IPN). Comparison of the final monomer conversions obtained in laminate and under air for the polymerization of a TMPTA/EPOX (50/50) blend 
revealed the conversion of TMPTA to be higher in laminate than under air as a result of oxygen inhibition,[113-116] whereas the opposite trend was found for EPOX, with a decrease of the monomer conversion in laminate compared to air and this behavior has already previously been reported in the literature (See Figure 6).[28,117-119] Noticeably, tack-free coatings could be obtained after only $60 \mathrm{~s}$, even while using a light source of low light intensity (blue LED), evidencing the remarkable reactivity of this three-component system NAPHT-1 $/$ lod/NVK $(0.5 \% / 2 \% / 3 \%, w / w / w)$.
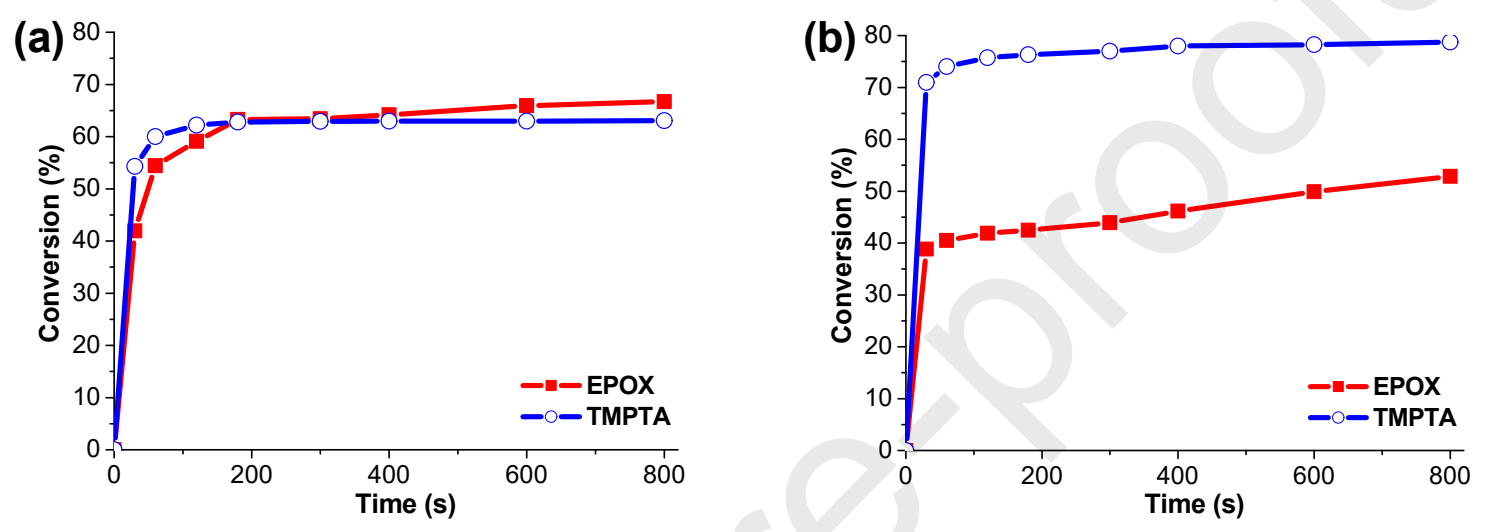

Figure 6. Photopolymerization profiles of an EPOX/TMPTA blend $(50 \% / 50 \%, w / w)$ in the presence of NAPHT-1 / lod/NVK $(0.5 \% / 2 \% / 3 \%, w / w / w)$ under air (a) and in laminate (b) upon irradiation with a LED emitting at $462 \mathrm{~nm}$. Reproduced with permission from Xiao et al. [97]. Copyright 2014 American Chemical Society.

Finally, the thiol-ene polymerization of trithiol/DEV-3 revealed the cationic polymerization of DVE-3 to be competitive with the thiol-ene reaction, the monomer conversion approaching of $100 \%$ within 20 s whereas only a final conversion of $42 \%$ could be obtained for trithiol after $50 \mathrm{~s}$ in laminate (see Figure 7). To support the formation of a polymer film, equations $r 9$ and $r 10$ were proposed as a plausible mechanism. 


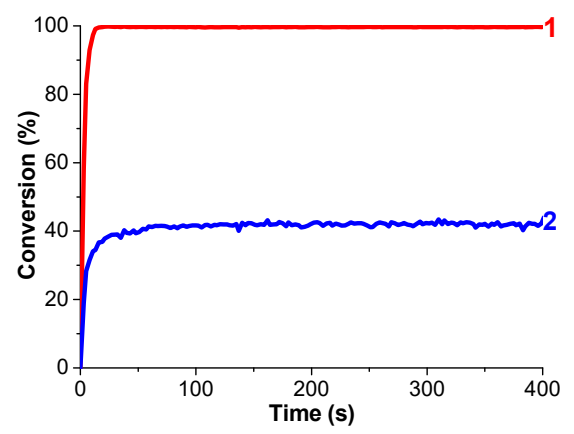

Figure 7. Photopolymerization profiles of a trithiol/DVE-3 blend $(57 \% / 43 \%, w / w)$ in laminate while using the two-component system NAPHT-1/lod $(0.5 \% / 2 \%, w / w)$ upon irradiation with a laser diode at $457 \mathrm{~nm}$ (1) DVE-3 conversion (2) trithiol conversion. Reproduced with permission from Xiao et al. [97]. Copyright 2014 American Chemical Society.

$$
\begin{gathered}
P h^{\bullet}+\mathrm{RS}^{-} \rightarrow \mathrm{Ph}^{-}+\mathrm{RS}^{\bullet}(r 9) \\
R S^{\bullet}+\mathrm{R}^{\prime}-\mathrm{CH}=\mathrm{CH}_{2} \rightarrow \mathrm{R}^{\prime}-\mathrm{CH}_{2}-\mathrm{CH}_{2} \mathrm{SR}(\mathrm{r} 10)
\end{gathered}
$$

\subsection{Influence of the substitution pattern on the optical properties.}

Following this pioneering work, the same group examined in 2014 a series of 8 naphthalic anhydride derivatives (NAPHT-2-NAPHT-9) differing by the substitution pattern. Two substituents were mainly examined, namely the nitro and the amino groups (See Scheme 3).[120]

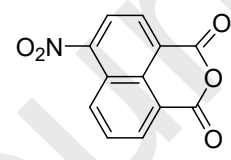

NAPHT-2

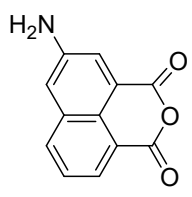

NAPHT-6

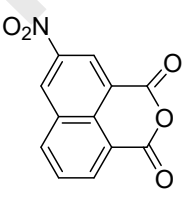

NAPHT-3

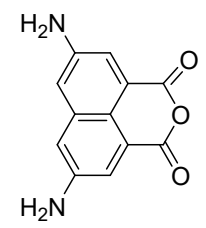

NAPHT-7

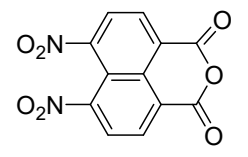

NAPHT-4

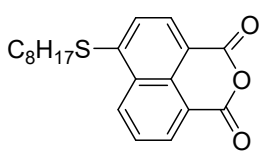

NAPHT-8

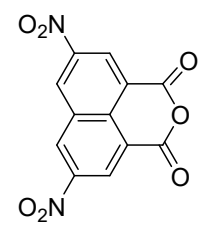

NAPHT-5

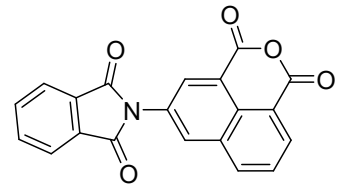

NAPHT-9

Scheme 3. Chemical structures of NAPHT-2-NAPHT-9. 
As shown in the Figure 8, a dramatic influence of the substitution position could be determined with both the nitro and the amino groups. Notably, a blue shift of ca. $50 \mathrm{~nm}$ of the absorption maximum was found for NAPHT-3 while shifting the nitro group from the 5position in NAPHT-2 to the 6-position in NAPHT-3. A similar behavior was found while comparing NAPHT-4 and NAPHT-5, with a blue shift of $75 \mathrm{~nm}$ being detected for the maximum absorption of NAPHT-5 compared to that of NAPHT-4. Therefore, it can be concluded that the substitution at the 5,8-positions of the naphthalic core with electron-withdrawing groups is not favorable to create visible light photoinitiators. The most red-shifted absorptions were found for NAPHT-6-NAPHT-8 exhibiting electron-donating groups such as amino and thioalkyl groups. Even if NAPHT-9 showed a good absorption in the visible range, its low solubility in common organic solvents but also in resins impeded all polymerization tests with this molecule so that only NAPHT-4, NAPTH-6, NAPTH-7 and NAPTH-8 could be examined as photoinitiators. While comparing NAPHT-4, NAPTH-6, NAPTH-7, NAPHT-8 with NAPTH-1, none of them could outperform NAPTH-1, both during the CP of EPOX under air or during the FRP of TMPTA in laminate (See Table 1). Besides, comparison with the two former reference systems revealed that all the newly proposed photoinitiating systems could outperform the reference camphorquinone/lod two-component systems during the FRP of acrylates, irrespective of the configuration used (two or three-component systems).

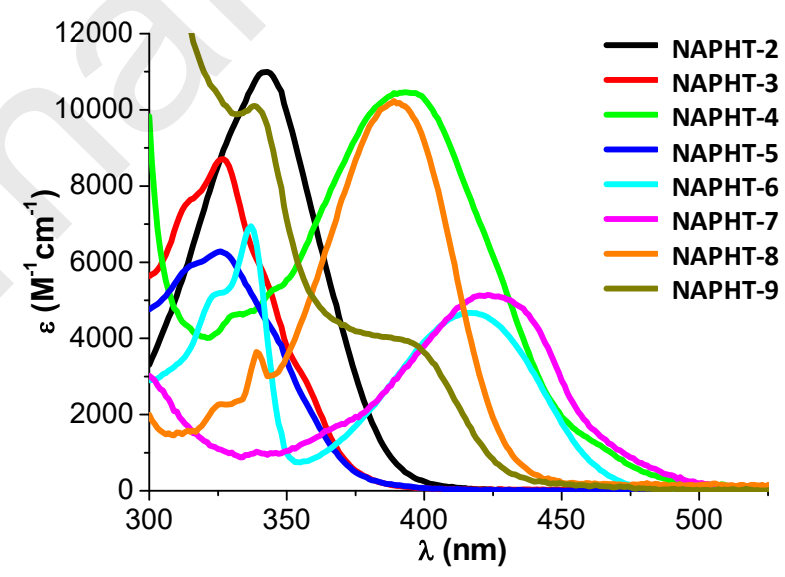

Figure 8. UV-visible absorption spectra of NAPHT-2-NAPHT-9 recorded in acetonitrile. Adapted from ref. [120] with permission from The Royal Society of Chemistry.

Opposite conclusions could be determined with the camphorquinone/MDEA photoinitiating system which could provide higher final monomer conversions during the FRP of TMPTA whatever the light source was. Only NAPHT-1 and NAPHT-7 could furnish higher 
final monomer conversions in these second conditions. Indeed, as previously mentioned, kinetic of production of initiating species is governed the interaction rate constants of the photoinitiators with lod or MDEA. When MDEA is used as the additive for the two component systems, only NAPHT-1 and NAPHT-7 exhibit a rate constant of interaction which is diffusion controlled $\left(4.2 \times 10^{9} \mathrm{M}^{-1} \cdot \mathrm{s}^{-1}\right)$. Parallel to this, the free energy changes $\Delta \mathrm{G}$ for the ${ }^{1} \mathrm{NAPHT}$ 1/MDEA and ${ }^{1}$ NAPHT-7/MDEA electron transfer reactions are highly negative (and higher than that determined for NAPHT-2-NAPHT-6, NAPHT-8 and NAPHT-9), indicating that the electron transfer is highly favorable for these two structures.

\subsection{Extension of aromaticity}

The previous results have evidenced that amino-substituted naphthalic anhydride could be efficient photoinitiators. To improve their light absorption properties in the visible range, extension of the aromaticity was envisioned with the introduction of aminothiazole groups in NAPHT-10 and NAPHT-11 (See Scheme 4).[50]

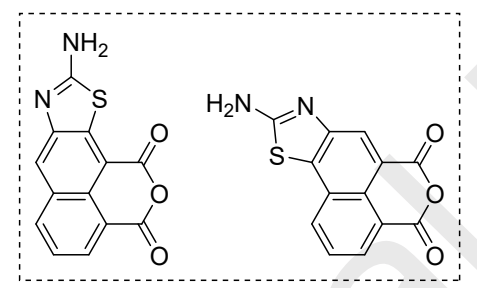

NAPHT-10

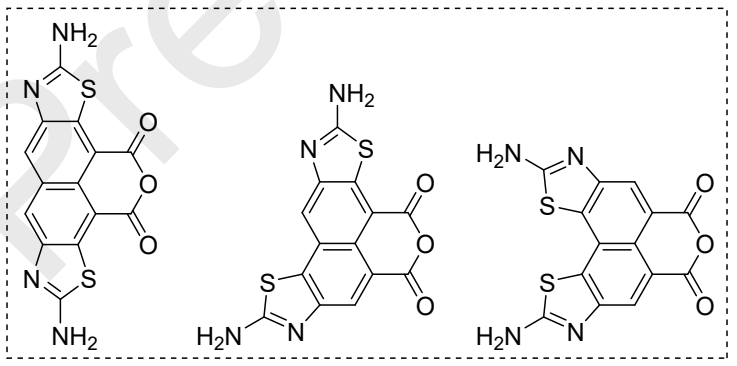

NAPHT-11

Scheme 4. Chemical structures of NAPHT-10 and NAPHT-11.

Interestingly, NAPHT-10 and NAPHT-11 were obtained as a mixture of regioisomers that could not be separated, subsequent to their syntheses. From a synthetic viewpoint, NAPHT-10 and NAPHT-11 could be prepared in one step starting from NAPHT-6 and NAPHT7 respectively, upon reaction with potassium isocyanate and bromine in acetic acid (See Scheme 5). It has to be noticed that the preparation of photoinitiators as a non-separable mixture of isomers is relatively unusual, but a few examples of type I photoinitiators based on 2,2-dimethoxy-2-phenylacetophenone (DMPA) have been previously reported in the literature.[121-122] Note that 2-isopropyl-9H-thioxanthen-9-one (ITX) which is a benchmark photoinitiator is often sold as a mixture of 2- and 4-isomers, the 4-isomers being a sideproduct of the synthesis of ITX.[123-124] 


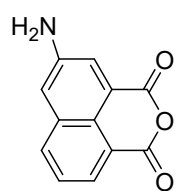

NAPHT-6

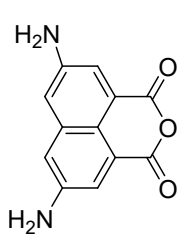

NAPHT-7

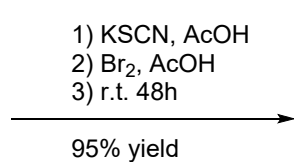

$95 \%$ yield

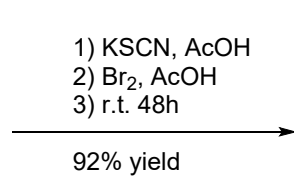

$92 \%$ yield

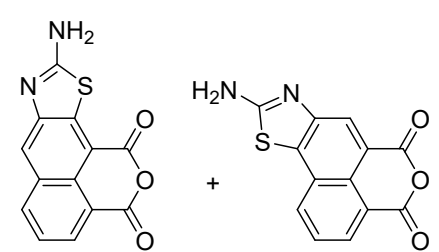

NAPHT-10

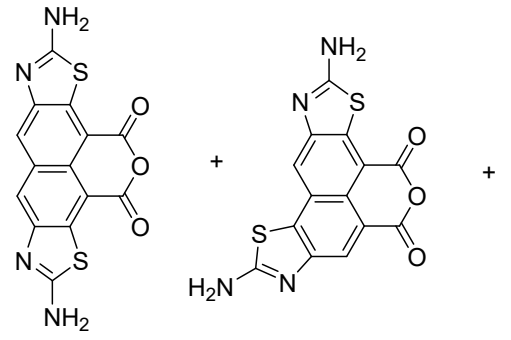

NAPHT-11

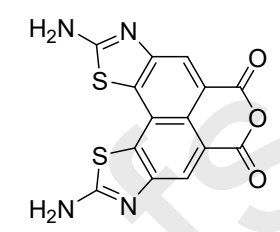

Scheme 5. Synthetic routes to NAPHT-10 and NAPHT-11.

While coming back to NAPHT-10 and NAPHT-11, the two compounds were characterized by a low solubility in most of the common organic solvents. Besides, their solubility was sufficient in resins to initiate a polymerization process. The dyes exhibited an absorption maximum at 419 and 432 for NAPHT-10 and NAPHT-11 respectively, demonstrating the pertinence of the approach. Absorption maximum of NAPHT-10 $\left(\lambda_{\max }=419\right.$ $\left.\mathrm{nm}, 6100 \mathrm{M}^{-1} \cdot \mathrm{cm}^{-1}\right)$ is close to that observed for NAPHT-1 $\left(\lambda_{\max }=413 \mathrm{~nm}, 9900 \mathrm{M}^{-1} \cdot \mathrm{cm}^{-1}\right)$. However, the molar extinction coefficient of NAPHT-11 $\left(\lambda_{\max }=432 \mathrm{~nm}, 10100 \mathrm{M}^{-1} . \mathrm{cm}^{-1}\right)$ is in better agreement with that of determined for NAPHT-1. More generally, the broad absorption of NAPHT-10 and NAPHT-11 extending between 350 and $600 \mathrm{~nm}$ made these two structures ideal candidates for photoinitiation upon irradiation at 405 and $455 \mathrm{~nm}$ or with a halogen lamp. Examination of the electronic distribution of their Highest Occupied Molecular Orbitals (HOMOs) and their Lowest Unoccupied Molecular Orbitals (LUMOs) revealed the HOMO levels of NAPHT-10 and NAPHT-11 to comprise the aminothiazole groups, destabilizing the HOMO energy level and red-shifting the absorption of these two dyes towards the visible range. By electrochemistry, only one oxidation peak was found for NAPHT-10 and NAPHT-11, suggesting that the different isomers have rather similar redox properties. A similar behavior was also evidenced by photoluminescence, only one fluorescence decay being detected for NAPHT-10 and NAPHT-11. However, determination of the excited state lifetime revealed a 4-fold enhancement of the lifetime for NAPHT-10 (28.3 ns) compared to NAPHT-11 (8.1 ns) ensuring a better reactivity for NAPHT-10, the dye having more time to react in the excited state with the different additives. By laser flash photolysis experiments, no triplet states were detected 
for the two dyes, evidencing that the singlet route would predominate during the interactions of NAPHT-10 and NAPHT-11 with the additives. In the same conditions than that used for NAPHT-1-NAPHT-9, higher final monomer conversions were obtained for the CP of EPOX upon irradiation with a LED at $405 \mathrm{~nm}\left(110 \mathrm{~mW} / \mathrm{cm}^{2}\right)$ with this three-component system NAPHT-10 /lod/NVK $(0.5 \% / 2 \% / 3 \%, w / w / w)(57 \%)$ than with this three-component system NAPHT-11 /lod/NVK $(0.5 \% / 2 \% / 3 \%, w / w / w) \quad(37 \%)$, consistent with the conclusions determined from the examination of their photophysical properties. A reduction of the monomer conversion was observed for the two dyes upon excitation with a LED at $455 \mathrm{~nm}$ (80 $\mathrm{mW} / \mathrm{cm}^{2}$ ), consistent with a decrease of the molar extinction coefficients at this wavelength. The two formulations were relatively stable since no reduction of the final monomer conversion was observed after one week of storage at room temperature. The FRP of TMPTA in laminate also revealed that a careful selection of the additives was necessary to get high monomer conversions. Thus, if moderate monomer conversions were obtained with 2,4,6tris(trichloromethyl)-1,3,5-triazine $(\mathrm{R}-\mathrm{Cl})$ as the additive, its replacement in the threecomponent system NAPHT-10 or NAPHT-11/MDEA $/ \mathrm{R}^{\prime}-\mathrm{Cl}(0.5 \% / 2 \% / 1 \%, \mathrm{w} / \mathrm{w} / \mathrm{w})$ by $\mathrm{R}^{\prime}-\mathrm{Cl}$ where $\mathrm{R}^{\prime}-\mathrm{Cl}$ stands for 2-(4-methoxystyryl)-4,6-bis(trichloromethyl)-1,3,5-triazine could increase the final monomer conversion of $16 \%$ ( $46 \%$ for the three-component system NAPHT$10 / \mathrm{MDEA} / \mathrm{R}-\mathrm{Cl}(0.5 \% / 2 \% / 1 \%, \mathrm{w} / \mathrm{w} / \mathrm{w})$ and $62 \%$ for the three-component system NAPHT$10 / \mathrm{MDEA} / \mathrm{R}^{\prime}-\mathrm{Cl}(0.5 \% / 2 \% / 1 \%, \mathrm{w} / \mathrm{w} / \mathrm{w})$ respectively). 
Table 1. EPOX and TMPTA conversions obtained under air upon exposure to different visible light sources for $800 \mathrm{~s}$ for the EPOX resins (under air), for 400s for the TMPTA resins (in laminate) for NAPHT-1-NAPH-11 photoinitiating systems and reference systems.

\begin{tabular}{|c|c|c|c|c|c|c|c|}
\hline & \multicolumn{3}{|c|}{ EPOX } & & \multicolumn{3}{|c|}{ TMPTA } \\
\hline & $\begin{array}{l}\text { Halogen } \\
\text { lamp }\end{array}$ & $\begin{array}{c}\text { Laser diode } \\
(405 \mathrm{~nm})\end{array}$ & $\begin{array}{l}\text { Laser diode } \\
\text { (455 } \mathrm{nm})\end{array}$ & $\begin{array}{l}\text { Laser diode } \\
(457 \mathrm{~nm})\end{array}$ & $\begin{array}{l}\text { Halogen } \\
\text { lamp }\end{array}$ & $\begin{array}{c}\text { Laser diode } \\
(405 \mathrm{~nm})\end{array}$ & $\begin{array}{c}\text { LED } \\
(455 \mathrm{~nm})\end{array}$ \\
\hline $\begin{array}{c}\text { NAPHT-1/lod } \\
(0.5 \% / 2 \%, w / w)\end{array}$ & $77 \%$ & - & - & - & $49 \%$ & - & - \\
\hline $\begin{array}{c}\text { NAPHT-1/lod/NVK } \\
(0.5 \% / 2 \% / 3 \%, \mathrm{w} / \mathrm{w} / \mathrm{w})\end{array}$ & $77 \%$ & $62 \%$ & - & $73 \%$ & $57 \%$ & - & - \\
\hline $\begin{array}{l}\text { NAPHT-1/MDEA } \\
(0.5 \% / 2 \%, w / w)\end{array}$ & - & - & - & - & $15 \%$ & - & - \\
\hline $\begin{array}{l}\text { NAPHT-1/MDEA/R-Cl } \\
(0.5 \% / 2 \% / 3 \%, w / w / w)\end{array}$ & - & - & - & - & $45 \%$ & - & - \\
\hline $\begin{array}{l}\text { NAPHT-4/lod } \\
(0.5 \% / 2 \%, w / w)\end{array}$ & $5 \%$ & - & - & - & - & $42 \%$ & $22 \%$ \\
\hline $\begin{array}{c}\text { NAPHT-4/lod/NVK } \\
(0.5 \% / 2 \% / 3 \%, w / w / w)\end{array}$ & $10 \%$ & $5 \%$ & $55 \%$ & - & - & - & - \\
\hline $\begin{array}{c}\text { NAPHT-6/lod } \\
(0.5 \% / 2 \%, w / w)\end{array}$ & $20 \%$ & - & - & - & - & $23 \%$ & $20 \%$ \\
\hline $\begin{array}{c}\text { NAPHT-6/lod/NVK } \\
(0.5 \% / 2 \% / 3 \%, \mathrm{w} / \mathrm{w} / \mathrm{w})\end{array}$ & $30 \%$ & $16 \%$ & $57 \%$ & - & - & - & $44 \%$ \\
\hline $\begin{array}{c}\text { NAPHT-7/lod } \\
(0.5 \% / 2 \%, w / w)\end{array}$ & $37 \%$ & - & - & - & - & $25 \%$ & $27 \%$ \\
\hline $\begin{array}{c}\text { NAPHT-7/lod/NVK } \\
(0.5 \% / 2 \% / 3 \%, w / w / w)\end{array}$ & $41 \%$ & $37 \%$ & $57 \%$ & - & $45 \%$ & $34 \%$ & $43 \%$ \\
\hline $\begin{array}{c}\mathrm{CQ} / \operatorname{lod}(0.5 \% / 2 \%, \mathrm{w} / \mathrm{w}) \\
\mathrm{CQ} / \mathrm{lod} / \mathrm{NVK} \\
(0.5 \% / 2 \% / 3 \%, \mathrm{w} / \mathrm{w} / \mathrm{w})\end{array}$ & $\begin{array}{l}n p^{\mathrm{a}} \\
\mathrm{np}\end{array}$ & - & - & - & 18 & - & - \\
\hline $\begin{array}{l}\text { NAPHT-7/MDEA } \\
(0.5 \% / 2 \%, w / w)\end{array}$ & - & - & - & - & - & - & $8 \%$ \\
\hline $\begin{array}{l}\text { NAPHT-7/MDEA/R-Cl } \\
(0.5 \% / 2 \% / 3 \%, w / w / w)\end{array}$ & - & - & - & - & $20 \%$ & $26 \%$ & $46 \%$ \\
\hline CQ/MDEA $(0.5 \% / 2 \%, w / w)$ & - & - & - & - & $35 \%$ & - & $34 \%$ \\
\hline $\begin{array}{l}\text { NAPHT-8/lod } \\
(0.5 \% / 2 \%, w / w)\end{array}$ & $n p^{a}$ & - & - & - & - & $41 \%$ & $21 \%$ \\
\hline $\begin{array}{c}\text { NAPHT-8/lod/NVK } \\
(0.5 \% / 2 \% / 3 \%, \mathrm{w} / \mathrm{w} / \mathrm{w})\end{array}$ & $n p^{a}$ & $5 \%$ & $57 \%$ & - & - & - & $42 \%$ \\
\hline $\begin{array}{l}\text { NAPHT-10/lod } \\
(0.5 \% / 2 \%, \mathrm{w} / \mathrm{w})\end{array}$ & - & $12 \%$ & - & - & - & $12 \%$ & - \\
\hline $\begin{array}{c}\text { NAPHT-10/lod/NVK } \\
(0.5 \% / 2 \% / 3 \%, \mathrm{w} / \mathrm{w} / \mathrm{w})\end{array}$ & $n p^{a}$ & $57 \%$ & $34 \%$ & - & $n p^{a}$ & $49 \%$ & $21 \%$ \\
\hline $\begin{array}{c}\text { NAPHT-10/MDEA } \\
(0.5 \% / 2 \%, w / w)\end{array}$ & - & - & - & - & & $16 \%$ & \\
\hline $\begin{array}{l}\text { NAPHT-10/MDEA/R'-Cl } \\
(0.5 \% / 2 \% / 3 \%, w / w / w)\end{array}$ & - & - & - & - & $62 \%$ & $58 \%$ & $57 \%$ \\
\hline $\begin{array}{l}\text { NAPHT-10/MDEA/R-Cl } \\
(0.5 \% / 2 \% / 3 \%, w / w / w)\end{array}$ & - & - & - & - & $46 \%$ & - & - \\
\hline $\begin{array}{l}\text { NAPHT-11/lod } \\
(0.5 \% / 2 \%, w / w)\end{array}$ & $n p^{a}$ & - & - & - & - & $<10 \%$ & - \\
\hline $\begin{array}{c}\text { NAPHT-11/lod/NVK } \\
(0.5 \% / 2 \% / 3 \%, w / w / w)\end{array}$ & $n p^{a}$ & $37 \%$ & $5 \%$ & - & - & $34 \%$ & - \\
\hline $\begin{array}{l}\text { NAPHT-11/MDEA } \\
(0.5 \% / 2 \%, w / w)\end{array}$ & - & - & - & - & - & $<10 \%$ & - \\
\hline $\begin{array}{l}\text { NAPHT-10/MDEA/R'-Cl } \\
(0.5 \% / 2 \% / 3 \%, w / w / w)\end{array}$ & - & - & - & - & $52 \%$ & $61 \%$ & $57 \%$ \\
\hline
\end{tabular}

a np: no polymerization. Light intensity of the different light sources: laser diode at $405 \mathrm{~nm}$ $\left(110 \mathrm{~mW} / \mathrm{cm}^{2}\right)$, laser diode at $457 \mathrm{~nm}\left(100 \mathrm{~mW} / \mathrm{cm}^{2}\right)$, LED at $455 \mathrm{~nm}\left(80 \mathrm{~mW} / \mathrm{cm}^{2}\right)$, halogen lamp : $380-800 \mathrm{~nm}\left(12 \mathrm{~mW} / \mathrm{cm}^{2}\right)$ 
Enhancement of the TMPTA conversion with $\mathrm{R}^{\prime}-\mathrm{Cl}$ as the additive in the threecomponent system was notably assigned to its significant absorption at $405 \mathrm{~nm},[125-127]$ what is not observed for $\mathrm{R}-\mathrm{Cl}$. Due to this additional absorption at $405 \mathrm{~nm}$, the threecomponent system NAPHT-10/MDEA/R'-Cl $(0.5 \% / 2 \% / 1 \%, \mathrm{w} / \mathrm{w} / \mathrm{w})$ could therefore be more efficient. Finally, 3D-printing experiments were carried out with NAPHT-10 to fabricate a dental crown. In this case, a mixture of triethylene glycol diacrylate/tricyclodecane dimethanol diacrylate $(70 \% / 30 \% \mathrm{w} / \mathrm{w})$ was used as the resin to fabricate the $3 \mathrm{D}$ object (See Figure 9).

a)

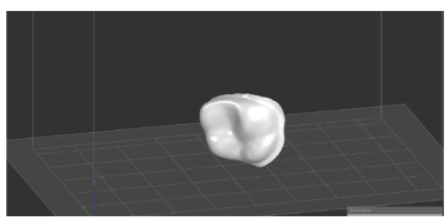

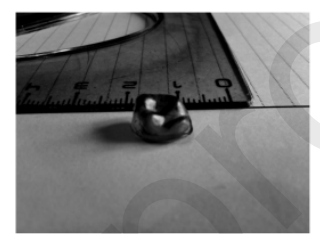

Figure 9. Dental crown fabricated with a 3D-printers while using NAPHT-10 as the photoinitiator (a) the virtual object. (b) the real object. Adapted from ref. [52] with permission from The Royal Society of Chemistry.

\section{Naphthalimides as photoinitiators of polymerization}

\subsection{Fine tuning of the optical properties by chemical engineering on the} naphthalene core

Solubility of photoinitiators in the photocurable resins is a major issue as it often determines the efficiency of the photoinitiating system. In this aim, introduction of alkyl chains to improve the solubility is an efficient strategy that was naturally applied to naphthalimides. From a synthetic viewpoint, the advantages of this strategy are twofold: improvement of the solubility of naphthalimides by the presence of the solubilizing chains and enhancement of the push-pull effect by converting the anhydride group as the phthalimide moiety. This approach was notably applied to a series of four dyes, namely NAPHT-12-NAPHT-15 that could be obtained in one step from their parent anhydrides NAPHT-6 and compounds 1-3 with reaction yields ranging from 74 to $89 \%$ (See Scheme 6).[128] 


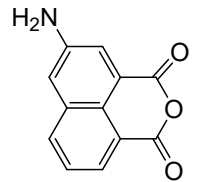

NAPHT-6

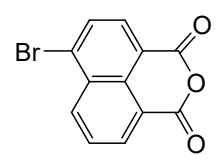

1

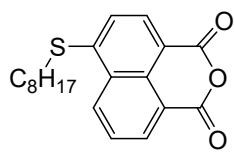

2

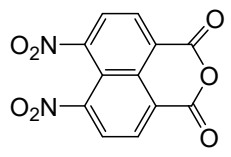

3

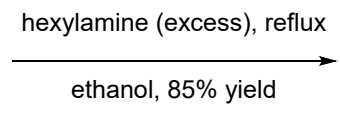

ethanol, $85 \%$ yield

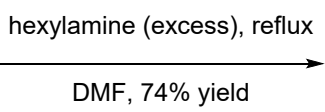

hexylamine (excess), reflux

DMF, $89 \%$ yield

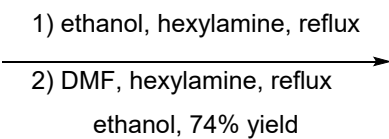

ethanol, $74 \%$ yield

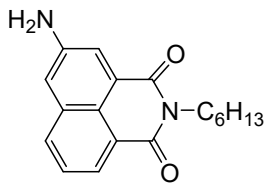

NAPHT-12

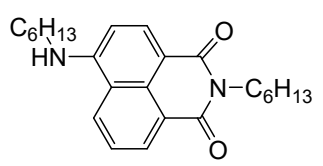

NAPHT-13

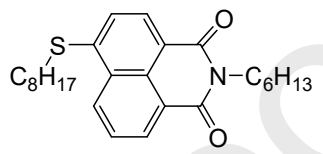

NAPTH-14

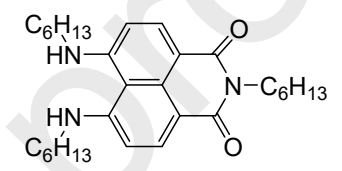

NAPHT-15

Scheme 6. Synthetic routes to NAPHT-12-NAPHT-15.

In this series, NAPHT-13 and NAPHT-15 showed the most red-shifted absorption as a result of the presence of the electron-donating groups at the 6- and the 6,7-positions respectively. Absorptions extending between 350 and $550 \mathrm{~nm}$ could be determined for these two dyes. Steady state photolysis experiments revealed the NAPHT-12-NAPTH-15/lod interaction to be diffusion control with interaction rate constants higher than $10^{9} \mathrm{M}^{-1}$. $\mathrm{s}^{-1}$. If the four dyes NAPHT-12-NAPTH-15 could efficiently promote the CP of EPOX or the FRP of acrylates and overcome the performances obtained with the reference camphorquinone (See Table 2). Interestingly, one of the most interesting features of this series was the possibility to prepare colorless polyether coatings with the three-component system NAPHT-14/lod/NVK $(0.5 \% / 2 \% / 3 \%, w / w / w)$ based on NAPHT-14 whereas yellowish coatings were obtained with NAPHT-13. With these two dyes, stable formulations based on TMPTA as the monomer could also be prepared, the final monomer conversion remaining unchanged after one week of storage at room temperature (See Table 2). Colorless coatings could also be obtained with TMPTA-based resins, but only with NAPHT-13 as the dye. Indeed, slightly colored coatings were obtained with NAPTH-14, as shown in the Table 3. Emission spectra of the different light source used to initiate polymerization processes with NAPHT-13 and NAPHT-14 are presented in the Figure 10. 
Table 2. EPOX and TMPTA conversions obtained under air upon exposure to different visible light sources for $800 \mathrm{~s}$ for the EPOX resins (under air), for 400s for the TMPTA resins (in laminate) for NAPHT-12-NAPH-15 photoinitiating systems and reference systems.

\begin{tabular}{|c|c|c|c|c|c|c|c|c|c|}
\hline & \multicolumn{5}{|c|}{ EPOX } & \multicolumn{4}{|c|}{ TMPTA } \\
\hline & $\begin{array}{l}\text { Halogen } \\
\text { lamp }\end{array}$ & $\begin{array}{l}\text { White } \\
\text { LED }\end{array}$ & $\begin{array}{c}\text { LED } \\
(405 \mathrm{~nm})\end{array}$ & $\begin{array}{c}\text { LED } \\
(455 \mathrm{~nm})\end{array}$ & $\begin{array}{c}\text { LED } \\
(470 \mathrm{~nm})\end{array}$ & $\begin{array}{c}\text { Halogen } \\
\text { lamp }\end{array}$ & $\begin{array}{l}\text { White } \\
\text { LED }\end{array}$ & $\begin{array}{c}\text { LED } \\
(405 \mathrm{~nm})\end{array}$ & $\begin{array}{c}\text { LED } \\
(455 \mathrm{~nm})\end{array}$ \\
\hline $\begin{array}{l}\text { NAPHT-12/lod } \\
(0.5 \% / 2 \%, w / w)\end{array}$ & $55 \%$ & - & - & - & - & - & - & - & - \\
\hline $\begin{array}{c}\text { NAPHT-12/lod/NVK } \\
(0.5 \% / 2 \% / 3 \%, w / w / w)\end{array}$ & $58 \%$ & $59 \%$ & $59 \%$ & $63 \%$ & $58 \%$ & - & - & - & - \\
\hline $\begin{array}{l}\text { NAPHT-13/lod } \\
(0.5 \% / 2 \%, w / w)\end{array}$ & $48 \%$ & - & - & - & - & - & $51 \%$ & & - \\
\hline $\begin{array}{c}\text { NAPHT-13/lod/NVK } \\
(0.5 \% / 2 \% / 3 \%, \mathrm{w} / \mathrm{w} / \mathrm{w})\end{array}$ & $51 \%$ & $58 \%$ & $60 \%$ & $60 \%, 62 \%^{b}$ & $60 \%$ & $53 \%$ & $60 \%$ & $56 \%$ & $61 \%, 60 \%^{b}$ \\
\hline $\begin{array}{l}\text { NAPHT-13/MDEA } \\
(0.5 \% / 2 \%, w / w)\end{array}$ & - & - & - & - & - & - & $28 \%$ & & \\
\hline $\begin{array}{l}\text { NAPHT-13/MDEA/R-Cl } \\
(0.5 \% / 2 \% / 3 \%, \mathrm{w} / \mathrm{w} / \mathrm{w})\end{array}$ & - & - & - & - & - & $58 \%$ & $62 \%$ & $66 \%$ & $64 \%, 55 \%^{b}$ \\
\hline $\begin{array}{l}\text { NAPHT-14/lod } \\
(0.5 \% / 2 \%, w / w)\end{array}$ & $<5 \%$ & - & - & - & - & - & $16 \%$ & - & - \\
\hline $\begin{array}{l}\text { NAPHT-14/lod/NVK } \\
(0.5 \% / 2 \% / 3 \%, \mathrm{w} / \mathrm{w} / \mathrm{w})\end{array}$ & $25 \%$ & $59 \%$ & $58 \%$ & $64 \%, 63 \%^{b}$ & $27 \%$ & $46 \%$ & $55 \%$ & $67 \%$ & $58 \%, 52 \%^{b}$ \\
\hline $\begin{array}{l}\text { NAPHT-14/MDEA } \\
(0.5 \% / 2 \%, w / w)\end{array}$ & - & - & - & - & - & - & $34 \%$ & & \\
\hline $\begin{array}{l}\text { NAPHT-14/MDEA/R-Cl } \\
(0.5 \% / 2 \% / 3 \%, w / w / w)\end{array}$ & - & - & - & - & - & $47 \%$ & $55 \%$ & $67 \%$ & $57 \%, 49 \%^{b}$ \\
\hline $\begin{array}{l}\text { NAPHT-15/lod } \\
(0.5 \% / 2 \%, \mathrm{w} / \mathrm{w})\end{array}$ & $31 \%$ & - & - & - & & - & - & - & - \\
\hline $\begin{array}{c}\text { NAPHT-15/lod/NVK } \\
(0.5 \% / 2 \% / 3 \%, \mathrm{w} / \mathrm{w} / \mathrm{w})\end{array}$ & $29 \%$ & $33 \%$ & $46 \%$ & $34 \%$ & $30 \%$ & - & - & - & - \\
\hline $\begin{array}{c}\text { CQ/lod } \\
(0.5 \% / 2 \%, w / w)\end{array}$ & $n p^{a}$ & - & & & - & $18 \%$ & - & - & - \\
\hline $\begin{array}{c}\mathrm{CQ} / \mathrm{lod} / \mathrm{NVK} \\
(0.5 \% / 2 \% / 3 \%, \mathrm{w} / \mathrm{w} / \mathrm{w})\end{array}$ & $n p^{a}$ & - & & - & $<70 \%$ & - & - & - & - \\
\hline $\begin{array}{c}\text { CO/MDEA } \\
(0.5 \% / 2 \%, w / w)\end{array}$ & - & - & & - & - & $35 \%$ & - & - & - \\
\hline
\end{tabular}

${ }^{a} \mathrm{np}$ : no polymerization ${ }^{\mathrm{b}}$ determined after one week of storage at room temperature. Light intensity of the different light sources: laser diode at $405 \mathrm{~nm}\left(110 \mathrm{~mW} / \mathrm{cm}^{2}\right)$, laser diode at $455 \mathrm{~nm}\left(80 \mathrm{~mW} / \mathrm{cm}^{2}\right)$, LED at $470 \mathrm{~nm}\left(80 \mathrm{~mW} / \mathrm{cm}^{2}\right)$, halogen lamp :380-800 nm $\left(12 \mathrm{~mW} / \mathrm{cm}^{2}\right)$, white LED : $80 \mathrm{~mW} / \mathrm{cm}^{2}$. 
Table 3. Color changes observed during the photopolymerization of TMPTA in laminate while using NAPHT-13 and NAPTH-14 in different photoinitiating systems upon irradiation with a LED at $455 \mathrm{~nm}\left(80 \mathrm{~mW} / \mathrm{cm}^{2}\right)$. Reprinted with permission from Xiao et al. [128] Copyright (C) 2015 John Wiley \& Sons, Inc.

\begin{tabular}{|c|c|c|c|c|c|}
\hline $\mathrm{PISs}^{1}$ & $\begin{array}{l}\text { Color before } \\
\text { irradiation }\end{array}$ & $\begin{array}{l}\text { Color after } \\
\text { irradiation }\end{array}$ & PISs & $\begin{array}{l}\text { Color before } \\
\text { irradiation }\end{array}$ & $\begin{array}{l}\text { Color after } \\
\text { irradiation }\end{array}$ \\
\hline & Yellowish-green++ & Yellowish-brown+ & & Yellowish+ & Colorless \\
\hline NAPHT- & & & NAPHT- & & \\
\hline 13/lod/NVK & & & 14/lod/NVK & & \\
\hline $\begin{array}{l}(0.5 \% / 2 \% / 3 \%, \\
w / w / w)\end{array}$ & & & $\begin{array}{l}(0.5 \% / 2 \% / 3 \%, \\
w / w / w)\end{array}$ & & \\
\hline & Yellowish-green++ & Yellow+ & & Yellowish+ & Colorless \\
\hline NAPHT- & & & NAPHT- & & \\
\hline 13/MDEA/R'-Cl & & & 14/MDEA/R'-Cl & & \\
\hline $\begin{array}{l}(0.5 \% / 2 \% / 3 \%, \\
w / w / w)\end{array}$ & & & $\begin{array}{l}(0.5 \% / 2 \% / 3 \%, \\
w / w / w)\end{array}$ & & \\
\hline
\end{tabular}

${ }^{1}$ PISs : Photoinitiating systems.

a)

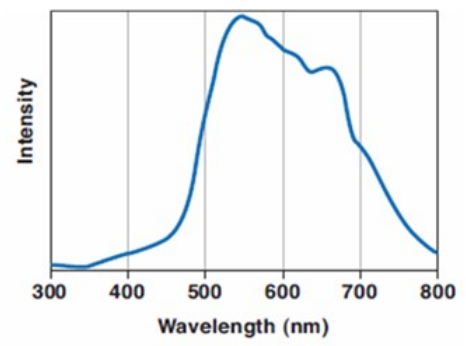

b)

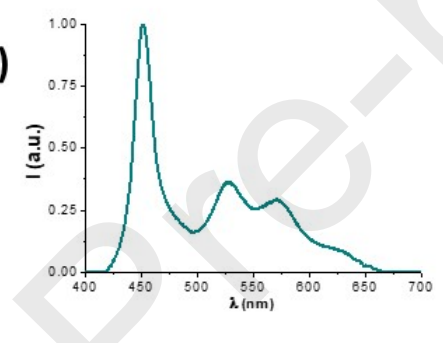

c)

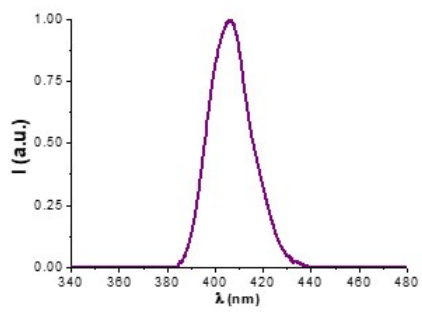

d)
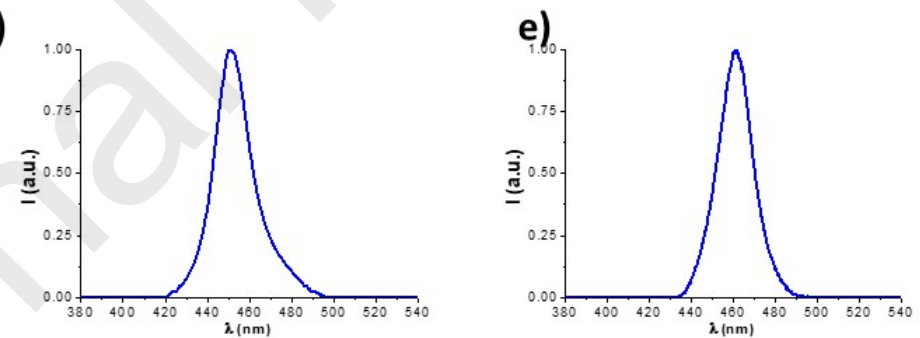

Figure 10. Emission spectra of the light sources used to investigate NAPHT-12-NAPHT-15. a) halogen lamp b) white LED c) LED at $405 \mathrm{~nm}$ d) LED at $455 \mathrm{~nm}$ e) LED at $470 \mathrm{~nm}$. Reprinted with permission from Xiao et al. [128] Copyright (C) 2015 John Wiley \& Sons, Inc.

Introduction of alkyl chains on the naphthalimide moiety was not the only way used to tune the position of the intramolecular charge transfer (ICT) band. Use of aromatic amines was also investigated, as exemplified with NAPTH-16-NAPHT-21 (See Scheme 7).[96,129] 


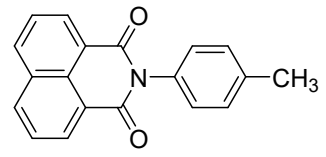

NAPHT-16

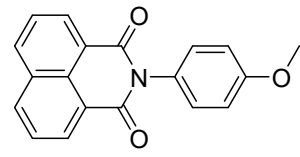

NAPHT-17

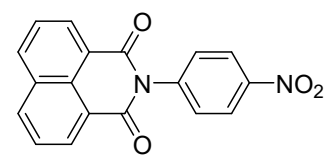

NAPHT-18

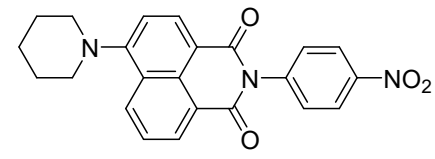

NAPHT-19

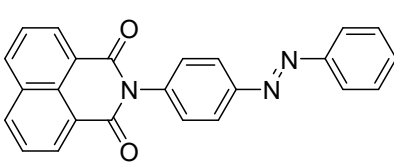

NAPHT-20

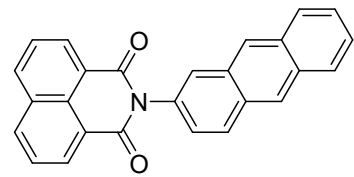

NAPHT-21

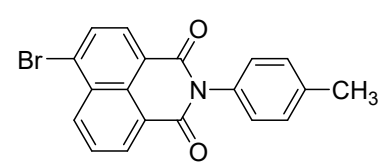

NAPHT-22

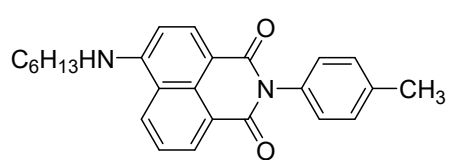

NAPHT-23

Scheme 7. Chemical structures of NAPHT-16-NAPHT-23.

Besides, for NAPHT-16-NAPHT-18, NAPHT21 and NAPHT-22, only a UV-centered absorption was found so that these different dyes could not be used as visible light photoinitiators. This is directly related to the lack of substitution on the naphthalene core so that not push-pull effect exists within these structures. Only NAPHT-20 showed a maximum absorption at $444 \mathrm{~nm}\left(\varepsilon=800 \mathrm{M}^{-1} \cdot \mathrm{cm}^{-1}\right)$ but resulting from the presence of the azobenzene group.[130-133] Conversely, the strong push-pull effect existing in NAPHT-19 or NAPHT-23 could give rise to an intense ICT band with an absorption maximum at $410 \mathrm{~nm}(\varepsilon=7600$ $\left.\mathrm{M}^{-1} \cdot \mathrm{cm}^{-1}\right)$ and at $431 \mathrm{~nm}\left(\varepsilon=17400 \mathrm{M}^{-1} \cdot \mathrm{cm}^{-1}\right)$ respectively, perfectly matching the emission spectra of a halogen lamp $\left(380-800 \mathrm{~nm}, 12 \mathrm{~mW} / \mathrm{cm}^{2}\right)$ or laser diodes emitting at $405 \mathrm{~nm}$ (110 $\left.\mathrm{mW} / \mathrm{cm}^{2}\right)$ or $457 \mathrm{~nm}\left(100 \mathrm{~mW} / \mathrm{cm}^{2}\right)$. Among this series, NAPHT-19 and NAPHT-23 proved to be the most efficient photoinitiators, providing final monomer conversions for the CP of EPOX under air or the FRP of TMPTA in laminate comparable to that obtained with NAPHT-1 (See Tables 1 and 4$)$. 
Table 4. EPOX and TMPTA conversions obtained under air upon exposure to different visible light sources for $800 \mathrm{~s}$ for the EPOX resins (under air), for 400s for the TMPTA resins (in laminate) for NAPHT-19-NAPH-23 photoinitiating systems and reference systems.

\begin{tabular}{|c|c|c|c|c|c|c|c|}
\hline & \multicolumn{4}{|c|}{ EPOX } & \multicolumn{3}{|c|}{ TMPTA } \\
\hline & $\begin{array}{l}\text { Halogen } \\
\text { lamp }\end{array}$ & $\begin{array}{c}\text { Laser } \\
\text { diode } \\
(405 \mathrm{~nm})\end{array}$ & $\begin{array}{c}\text { Laser } \\
\text { diode } \\
(455 \mathrm{~nm}) \\
\end{array}$ & $\begin{array}{c}\text { Laser } \\
\text { diode } \\
(457 \mathrm{~nm}) \\
\end{array}$ & $\begin{array}{c}\text { Halogen } \\
\text { lamp }\end{array}$ & $\begin{array}{c}\text { LED } \\
(405 \mathrm{~nm})\end{array}$ & $\begin{array}{c}\text { Laser } \\
\text { diode } \\
(457 \mathrm{~nm}) \\
\end{array}$ \\
\hline $\begin{array}{l}\text { NAPHT-19/lod } \\
(0.5 \% / 2 \%, w / w)\end{array}$ & $14 \%$ & - & - & - & $34 \%$ & - & - \\
\hline $\begin{array}{l}\text { NAPHT-19/lod/NVK } \\
(0.5 \% / 2 \% / 3 \%, w / w / w)\end{array}$ & $62 \%$ & $39 \%$ & - & $68 \%$ & $46 \%$ & - & $51 \%$ \\
\hline $\begin{array}{l}\text { NAPHT-19/MDEA } \\
(0.5 \% / 2 \%, w / w)\end{array}$ & - & - & - & - & $21 \%$ & - & - \\
\hline $\begin{array}{l}\text { NAPHT-19/MDEA/R-Cl } \\
(0.5 \% / 2 \% / 3 \%, w / w / w)\end{array}$ & - & - & - & - & $39 \%$ & - & $43 \%$ \\
\hline $\begin{array}{l}\text { NAPHT-20/lod } \\
(0.5 \% / 2 \%, w / w)\end{array}$ & $n p^{a}$ & - & - & - & - & - & - \\
\hline $\begin{array}{c}\text { NAPHT-20/lod/NVK } \\
(0.5 \% / 2 \% / 3 \%, w / w / w)\end{array}$ & $n p^{a}$ & - & - & $n p^{a}$ & - & 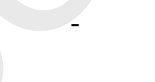 & - \\
\hline $\begin{array}{l}\text { NAPHT-23/lod } \\
(0.5 \% / 2 \%, \mathrm{w} / \mathrm{w})\end{array}$ & $53 \%$ & $63 \%$ & $62 \%$ & $61 \%$ & - & - & - \\
\hline $\begin{array}{c}\text { NAPHT-23/lod/NVK } \\
(0.5 \% / 2 \% / 3 \%, w / w / w)\end{array}$ & - & $58 \%$ & & & - & - & - \\
\hline $\begin{array}{l}\text { NAPHT-24/lod } \\
(0.5 \% / 2 \%, \mathrm{w} / \mathrm{w})\end{array}$ & - & $27 \%$ & $18 \%$ & & - & - & - \\
\hline $\begin{array}{c}\text { NAPHT-24/lod/NVK } \\
(0.5 \% / 2 \% / 3 \%, \mathrm{w} / \mathrm{w} / \mathrm{w})\end{array}$ & - & $67 \%$ & - & & - & - & - \\
\hline $\begin{array}{l}\text { NAPHT-25/lod } \\
(0.5 \% / 2 \%, \mathrm{w} / \mathrm{w})\end{array}$ & $59 \%$ & $59 \%$ & $62 \%$ & $59 \%$ & - & - & - \\
\hline $\begin{array}{l}\text { NAPHT-25/lod/NVK } \\
(0.5 \% / 2 \% / 3 \%, w / w / w)\end{array}$ & $59 \%$ & $62 \%, 62 \%^{\mathrm{b}}$ & & - & - & - & - \\
\hline $\begin{array}{l}\text { NAPHT-27/lod } \\
(0.5 \% / 2 \%, w / w)\end{array}$ & $55 \%$ & $62 \%$ & $56 \%$ & $60 \%$ & - & - & - \\
\hline $\begin{array}{l}\text { NAPHT-27/lod/NVK } \\
(0.5 \% / 2 \% / 3 \%, \mathrm{w} / \mathrm{w} / \mathrm{w})\end{array}$ & - & $60 \%$ & - & 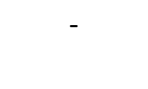 & - & - & - \\
\hline $\begin{array}{l}\text { NAPHT-29/lod } \\
(0.5 \% / 2 \%, \mathrm{w} / \mathrm{w})\end{array}$ & $n p^{a}$ & - & - & $30 \%$ & - & - & - \\
\hline $\begin{array}{c}\text { NAPHT-29/lod/NVK } \\
(0.5 \% / 2 \% / 3 \%, w / w / w)\end{array}$ & $n p^{a}$ & & & - & - & - & - \\
\hline $\begin{array}{l}\text { NAPHT-31/lod } \\
(0.5 \% / 2 \%, \mathrm{w} / \mathrm{w})\end{array}$ & & $28 \%$ & $13 \%$ & - & - & - & - \\
\hline $\begin{array}{c}\text { NAPHT-31/lod/NVK } \\
(0.5 \% / 2 \% / 3 \%, w / w / w)\end{array}$ & & $52 \%$ & - & - & - & - & - \\
\hline
\end{tabular}

${ }^{\text {a }} \mathrm{np}$ : no polymerization. Light intensity of the different light sources: laser diode at $405 \mathrm{~nm}$ $\left(110 \mathrm{~mW} / \mathrm{cm}^{2}\right)$, laser diode at $455 \mathrm{~nm}\left(80 \mathrm{~mW} / \mathrm{cm}^{2}\right)$, laser diode at $457 \mathrm{~nm}\left(100 \mathrm{~mW} / \mathrm{cm}^{2}\right)$, halogen lamp : 380-800 $\mathrm{nm}\left(12 \mathrm{~mW} / \mathrm{cm}^{2}\right)$.

Considering that NAPHT-19 was prepared from NAPHT-1 by use of 4-nitroaniline to form the phthalimide group, and in light of the performances obtained, no further modification of NAPHT-1 was necessary as no improvement of the light absorption properties or modification of the final monomer conversion could be clearly demonstrated with the chemical modification. Conversely, chemical engineering around NAPHT-23 was justified as it allowed to convert a UV photoinitiator (NAPHT-22) into a visible light photoinitiator in one 
step, by alkylation of NAPHT-22. As an intermediate strategy between the use of aliphatic amines (NAPHT-12-NAPHT-15) or aromatic amines (NAPHT-16-NAPHT-23) to form the phthalimide function was benzylamine offering a flexible linkage between the phthalimide group and the aromatic end-group. Four derivatives, namely NAPHT-24-NAPHT-27, were developed, bearing different substituents on the naphthalene core (See Scheme 8).

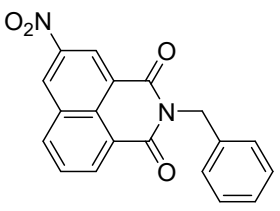

NAPHT-24

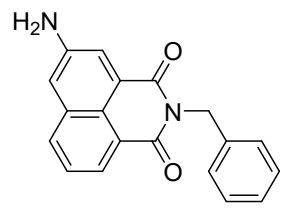

NAPHT-25

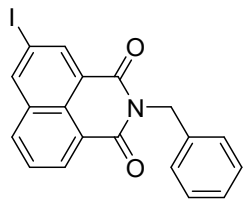

NAPHT-26

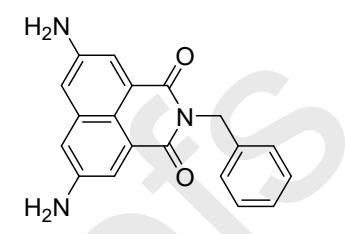

NAPHT-27

Scheme 8. Chemical structures of NAPHT-24-NAPHT-27.

Here again, only NAPHT-25 and NAPHT-27 displayed an absorption centered in the visible range (417 and $426 \mathrm{~nm}$ respectively). However, besides this chemical modification, performances of NAPHT25 and NAPHT-27 remained comparable to that observed for NAPHT12-NAPHT-23 (see Table 4).

\subsection{Combination of photoinitiators}

As previously demonstrated in this review, naphthalic anhydride and naphthalimide can be efficient photoinitiators of polymerization. This efficiency can be further increased by combining these two structures with well-known photoinitiators such as pyrene,[122,134138] anthraquinone[139-140] or benzophenone[141-146] which are well-established UV/near UV-visible photoinitiators. Especially, a synergetic effect can be expected by the presence of two photoinitiators onto the same molecule. From a synthetic viewpoint, the covalent linkage of anthraquinone, benzophenone or pyrene to the naphthalimide core was easy, simply requiring 1,8-naphthalic anhydride to be engaged in reaction with 2-aminoanthraquinone, 4aminobenzophenone or 2-aminopyrene.[97] NAPHT-28-NAPHT-31 could be obtained in high yields, ranging between 89 and 98\% (See Scheme 9). However, due to the lack of push-pull effects in NAPHT-28 and NAPHT-30, no polymerization under visible light could be carried out with these two dyes, their absorptions being centered in the UV range. Here again, the absorption maximum detected at $426 \mathrm{~nm}\left(\varepsilon=4300 \mathrm{M}^{-1} . \mathrm{cm}^{-1}\right)$ for NAPHT-29 can be assigned to the presence of the anthraquinone,[147-151] furnishing the desired visible light absorption. Polymerization tests revealed NAPHT-29 to remain a poor photoinitiator and a two-fold 
reduction of the final monomer conversion compared to that of NAPHT1 or NAPHT-19 could be determined during the CP of EPOX, irrespective of the formulations (two or threecomponent systems) or the irradiation wavelengths (see Table 4). Conversely, a less dramatic decrease of efficiency was found for NAPHT-31, a final monomer conversion of $52 \%$ being found for the three-component system NAPHT-31/lod/NVK $(0.5 \% / 2 \% / 3 \%, w / w / w)$ at $405 \mathrm{~nm}$.
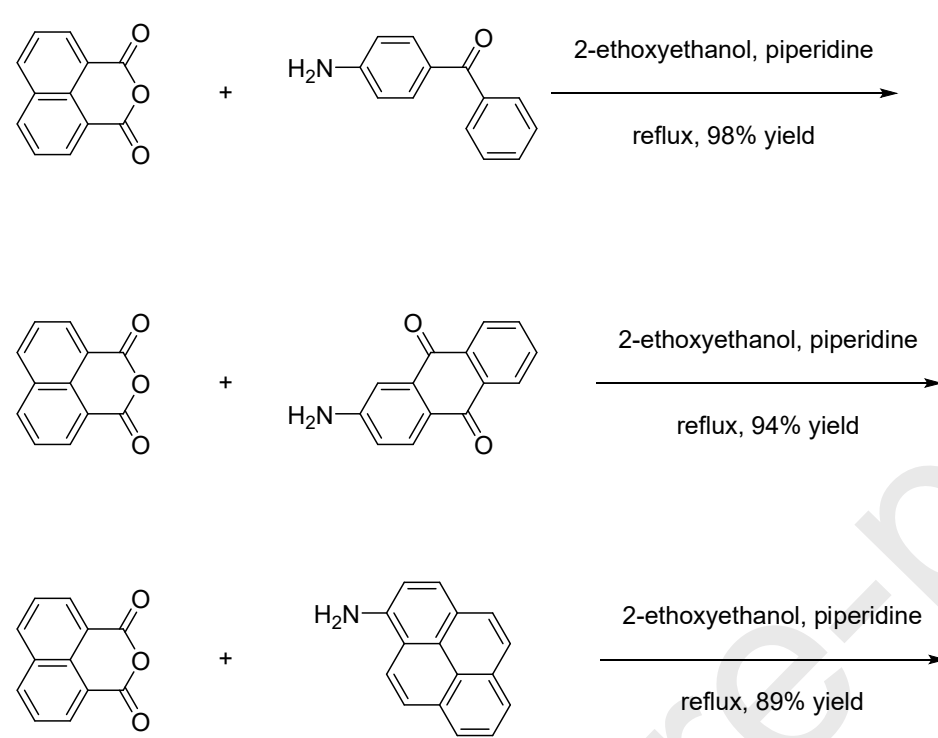

reflux, $89 \%$ yield

2-ethoxyethanol, piperidine

reflux, $94 \%$ yield

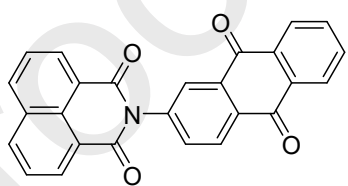

NAPHT-29

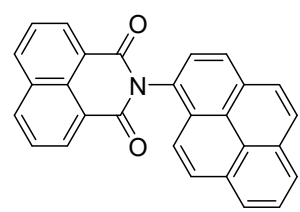

NAPHT-30

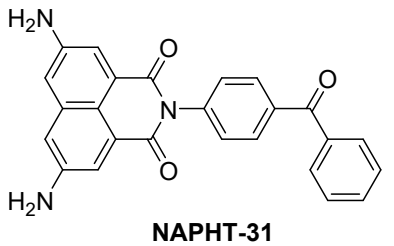

Scheme 9. Synthetic routes to NAPHT-28-NAPHT-31.

In 2015, in the frame of the previous works, the light absorption properties of NAPHT28 were improved in terms of molar extinction coefficient and position of the absorption maximum with the synthesis of NAPHT-32 (See Scheme 10).[142] By introducing an alkyl chain ended with a tertiary amine at the 4-position of the naphthalimide, a benzophenone derivative with an absorption drastically differing from the benzophenone $\left(\lambda_{\max }=340 \mathrm{~nm}, 100\right.$ $\mathrm{M}^{-1} . \mathrm{cm}^{-1}$ ) was obtained. Thus, NAPHT-32 displayed an absorption maximum at $431 \mathrm{~nm}$ with a molar extinction coefficient of $15,700 \mathrm{M}^{-1} \cdot \mathrm{cm}^{-1}$. Interestingly, steady state photolysis experiments revealed NAPHT-32 to be capable to produce radicals without any added hydrogen donor, simply by intermolecular interaction according to equations r11-r13. Electron spin resonance (ESR) spin trapping experiments revealed the formation of $\alpha$ - 
aminoalkyl radicals. When combined with lod or R-Cl, NAPHT-32 proved to be highly reactive since a photobleaching occurring within $20 \mathrm{~s}$ with the two additives was found. ESR spin trapping experiments confirmed the formation of $\mathrm{R}^{\bullet}$ and $\mathrm{Ph}^{\bullet}$ as the initiating species for photopolymerization. These radicals are formed according the equations r14-r19 detailed below. The low photoluminescence quantum yield $(\phi=0.017)$ are consistent with an intramolecular electron transfer occurring upon photoexcitation. A long fluorescence lifetime was also found for NAPHT-32 (15.9 ns), enabling this dye to efficiently interact with the different additives.

$$
\begin{aligned}
& \text { NAPHT }-32 \rightarrow 1_{\text {NAPHT }-32}(h v) \text { and } 1_{\text {NAPHT }-32} \rightarrow 3_{\text {NAPHT }-32}(r 11) \\
& 1^{1,3} \text { NAPHT }-32+\text { NAPHT }-32 \rightarrow \text { NAPHT }-32^{\bullet-}+\text { NAPHT }-32^{\bullet+}(r 12) \\
& \text { NAPHT }-32^{\bullet-}+N A P H T-32^{\bullet+} \rightarrow N A P H T-32-H^{\bullet}+N A P H T-32\left(-{ }^{\bullet}\right. \\
& (r 13) \\
& \text { NAPHT }-32^{\bullet}-+\mathrm{R}-\mathrm{Cl} \rightarrow \boldsymbol{N A P H T}-32+(\mathrm{R}-\mathrm{Cl})^{\bullet-} \\
& \text { NAPHT }-32-\mathrm{H}^{\bullet}+\mathrm{R}-\mathrm{Cl} \rightarrow \boldsymbol{N A P H T}-32+\mathrm{H}^{+}+(\mathrm{R}-\mathrm{Cl})^{\bullet}(r 15) \\
& { }^{1,3} \mathbf{N A P H T}-32+\mathrm{R}-\mathrm{Cl} \rightarrow \mathbf{N A P H T}-32^{\bullet+}+(\mathrm{R}-\mathrm{Cl})^{\bullet-} \\
& (\mathrm{R}-\mathrm{Cl})^{\bullet-} \rightarrow \mathrm{R}^{\bullet}+\mathrm{Cl}^{-}(r 17) \\
& 1,3_{\text {NAPHT }-32}+\mathrm{Ph}_{2} I^{+} \rightarrow \mathbf{N A P H T}-\mathbf{3 2}^{\bullet+}+P h_{2} I^{\bullet}(r 18) \\
& P h_{2} I^{\bullet} \rightarrow P h^{\bullet}+P h-I(r 19)
\end{aligned}
$$

As anticipated from the steady state experiments, NAPHT-32 could initiate as a singlecomponent system the FRP of TMPTA but the polymerization process was slow and final monomer conversions of 27 and 19\% were determined after $400 \mathrm{~s}$ of irradiation with a LED at $405 \mathrm{~nm}\left(110 \mathrm{~mW} / \mathrm{cm}^{2}\right)$ and $455 \mathrm{~nm}\left(80 \mathrm{~mW} / \mathrm{cm}^{2}\right)$ respectively. Conversely, the polymerization process with the two-component systems NAPHT-32/R-Cl $(0.5 \% / 2 \%, \mathrm{w} / \mathrm{w})$ or NAPHT-32/lod $(0.5 \% / 2 \%, w / w)$ was extremely fast since final monomer conversions of ca. $60 \%$ and $55 \%$ were obtained with the two-component systems NAPHT-32/R-Cl $(0.5 \% / 2 \%, w / w)$ or NAPHT-32/lod $(0.5 \% / 2 \%, w / w)$ within $100 \mathrm{~s}$ (see Table 5). Comparison with reference photoinitiating systems such as bis(2,4,6-trimethylbenzoyl)phenylphosphine oxide (BAPO), camphorquinone/lod or camphorquinone/MDEA revealed NAPHT-32 to outperform these systems irrespective of the 
light source or the photoinitiating systems. Stability of the resins was also examined and a stability over one weak was found for the two-component system NAPHT-32/R-Cl. The CP of EPOX under air could also be initiated with the two-component system NAPHT-32/lod $(0.5 \% / 2 \%, w / w)$ and final monomer conversions ranging between $56 \%$ and $70 \%$ could be determined, depending of the selected irradiation wavelength $(385-470 \mathrm{~nm})$.

Table 5. EPOX and TMPTA conversions obtained under air upon exposure to different visible light sources for $800 \mathrm{~s}$ for the EPOX resins (under air), for 400s for the TMPTA resins (in laminate) for NAPHT-32 photoinitiating systems and reference systems.

\begin{tabular}{|c|cccc|ccc|}
\hline & \multicolumn{3}{|c|}{ EPOX } & \multicolumn{3}{c|}{ TMPTA } \\
\hline & $\begin{array}{c}\text { Halogen } \\
\text { lamp }\end{array}$ & $\begin{array}{c}\text { LED } \\
(405 \mathrm{~nm})\end{array}$ & $\begin{array}{c}\text { LED } \\
(455 \mathrm{~nm})\end{array}$ & $\begin{array}{c}\text { LED } \\
(470 \mathrm{~nm})\end{array}$ & $\begin{array}{c}\text { Halogen } \\
\text { lamp }\end{array}$ & $\begin{array}{c}\text { LED } \\
(405 \mathrm{~nm})\end{array}$ & $\begin{array}{c}\text { LED } \\
(455 \mathrm{~nm})\end{array}$ \\
$(470 \mathrm{~nm})$
\end{tabular}

${ }^{\mathrm{a}} \mathrm{np}$ : no polymerization ${ }^{\mathrm{b}}$ determined after one week of storage at room temperature. Light intensity of the different light sources: laser diode at $405 \mathrm{~nm}\left(110 \mathrm{~mW} / \mathrm{cm}^{2}\right)$, laser diode at $455 \mathrm{~nm}\left(80 \mathrm{~mW} / \mathrm{cm}^{2}\right)$, laser diode at $470 \mathrm{~nm}\left(70 \mathrm{~mW} / \mathrm{cm}^{2}\right)$, halogen lamp : 380-800 $\mathrm{nm}$ (12 $\mathrm{mW} / \mathrm{cm}^{2}$ )

\subsection{Naphthalimides with tertiary amines as co-initiators}

Based on the pioneering work developed with NAPHT-32, many efforts have been devoted to design and synthesize a wide range of naphthalimides comprising a tertiary amine at different positions. Interests of these structures are numerous that these molecules can be considered as one-component photoinitiators combining both the photoinitiator and the amine classically used in two-component systems within a unique molecule. Indeed, amines are classically used as co-initiators in hydrogen abstraction-based photoinitiating systems.[152, 153] By mean of this strategy, drawbacks inherent to the use of amines (odor, toxicity) could be overcome[57,154-156] and the migration issue resulting from the use of low molecular-weight compound can also be advantageously addressed.[157-160] With aim at establishing a structure-performance relationship, 21 molecules NAPHT-33-NAPHT-53 were synthesized and tested as photoinitiators (See Scheme 10).[161-165] First, almost all dyes could produce radicals alone and therefore initiate the FRP of TMPTA in laminates (See Tables 
6 and 7). However, the final monomer conversions remained moderate, ranging from 30 to $35 \%$. For a higher efficiency, their combination with $\mathrm{R}-\mathrm{Cl}$ or lod in two-component systems could lead to radicals without addition of a hydrogen donor. If differences in terms of final monomer conversions could be found between NAPHT-33-NAPHT-53, these variations can be mostly assigned to their different light absorption properties and their differences of molar extinction coefficients at the considered irradiation wavelengths $(405,455$ or $470 \mathrm{~nm})$. At 405 $\mathrm{nm}\left(110 \mathrm{~mW} / \mathrm{cm}^{2}\right)$, for the two-component systems NAPHT-x/lod $(0.5 \% / 2 \%, \mathrm{w} / \mathrm{w})$, the best monomer conversions for TMPTA were obtained with NAPHT-33, NAPHT-37, or NAPHT-42 reaching ca. $60 \%$ in laminate after 400 s of irradiation. Conversely, at $405 \mathrm{~nm}$, more dyes could produce efficient two-component photoinitiating systems with $\mathrm{R}-\mathrm{Cl}$, as exemplified with NAPHT-33, NAPHT-34, NAPHT-37, NAPHT-42-NAPHT-46. 


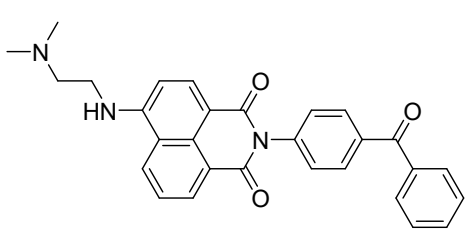

NAPHT-32

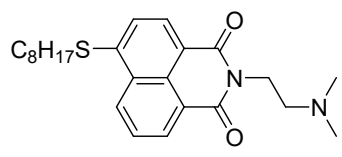

NAPHT-33

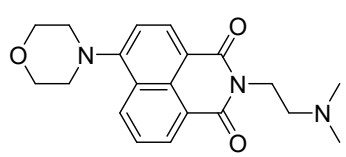

NAPHT-34

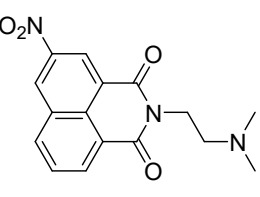

NAPHT-35

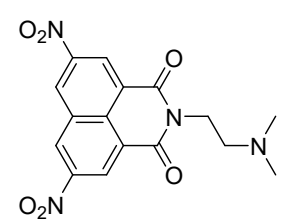

NAPHT-36

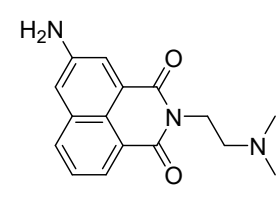

NAPHT-37

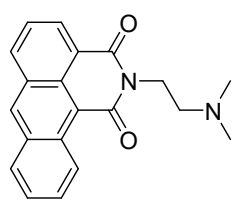

NAPHT-38

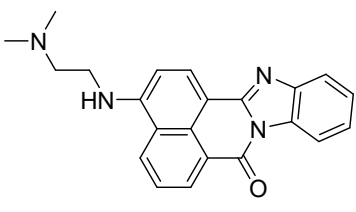

NAPHT-39

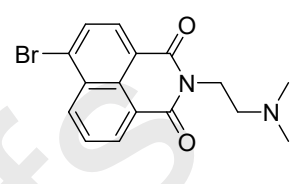

NAPHT-40

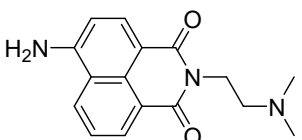

NAPHT-41

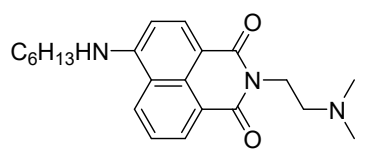

NAPHT-42

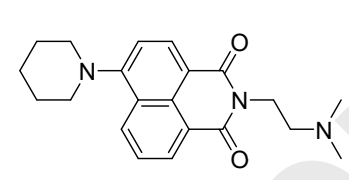

NAPHT-43

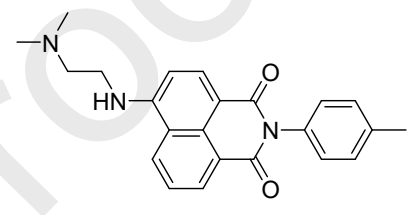

NAPHT-44<smiles>CCCCCCCCN1C(=O)c2cccc3c(NCCN(C)C)ccc(c23)C1=O</smiles>
NAPHT-45

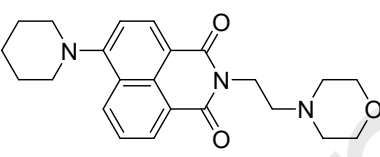

NAPHT-48

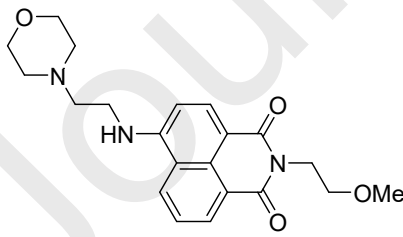

NAPHT-51

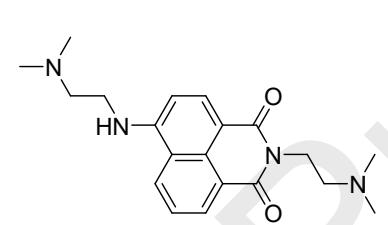

NAPHT-46

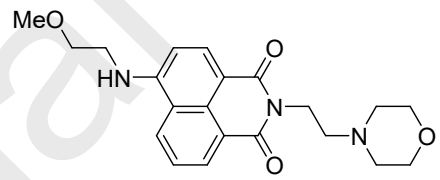

NAPHT-49

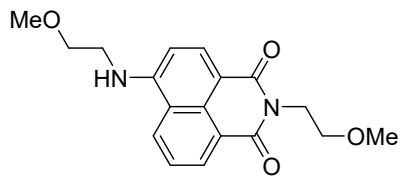

NAPHT-52

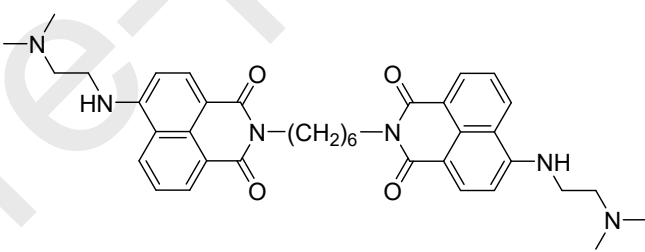

NAPHT-47

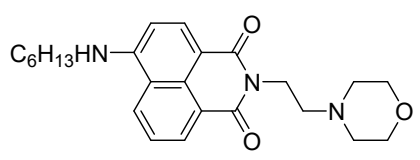

NAPHT-50

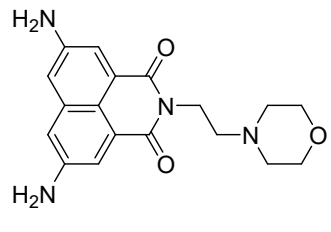

NAPHT-53

Scheme 10. Chemical structures of NAPHT-32-NAPHT-53.

In this last case, monomer conversions close to $65 \%$ were obtained. Concerning the three-component systems NAPHT-x/lod/NVK (0.5\%/2\%/3\%, w/w/w), NAPHT-37, NAPHT-40NAPHT-42 and NAPTH-44 proved to be the most efficient dyes with conversions of ca. $65 \%$. 
Table 6. EPOX and TMPTA conversions obtained under air upon exposure to different visible light sources for $800 \mathrm{~s}$ for the EPOX resins (under air), for 400s for the TMPTA resins (in laminate) for NAPHT-33-NAPH-39 photoinitiating systems and reference systems.

\begin{tabular}{|c|c|c|c|c|c|c|c|c|}
\hline & \multicolumn{4}{|c|}{ EPOX } & \multicolumn{4}{|c|}{ TMPTA } \\
\hline & $\begin{array}{l}\text { Halogen } \\
\text { lamp }\end{array}$ & $\begin{array}{c}\text { LED } \\
(405 \mathrm{~nm})\end{array}$ & $\begin{array}{c}\text { LED } \\
(455 \mathrm{~nm})\end{array}$ & $\begin{array}{c}\text { LED } \\
(470 \mathrm{~nm})\end{array}$ & $\begin{array}{c}\text { Halogen } \\
\text { lamp }\end{array}$ & $\begin{array}{c}\text { LED } \\
(405 \mathrm{~nm})\end{array}$ & $\begin{array}{c}\text { LED } \\
(455 \mathrm{~nm})\end{array}$ & $\begin{array}{c}\text { LED } \\
(470 \mathrm{~nm})\end{array}$ \\
\hline NAPHT-33 $(0.5 \% \mathrm{w})$ & - & - & - & - & - & $36 \%$ & $n p^{a}$ & - \\
\hline $\begin{array}{l}\text { NAPHT-33/lod } \\
(0.5 \% / 2 \%, w / w)\end{array}$ & - & $70 \%$ & $22 \%$ & - & - & $61 \%$ & - & - \\
\hline $\begin{array}{c}\text { NAPHT-33/lod/NVK } \\
(0.5 \% / 2 \% / 3 \%, w / w / w)\end{array}$ & $n p^{a}$ & $64 \%, 69 \% \mathrm{~b}$ & $64 \%$ & - & - & - & - & - \\
\hline $\begin{array}{l}\text { NAPHT-33/R-Cl } \\
(0.5 \% / 3 \%, \mathrm{w} / \mathrm{w})\end{array}$ & - & - & - & - & $46 \%$ & $68 \%, 65 \%^{\mathrm{b}}$ & $59 \%$ & - \\
\hline NAPHT-34 (0.5\% w) & - & - & - & - & - & $32 \%$ & - & - \\
\hline $\begin{array}{l}\text { NAPHT-34/lod } \\
(0.5 \% / 2 \%, \mathrm{w} / \mathrm{w})\end{array}$ & $37 \%$ & $68 \%, 71 \%^{b}$ & $63 \%$ & - & - & & - & - \\
\hline $\begin{array}{l}\text { NAPHT-34/R-Cl } \\
(0.5 \% / 3 \%, w / w)\end{array}$ & - & - & - & - & $47 \%$ & $62 \%, 61 \%^{b}$ & $58 \%$ & - \\
\hline $\begin{array}{c}\mathrm{CQ} / \mathrm{lod} \\
(0.5 \% / 2 \%, \mathrm{w} / \mathrm{w})\end{array}$ & $n p^{a}$ & - & - & - & $18 \%$ & - & - & - \\
\hline $\begin{array}{c}\mathrm{CO} / \mathrm{lod} / \mathrm{NVK} \\
(0.5 \% / 2 \% / 3 \%, \mathrm{w} / \mathrm{w} / \mathrm{w})\end{array}$ & $n p^{a}$ & - & - & - & & - & - & - \\
\hline $\begin{array}{c}\text { CO/MDEA } \\
(0.5 \% / 2 \%, w / w)\end{array}$ & - & - & - & - & $35 \%$ & - & - & - \\
\hline $\begin{array}{l}\text { NAPHT-35/lod } \\
(0.5 \% / 2 \%, w / w)\end{array}$ & - & $n p^{a}$ & - & - & - & - & - & - \\
\hline $\begin{array}{l}\text { NAPHT-35/lod/NVK } \\
(0.5 \% / 2 \% / 3 \%, \mathrm{w} / \mathrm{w} / \mathrm{w})\end{array}$ & - & $36 \%$ & - & - & - & - & - & - \\
\hline $\begin{array}{l}\text { NAPHT-35/R-Cl } \\
(0.5 \% / 3 \%, w / w)\end{array}$ & - & - & & - & - & $41 \%$ & - & - \\
\hline $\begin{array}{l}\text { NAPHT-36/lod } \\
(0.5 \% / 2 \%, \mathrm{w} / \mathrm{w})\end{array}$ & - & - & - & - & - & $37 \%$ & - & - \\
\hline $\begin{array}{l}\text { NAPHT-36/lod/NVK } \\
(0.5 \% / 2 \% / 3 \%, \mathrm{w} / \mathrm{w} / \mathrm{w})\end{array}$ & - & - & - & - & - & - & - & - \\
\hline NAPHT-37 $(0.5 \%$ w) & - & - & - & - & - & $25 \%$ & $n p^{a}$ & - \\
\hline $\begin{array}{l}\text { NAPHT-37/lod } \\
(0.5 \% / 2 \%, \mathrm{w} / \mathrm{w})\end{array}$ & $42 \%$ & $66 \%, 67 \%^{b}$ & $66 \%$ & $68 \%$ & - & $57 \%$ & $53 \%$ & - \\
\hline $\begin{array}{l}\text { NAPHT-37/R-Cl } \\
(0.5 \% / 3 \%, w / w)\end{array}$ & - & - & - & - & - & $60 \%$ & - & - \\
\hline $\begin{array}{c}\text { NAPHT-37/lod/NVK } \\
(0.5 \% / 2 \% / 3 \%, \mathrm{w} / \mathrm{w} / \mathrm{w})\end{array}$ & - & - & - & - & - & $63 \%, 63 \%^{b}$ & - & - \\
\hline $\begin{array}{l}\text { NAPHT-38/lod } \\
(0.5 \% / 2 \%, w / w)\end{array}$ & c. & $n p^{a}$ & - & - & - & $29 \%$ & - & - \\
\hline $\begin{array}{c}\text { NAPHT-38/lod/NVK } \\
(0.5 \% / 2 \% / 3 \%, w / w / w)\end{array}$ & - & $63 \%$ & $57 \%$ & - & - & $55 \%$ & $49 \%$ & - \\
\hline $\begin{array}{l}\text { NAPHT-39/lod } \\
(0.5 \% / 2 \%, \mathrm{w} / \mathrm{w})\end{array}$ & - & $66 \%$ & - & - & - & - & - & - \\
\hline $\begin{array}{l}\text { NAPHT-39/R-Cl } \\
(0.5 \% / 3 \%, w / w)\end{array}$ & - & - & - & - & $42 \%$ & - & $54 \%, 54 \%^{\mathrm{b}}$ & - \\
\hline $\begin{array}{l}\text { NAPHT-39/MDEA/R-Cl } \\
(0.5 \% / 2 \% / 3 \%, w / w / w)\end{array}$ & - & - & - & - & - & $61 \%$ & $64 \%, 61 \%^{\mathrm{b}}$ & $58 \%$ \\
\hline BAPO $(0.5 \%$ w) & - & - & - & - & - & $56 \%$ & $54 \%$ & - \\
\hline
\end{tabular}

${ }^{\mathrm{a}} \mathrm{np}$ : no polymerization ${ }^{\mathrm{b}}$ determined after one week of storage at room temperature. Light intensity of the different light sources: laser diode at $405 \mathrm{~nm}\left(110 \mathrm{~mW} / \mathrm{cm}^{2}\right)$, laser diode at $455 \mathrm{~nm}\left(80 \mathrm{~mW} / \mathrm{cm}^{2}\right)$, laser diode at $470 \mathrm{~nm}\left(70 \mathrm{~mW} / \mathrm{cm}^{2}\right)$, halogen lamp : 380-800 nm (12 $\left.\mathrm{mW} / \mathrm{cm}^{2}\right)$ 
Table 7. EPOX and TMPTA conversions obtained under air upon exposure to different visible light sources for $800 \mathrm{~s}$ for the EPOX resins (under air), for 400s for the TMPTA resins (in laminate) for NAPHT-40-NAPH-47 photoinitiating systems and reference systems.

\begin{tabular}{|c|c|c|c|c|c|c|c|c|}
\hline & & EPOX & & & & TMPTA & & \\
\hline & $\begin{array}{l}\text { Halogen } \\
\text { lamp }\end{array}$ & $\begin{array}{c}\text { LED } \\
(405 \mathrm{~nm})\end{array}$ & $\begin{array}{c}\text { LED } \\
(455 \mathrm{~nm})\end{array}$ & $\begin{array}{c}\text { LED } \\
(470 \mathrm{~nm})\end{array}$ & $\begin{array}{c}\text { Halogen } \\
\text { lamp }\end{array}$ & $\begin{array}{c}\text { LED } \\
(405 \mathrm{~nm})\end{array}$ & $\begin{array}{l}\text { LED } \\
(455 \mathrm{~nm})\end{array}$ & $\begin{array}{c}\text { LED } \\
(470 \mathrm{~nm})\end{array}$ \\
\hline NAPHT-40 $(0.5 \%$ w) & & & & & & $n p^{\mathrm{a}}$ & & \\
\hline NAPHT-41 $(0.5 \%$ w) & & & & & & $\mathrm{np}^{\mathrm{a}}$ & & \\
\hline NAPHT-42 $(0.5 \% \mathrm{w})$ & & & & & & $37 \%$ & $33 \%$ & \\
\hline NAPHT-43 $(0.5 \% \mathrm{w})$ & & & & & & $34 \%$ & & \\
\hline NAPHT-40/lod $(0.5 \% / 2 \%, w / w)$ & & & & & & $n p^{a}$ & & \\
\hline NAPHT-41/lod $(0.5 \% / 2 \%, \mathrm{w} / \mathrm{w})$ & & $70 \%$ & $67 \%$ & & & $52 \%$ & & \\
\hline NAPHT-42/lod $(0.5 \% / 2 \%, w / w)$ & $43 \%$ & $64 \%$ & $61 \%$ & $64 \%$ & & $60 \%$ & & \\
\hline NAPHT-43/lod $(0.5 \% / 2 \%, \mathrm{w} / \mathrm{w})$ & & $65 \%$ & & & & & & \\
\hline $\begin{array}{l}\text { NAPHT-41/R-Cl } \\
(0.5 \% / 3 \%, \mathrm{w} / \mathrm{w})\end{array}$ & & & & & & $42 \%$ & & \\
\hline $\begin{array}{l}\text { NAPHT-42/R-Cl } \\
(0.5 \% / 3 \%, w / w)\end{array}$ & & & & & $60 \%$ & $64 \% / 64 \%^{b}$ & $62 \%$ & $62 \%$ \\
\hline $\begin{array}{l}\text { NAPHT- } 43 / \mathrm{R}-\mathrm{Cl} \\
(0.5 \% / 3 \%, \mathrm{w} / \mathrm{w})\end{array}$ & & & & & $49 \%$ & $60 \% / 60 \%{ }^{\mathrm{b}}$ & $56 \%$ & $56 \%$ \\
\hline $\begin{array}{l}\text { NAPHT-40/lod/NVK } \\
(0.5 \% / 2 \% / 3 \%, w / w / w)\end{array}$ & & $70 \%$ & & & & $62 \%$ & & \\
\hline $\begin{array}{l}\text { NAPHT- } 41 / \mathrm{lod} / \mathrm{NVK} \\
(0.5 \% / 2 \% / 3 \% \mathrm{w} / \mathrm{w} / \mathrm{w})\end{array}$ & & & & & & $61 \%$ & $59 \%$ & \\
\hline $\begin{array}{l}\text { NAPHT-42/lod/NVK } \\
(0.5 \% / 2 \% / 3 \%, w / w / w)\end{array}$ & & & $65 \%$ & & & $64 \% / 65 \%{ }^{b}$ & & \\
\hline $\begin{array}{l}\text { NAPHT-41/MDEA } \\
(0.5 \% / 2 \%, w / w)\end{array}$ & & & & & & $59 \%$ & & \\
\hline $\begin{array}{l}\text { NAPHT-42/MDEA } \\
(0.5 \% / 2 \%, w / w)\end{array}$ & & & & & & $65 \% / 61 \%^{\mathrm{b}}$ & & \\
\hline BAPO $(0.5 \%$ w) & - & - & - & - & - & $56 \%, 30 \%^{b}$ & - & - \\
\hline NAPHT-44 (0.5\% w) & & & & & & $24 \%$ & & \\
\hline NAPHT-45 $(0.5 \% \mathrm{w})$ & & & & & & $29 \%$ & $20 \%$ & \\
\hline NAPHT-46 $(0.5 \%$ w) & & & & & & $40 \%$ & $29 \%$ & \\
\hline NAPHT-47 $(0.5 \% \mathrm{w})$ & & & & & & $n p^{a}$ & & \\
\hline NAPHT- $44 / \operatorname{lod}(0.5 \% / 2 \%, w / w)$ & $53 \%$ & $63 \%$ & $67 \%$ & $68 \%$ & & $57 \%$ & & \\
\hline NAPHT- $45 / \operatorname{lod}(0.5 \% / 2 \%, w / w)$ & $54 \%$ & & $63 \%$ & & & & & \\
\hline NAPHT- $46 / \operatorname{lod}(0.5 \% / 2 \%, w / w)$ & $23 \%$ & & $65 \%$ & & & & & \\
\hline NAPHT-47/lod $(0.5 \% / 2 \%, w / w)$ & & $67 \%$ & $58 \%$ & & & $\mathrm{np}^{\mathrm{a}}$ & & \\
\hline $\begin{array}{l}\text { NAPHT-44/R-Cl } \\
(0.5 \% / 3 \%, w / w)\end{array}$ & & & & & $50 \%$ & $62 \%, 60 \%$ b & $59 \%$ & $57 \%$ \\
\hline $\begin{array}{l}\text { NAPHT-45/R-Cl } \\
(0.5 \% / 3 \%, w / w)\end{array}$ & & & & & $54 \%$ & $63 \%$ & $62 \%$ & \\
\hline $\begin{array}{l}\text { NAPHT- } 46 / \mathrm{R}-\mathrm{Cl} \\
(0.5 \% / 3 \%, \mathrm{w} / \mathrm{w})\end{array}$ & & & & & $58 \%$ & $64 \%$ & $60 \%$ & \\
\hline $\begin{array}{l}\text { NAPHT-47/R-Cl } \\
(0.5 \% / 3 \%, w / w)\end{array}$ & & & & & & $n p^{a}$ & & \\
\hline $\begin{array}{l}\text { NAPHT-44/lod/NVK } \\
(0.5 \% / 2 \% / 3 \%, w / w / w)\end{array}$ & & $69,65 \%{ }^{b}$ & & & & $63 \%, 64 \%^{b}$ & & \\
\hline NAPHT-45/lod/NVK & & & $65 \%$ & & & & & \\
\hline NAPHT-46/lod/NVK & & & $64 \%$ & & & & & \\
\hline$(0.5 \% / 2 \% / 3 \%, w / w / w)$ & & & & & & & & \\
\hline $\begin{array}{c}\text { NAPHT-47/lod/NVK } \\
(0.5 \% / 2 \% / 3 \%, w / w / w)\end{array}$ & & & & & & $36 \%$ & & \\
\hline $\begin{array}{l}\text { NAPHT-47/MDEA/R-Cl } \\
(0.5 \% / 2 \% / 3 \%, w / w / w)\end{array}$ & & & & & & $48 \%$ & & \\
\hline
\end{tabular}

${ }^{\mathrm{a}} \mathrm{np}$ : no polymerization ${ }^{\mathrm{b}}$ determined after one week of storage at room temperature. Light intensity of the different light sources: laser diode at $405 \mathrm{~nm}\left(110 \mathrm{~mW} / \mathrm{cm}^{2}\right)$, laser diode at $455 \mathrm{~nm}(80$ $\left.\mathrm{mW} / \mathrm{cm}^{2}\right)$, laser diode at $470 \mathrm{~nm}\left(70 \mathrm{~mW} / \mathrm{cm}^{2}\right)$, halogen lamp : 380-800 nm $\left(12 \mathrm{~mW} / \mathrm{cm}^{2}\right)$ 
Finally, for the three-component system NAPHT-x/MDEA/R-Cl $(0.5 \% / 2 \% / 3 \%, w / w / w)$, only NAPHT-39 could initiate an efficient FRP with a conversion of $61 \%$ at $405 \mathrm{~nm}$. To support the formation of radicals, NAPHT- $\mathrm{x}_{(-\mathrm{H})}{ }^{\bullet}$ and $\mathrm{R}^{\bullet}$ were proposed as the initiating species, based on the equations r20-r24 detailed below.

$$
\begin{aligned}
& \boldsymbol{N A P H T}_{-\boldsymbol{x}} \rightarrow 1_{\mathrm{NAPHT}_{-x}}(h v) \text { and } 1_{\text {NAPHT }_{-x}} \rightarrow 3_{\text {NAPHT }_{-x}}(r 20) \\
& 1,3_{\text {NAPHT }_{-x}} \rightarrow \text { NAPHT }_{-x}^{\bullet-}+\text { NAPHT }_{-x}^{\bullet+} \rightarrow \text { NAPHT }_{-x}-\mathrm{H}^{\bullet}+\text { NAPHT }_{-x}-\mathrm{H}^{\bullet} \\
& \text { (r21) } \\
& \boldsymbol{N A P H T}_{-\boldsymbol{x}}^{\bullet-}+\mathrm{R}^{\prime}-\mathrm{Cl} \rightarrow \boldsymbol{N A P H T}{ }_{-\boldsymbol{x}}+\left(\mathrm{R}^{\prime}-\mathrm{Cl}\right)^{\bullet-}(r 22)
\end{aligned}
$$

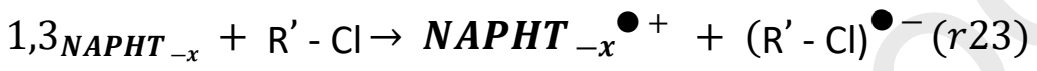

$$
\begin{aligned}
& \left(\mathrm{R}^{\prime}-\mathrm{Cl}\right)^{\bullet-} \rightarrow \mathrm{R}^{\bullet}+\mathrm{Cl}^{-}
\end{aligned}
$$

Similarly, high monomer conversions could also be obtained at $405 \mathrm{~nm}$ for the CP of EPOX. Notably, at $405 \mathrm{~nm}\left(110 \mathrm{~mW} / \mathrm{cm}^{2}\right)$, the best conversions for the EPOX resins were obtained with NAPHT-33, NAPHT-34 and NAPHT-41 when used in the two-component systems NAPHT-x $(x=33,47) / \operatorname{lod}(0.5 \% / 2 \%, w / w)$, approaching $70 \%$. When used in threecomponent systems NAPHT-x/lod/NVK $(0.5 \% / 2 \% / 3 \%, \mathrm{w} / \mathrm{w} / \mathrm{w})$, the best polymerization profiles were obtained with NAPHT-33, NAPHT-41 and NAPHT-44 with final monomer conversions close to $70 \%$. If similar monomer conversions close to $70 \%$ could be obtained with the aforementioned two- and three-component systems, a faster polymerization process was however obtained with the three-component systems, resulting from the formation of the highly reactive cation $\mathrm{Ph}-\mathrm{NVK}^{+}$according to the equations r25-r29.

$$
\begin{aligned}
& \boldsymbol{N A P H T}-\boldsymbol{x} \rightarrow 1_{\text {NAPHT }_{-x}}(h v) \text { and } 1_{\text {NAPHT }_{-x}} \rightarrow 3_{\text {NAPHT }_{-x}}(r 25) \\
& 1,3_{\text {NAPHT }_{-x}}+\mathrm{Ph}_{2} I^{+} \rightarrow \mathbf{N A P H T} \boldsymbol{A}_{-\boldsymbol{x}}^{\bullet+}+P h_{2} I^{\bullet}(r 26) \\
& P h_{2} I^{\bullet} \rightarrow \rightarrow P h \bullet+P h-I \\
& P h^{\bullet}+N V K \rightarrow P h-N V K^{\bullet}(r 28) \\
& P h-N V K^{\bullet}+P h_{2} I^{\bullet} \rightarrow P h-N V K^{+}+P h^{\bullet}+P h-I(r 29)
\end{aligned}
$$

In the specific case of NAPHT-44, the possibility to initiate concomitantly the cationic/radical polymerization of an EPOX/TMPTA blend (50\%/ 50\% w/w) upon exposure to 
a LED at $405 \mathrm{~nm}$ under air or in laminate was examined. Typical polymerization profiles under air and in laminates are presented in the Figure 11. Under air, a lower TMPTA conversion was determined than in laminates, attributable to oxygen inhibition. Almost similar conversions could be obtained for EPOX and TMPTA, around 60\%. Conversely, in laminate, a severe reduction of the EPOX conversion could be evidenced and this behaviour is classically observed for the photopolymerization of EPOX/TMPTA blends.[97,166] Indeed, the lower conversion for EPOX monomer results from the fact that most of the free radicals generated are consumed to initiate the FRP of TMPTA, leading to a reduction of the radicals used to promote the FRPCP of EPOX.
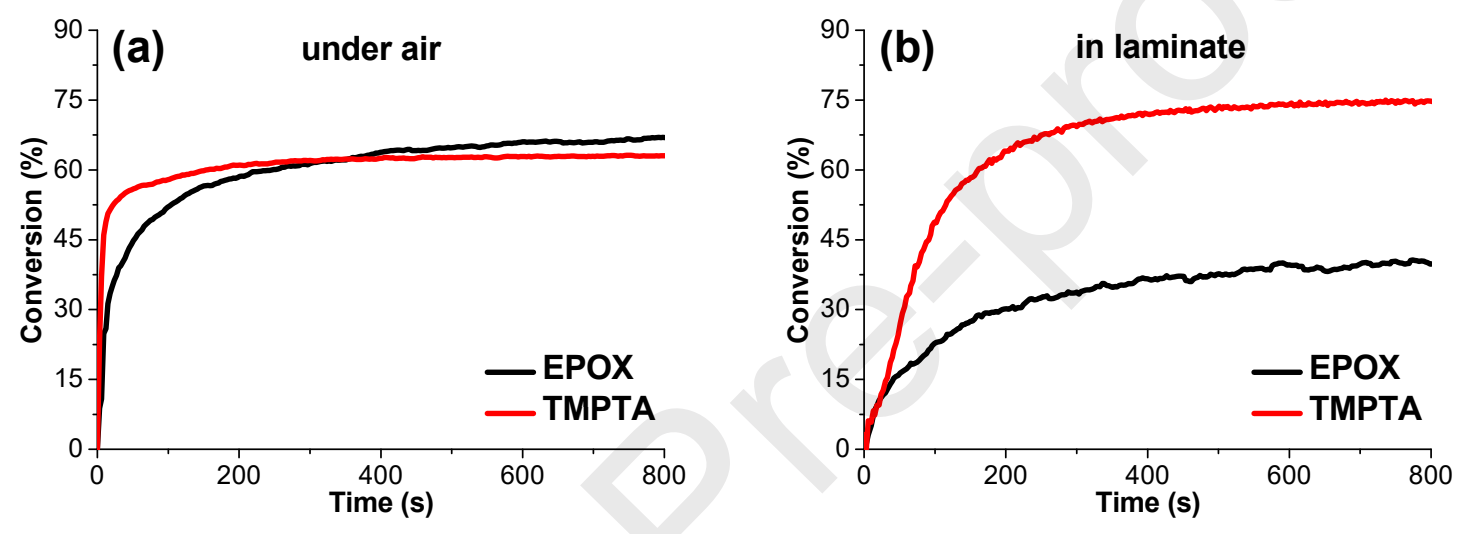

Figure 11. Photopolymerization profile of an EPOX/TMPTA blend $(50 \% / 50 \%, w / w)$ in the presence of NAPHT-44/lod/NVK $(0.5 \% / 2 \% / 3 \%, w / w / w)$ under air (a) or in laminate (b). upon irradiation with a LED at $405 \mathrm{~nm}$. Reprinted with permission from Zhang et al. [163] Copyright (C) 2018 John Wiley \& Sons, Inc.

Finally, only NAPHT-48-NAPHT-53 were tested in conditions differing from those used to investigate NAPHT-33-NAPHT-47. Notably, only the FRP of a methacrylate resin (Mix-MA) was examined, consisting in a mixture of three monomers (33.3 wt\% of (hydroxypropyl) methacrylate (HPMA), $33.3 \mathrm{wt} \%$ of 1,4-butanediol dimethacrylate (1,4-BDDMA) and $33.3 \mathrm{wt} \%$ of a urethane dimethacrylate monomer) (See Scheme 11). Parallel to this, different additives were also used as exemplified with the iodonium salt, bis(4-tert-butylphenyl)iodonium hexafluorophosphate (lod2) and the phosphine 4-(diphenylphosphino)benzoic acid (4-dppba). Notably, 4-dppba has previously been used in numerous photoinitiating systems based on flavones,[41,63] cyanines,[167-168] squaraines, BODIPYs and porphyrins[22,29] to overcome 
the oxygen inhibition. Numerous examples of phosphines are also reported in the literature for this purpose.[113,169,170]

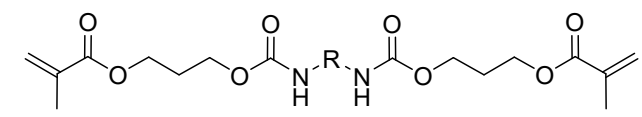

33 wt\%

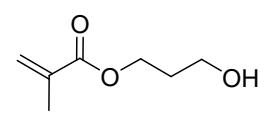

HPMA

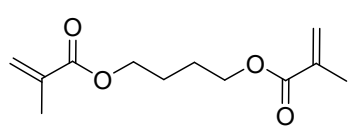

1,4-BDDMA 33 wt $\%$

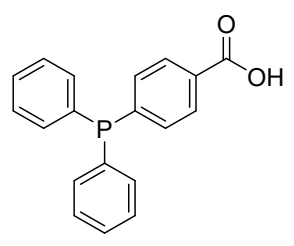

4-dppba

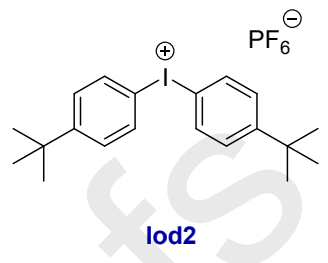

$\operatorname{lod} 2$

Mix-MA

Scheme 11. Chemical structures of monomers and additives used with NAPHT-48-NAPHT-

53.

At the three selected wavelengths $\left(395 \mathrm{~nm}\left(110 \mathrm{~mW} / \mathrm{cm}^{2}\right), 405 \mathrm{~nm}\left(110 \mathrm{~mW} / \mathrm{cm}^{2}\right)\right.$, and $\left.470 \mathrm{~nm}\left(80 \mathrm{~mW} / \mathrm{cm}^{2}\right)\right)$, NAPHT-48-NAPHT-53 worked clearly better than the benchmark camphorquinone which a reference for the dental composites[171] or ethyl 4(dimethylamino) benzoate (EDB) which is a well-established reference for photopolymerization of methacrylates in the near-UV or visible range.[102,172] Notably, due to their extreme efficiency, a 5-fold reduction of the photoinitiator content could be applied to NAPHT-48-NAPHT-53 compared to the former NAPHT-1-NAPHT-47 so that threecomponent systems with the following composition could be used : NAPHT-x $(\mathbf{x}=\mathbf{4 8 -}$ 53)/lod/4-dppba $(0.1 \% / 3 \% / 2 \%, w / w / w)$. At such a low photoinitiator content, the reference two-component system CQ/EDB $(0.1 \% / 1 \% \mathrm{w} / \mathrm{w})$ proved to be ineffective at 395 and $405 \mathrm{~nm}$ for the FPR of MIX-MA under air despites the averred absorption of camphorquinone at these wavelengths whereas final monomer conversions ranging between 70 and $80 \%$ could be obtained with the newly developed NAPHT-48-NAPHT-53. Only at $470 \mathrm{~nm}$, the CQ/EDB system could compete with the three-component systems NAPHT-x ( $x=48-53) / l o d / 4-d p p b a$ $(0.1 \% / 3 \% / 2 \%, w / w / w)$ due to a better adequation of its absorption with the emission of the lamp (See Figure 12).[165] 


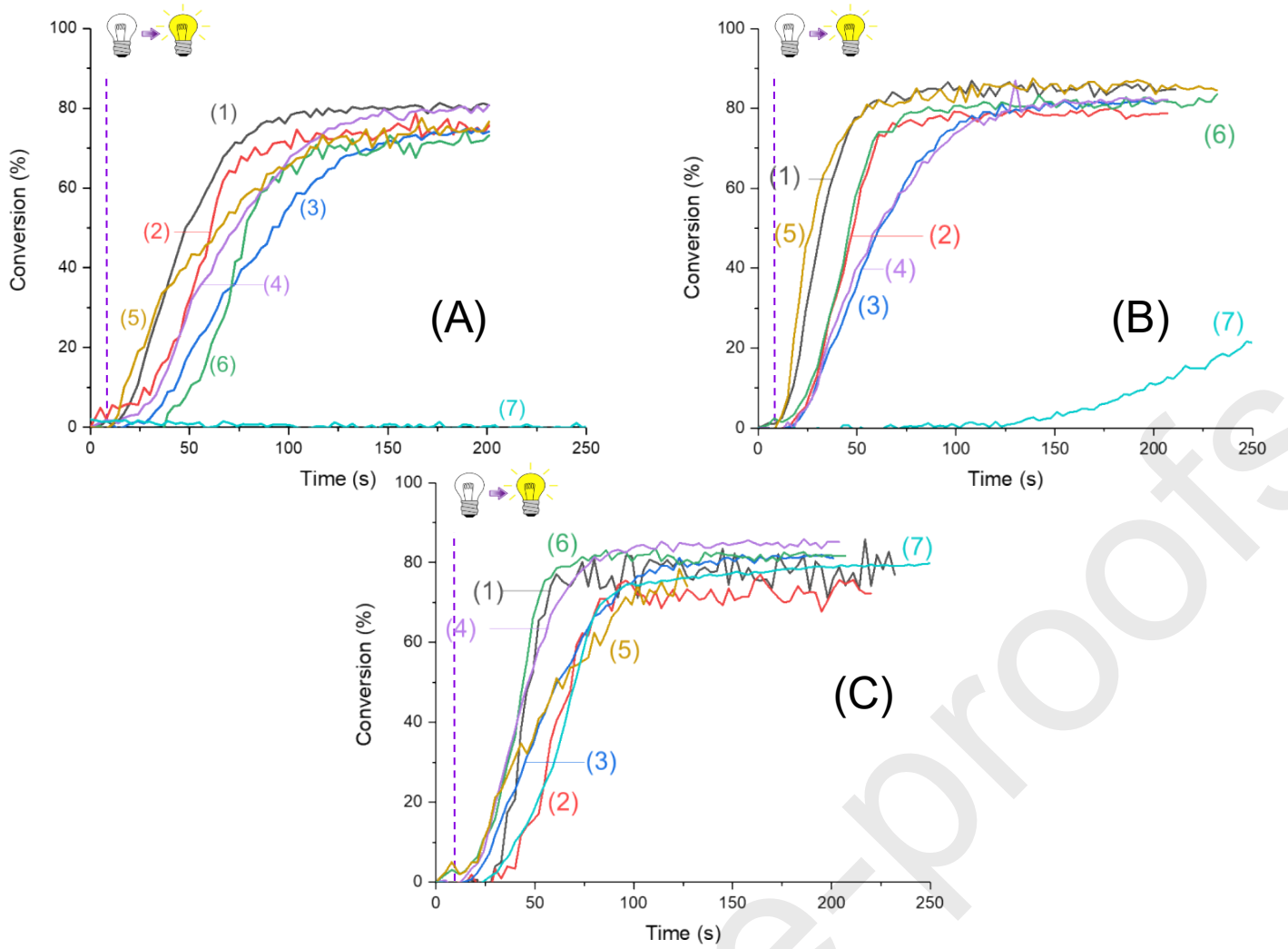

Figure 12. Photopolymerization profiles of Mix-MA under air for (1) NAPHT-48/lod2/4-dppba $(0.1 \% / 3 \% / 2 \% \mathrm{w} / \mathrm{w} / \mathrm{w})$ (2) NAPHT-49/lod $2 / 4-d p p b a ~(0.1 \% / 3 \% / 2 \% \mathrm{w} / \mathrm{w} / \mathrm{w})$ (3) NAPHT50/lod2/4-dppba $(0.1 \% / 3 \% / 2 \% \mathrm{w} / \mathrm{w} / \mathrm{w})$ (4) NAPHT-52/lod2/4-dppba $(0.1 \% / 3 \% / 2 \% \mathrm{w} / \mathrm{w} / \mathrm{w})$ (5) NAPHT-53/lod2/4-dppba $(0.1 \% / 3 \% / 2 \% \quad w / w / w) \quad(6) \quad$ NAPHT-51/lod2/4-dppba $(0.1 \% / 3 \% / 2 \% \mathrm{w} / \mathrm{w} / \mathrm{w})(7)$ CQ/EDB $(0.1 \% / 1 \% \mathrm{w} / \mathrm{w})$ for irradiations done at (A) $395 \mathrm{~nm},(\mathrm{~B}) 405$ $\mathrm{nm}$ and (C) $470 \mathrm{~nm}$. Reprinted with permission from Bonardi et al. [165] Copyright (C) 2019 MDPI.

\subsection{Water-soluble photoinitiators}

The search for new photoinitiators activable under visible light is the focus of numerous efforts. If encouraging results have been obtained with photoinitiating systems that can operate in solvent-free conditions i.e. in purely organic conditions, less efforts have been devoted to elaborate water-soluble photoinitiators. In this aim, several strategies were proposed to chemically modify the photoinitiators such as the covalent linkage of alkyl chains bearing acid end groups,[173-174] the introduction of poly(ethylene glycol) chains,[175] ammonium or sulfonate groups.[176] An innovative strategy consisting in encapsulating the photoinitiator inside a water-soluble macrocycle (cyclodextrin (CD)) was examined with NAPHT-25[129] and NAPHT-38.[162] As interesting feature of this strategy, no chemical modification of the photoinitiator is required prior to its encapsulation in the macrocycle so 
that this strategy can be applied to almost all photoinitiators reported in the literature. However, the complexation constant must be sufficient in order the photoinitiator to remain inside the cavity of the macrocycle. When tested in water for the polymerization of the hydrophilic monomer 2-hydroxyethyl acrylate (HEA) using the two-component system NAPHT-25-CD/MDEA $(0.2 \% / 3 \% \mathrm{w} / \mathrm{w})$, a monomer conversion of $80 \%$ could be obtained within 10 min of irradiation with a LED@405 nm $\left(110 \mathrm{~mW} / \mathrm{cm}^{2}\right)$. Formation of a gel containing 70\% of water was obtained (See Figure 13). If photoinitiators encapsulated in cyclodextrin have previously reported in the literature,[177-182] none of them could initiate a polymerization under low light intensity as NAPHT-25-CD could do.

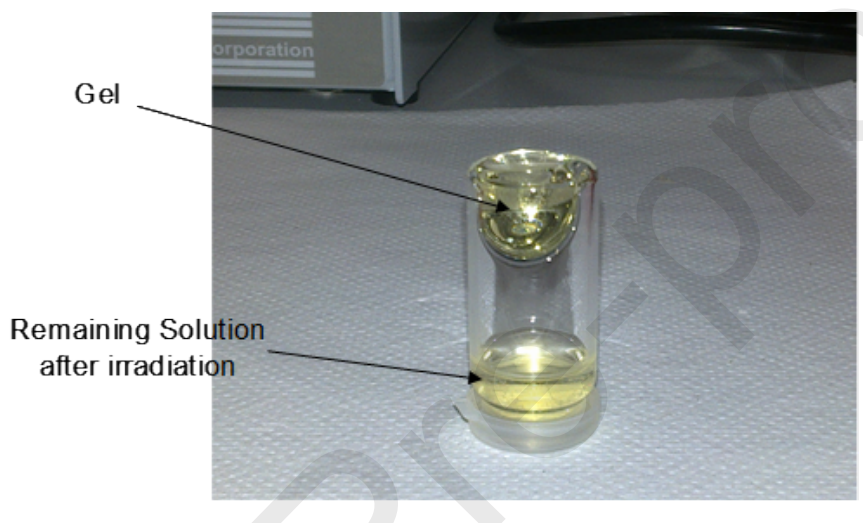

Figure 13. Gel formed by photopolymerization at $405 \mathrm{~nm}$ of HEA in water. Reproduced with permission from Zhang et al. [129]. Copyright 2015 American Chemical Society.

In 2016, a similar strategy was developed with NAPHT-38, which is an anti-cancer agent known under the name of azonafide.[183-185] It has to be noticed that NAPHT-37 (known under the name of amonafide)[186-187] also exhibits anticancer properties but the potential biological activities of NAPHT-37 and NAPHT-38 in polymer films such as bactericides or fungicides have never been examined. Interestingly, inclusion of NAPHT-38 in cyclodextrin was not an easy task and after numerous unsuccessful trials, sulfobutylether- $\beta$-cyclodextrin (SBE- $\beta-C D)$ was selected as the appropriate macrocycle.[188] Notably, this macrocycle was selected due its elongated cavity size and a ratio of $1 / 24$ was found between the complexed SBE- $\beta-C D$ and the free SBE- $\beta-C D$. Further experiments also revealed that only one unit of NAPHT-38 was complexed inside the inclusion cavity. While using the two-component system NAPHT-38-SBE- $\beta-C D / M D E A \quad(0.1 \% / 3 \% \mathrm{w} / \mathrm{w})$ for the polymerization of hydroxyethylmethacrylate (HEMA) or HEA, a slower polymerization process compared to that found for the 
two-component system NAPHT-25-CD/MDEA was observed, a monomer conversion for HEMA of only $68 \%$ after one hour of irradiation at $405 \mathrm{~nm}\left(110 \mathrm{~mW} / \mathrm{cm}^{2}\right)$ being determined. A hydrogel formed with the resulting poly(hydroxyethylmethacrylate) containing $70 \%$ of water as observed for the previous hydrogel.

\subsection{Crosslinkable photoinitiators}

Migratability of photoinitiators and additives inside the polymer films is a major issue that can drastically limit the potential applications of polymers. Notably, this issue should be addressed for the polymer films to comply with the requirements of food packaging or biocompatibility.[189-190] Over the years, several strategies have been developed to overcome this drawback and low migratable photoinitiators based on oligomers, trifunctional and bifunctional architectures or photoinitiators bearing a polymerizable unit have been proposed.[104,107,191-208] With aim at designing low migratable initiators, the best strategy is undoubtedly the introduction of a polymerizable group so that the photoinitiator is covalently linked to the final polymer. Concerning naphthalimides, numerous derivatives have been reported in the literature, as exemplified with NAPHT-54-NAPHT-63. The first crosslinkable naphthalimides NAPHT-54 and NAPHT-55 were reported in 2013 by the group of Lalevée et al. (See Scheme 12).[117] By modifying the functional group used to connect the methacrylate group to the naphthalene core, major differences could be found for the absorption properties. To illustrate this, a shift of the absorption maximum at $409 \mathrm{~nm}$ for NAPHT-54 vs. $360 \mathrm{~nm}$ for NAPHT-55 was found for the photoinitiator exhibiting the best electron-donating group. Due to the lower electron-donating ability of the alkoxy group, ICT bands extending between 325 and $500 \mathrm{~nm}$ for NAPHT-54, 320 and $420 \mathrm{~nm}$ for NAPHT-55 were evidenced by UV-visible absorption spectroscopy.

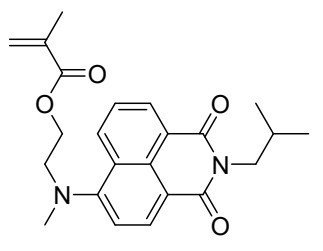

NAPHT-54

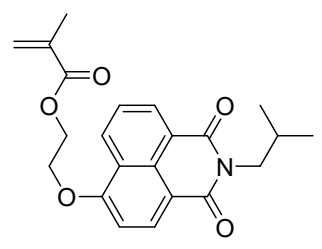

NAPHT-55

Scheme 12. Chemical structures of NAPHT-54-NAPHT-55.

Due to the weak absorption at $405 \mathrm{~nm}$, NAPHT-55 could only initiate polymerization while using a halogen lamp $\left(12 \mathrm{~mW} / \mathrm{cm}^{2}\right)$. Thus, NAPHT-54/lod/NVK $(1 \% / 2 \% / 3 \%, \mathrm{w} / \mathrm{w} / \mathrm{w})$ 
could induce a faster polymerization and provide a higher EPOX conversion than its analogue three-component system NAPHT-55/lod/NVK (1\%/2\%/3\%, w/w/w). A final conversion of 65\% could be obtained with NAPHT-54, far from the $40 \%$ monomer conversion obtained with NAPHT-55. A similar trend was observed for the FRP of TMPTA (See Table 8). Examination of the extractability revealed that less than $0.3 \%$ (based on the initial amount of NAPHT-54) could be extracted from the polymer film. It has to be noticed that not only the photoinitiator is rendered not extractible. Indeed, concerning the two additives, $N$-vinylcarbazole (NVK) is also supposed to be immobilized into the polymer network by polymerization with its vinyl group and lod by the production of the $\mathrm{Ph}^{\bullet}$ radicals at the origin of the polymerization process.[209]

Table 8. EPOX and TMPTA conversions obtained under air upon exposure to different visible light sources for $800 \mathrm{~s}$ for the EPOX resins (under air), for 400s for the TMPTA resins (in laminate) for NAPHT-54 and NAPH-55-based photoinitiating systems.

\begin{tabular}{|c|c|c|c|c|c|c|}
\hline & \multicolumn{3}{|c|}{ EPOX } & \multicolumn{3}{|c|}{ TMPTA } \\
\hline & $\begin{array}{c}\text { Halogen } \\
\text { lamp }\end{array}$ & $\begin{array}{c}\text { Laser } \\
\text { diode } \\
(405 \mathrm{~nm})\end{array}$ & $\begin{array}{c}\text { Laser } \\
\text { diode } \\
(457 \mathrm{~nm})\end{array}$ & $\begin{array}{c}\text { Halogen } \\
\text { lamp }\end{array}$ & $\begin{array}{c}\text { LED } \\
(405 \mathrm{~nm})\end{array}$ & $\begin{array}{c}\text { LED } \\
(470 \mathrm{~nm})\end{array}$ \\
\hline NAPHT-54 (1\% w) & $61 \%$ & 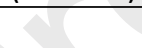 & & $50 \%$ & $n p^{a}$ & \\
\hline NAPHT-55 (1\% w) & $11 \%$ & & & & & \\
\hline NAPHT-54/lod/NVK (1\%/2\%/3\%, w/w/w) & $64 \%$ & $51 \%$ & $64 \%$ & $61 \%$ & $57 \%$ & $65 \%$ \\
\hline NAPHT-55/lod/NVK (1\%/2\%/3\%, w/w/w) & $41 \%$ & & & & & \\
\hline NAPHT-54/MDEA $(1 \% / 2 \%, w / w)$ & & & & $23 \%$ & & \\
\hline NAPHT-55/MDEA (1\%/2\%, w/w) & & & & $41 \%$ & & \\
\hline
\end{tabular}

Light intensity of the different light sources: laser diode at $405 \mathrm{~nm}\left(110 \mathrm{~mW} / \mathrm{cm}^{2}\right)$, laser diode at $457 \mathrm{~nm}\left(100 \mathrm{~mW} / \mathrm{cm}^{2}\right)$, halogen lamp : $380-800 \mathrm{~nm}\left(12 \mathrm{~mW} / \mathrm{cm}^{2}\right)$

In 2018, two naphthalimides NAPHT-56 and NAPHT-57 bearing methacryloyl groups were designed and synthesized by the group of Tang et al.[210] As shown in the Scheme 13, NAPHT-56 and NAPHT-57 combine within a unique molecule a strong electron donor i.e. the piperidinyl group introduced at the 6-position of naphthalimide and this tertiary amine that can act as a co-initiator is functionalized with one or two polymerizable group. By mean of this strategy, the absorption properties of NAPHT-56 and NAPHT-57 remained identical to that of NAPHT-43. 


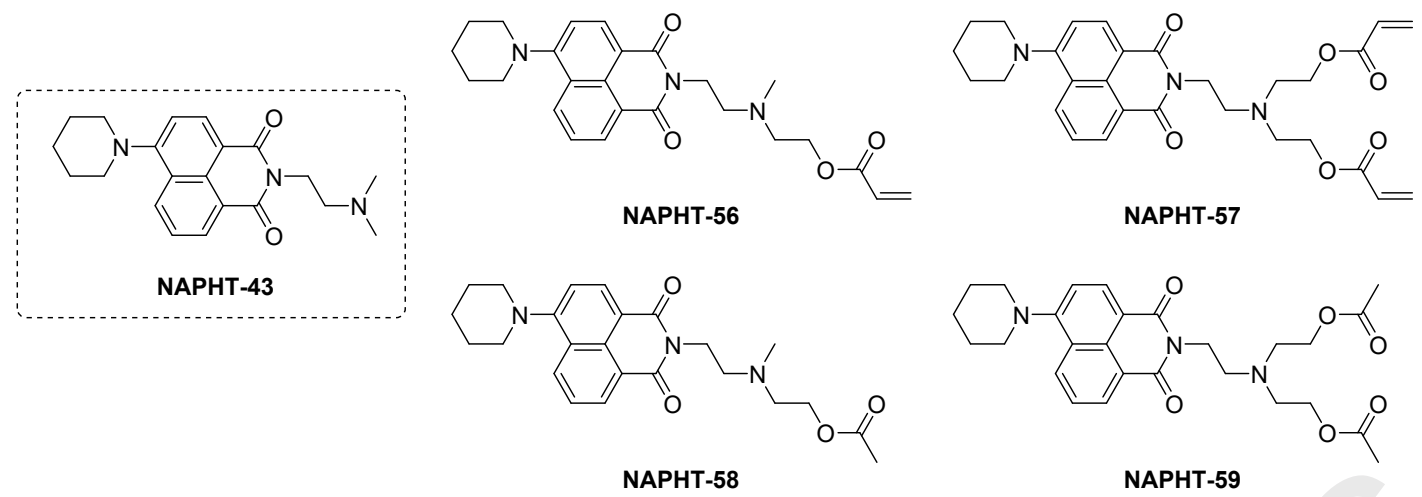

Scheme 13. Chemical structures of NAPHT-56-NAPHT-59.

However, if NAPHT-56 and NAPHT-57 were tested in similar conditions to that used for NAPHT-43 but with another monomer (1,6-hexanediol diacrylate (HDDA)), the polymerization of HDDA while using NAPHT-56 and NAPHT-57 as one component system was extremely slow, requiring $20 \mathrm{~min}$. to reach a final monomer conversion of $60 \%$ upon irradiation with a xenon lamp $\left(\lambda>400 \mathrm{~nm}, 50 \mathrm{~mW} / \mathrm{cm}^{2}\right)$. Comparison with their analogues NAPHT-58 and NAPHT-59 furnished similar polymerization profiles but lower final monomer conversions. If the methacryloyl and the acetyl groups could provide a similar solubility to NAPHT-56-NAPHT-59, a synergetic effect resulting from the proximity of the methacryloyl group and the photogenerated aminoalkyl radicals was tentatively proposed to support the higher final monomer conversions in the case of NAPHT-56 and NAPHT-57 substituted with an acryloyl group. Indeed, after generation of the aminoalkyl radicals, these latter can be directly transferred onto the adjacent methacryloyl group, launching directly the polymerization. Comparison of the photoinitiating ability of NAPHT-56 ( $2 \% \mathrm{w})$ alone in a tripropylene glycol diacrylate (TPGDA) resin with the reference system CQ/MDEA (2\%/5\% w/w) revealed NAPHT-56 to furnish a similar monomer conversion (80\%) after $20 \mathrm{~min}$. of irradiation than camphorquinone (CQ) but with a longer induction time. Examination of the extractability of photoinitiators from the polymer films revealed that higher amounts of photoinitiators could be extracted, ranging from 6.7 and $6.6 \%$ for NAPHT-56 and NAPHT-57, 19.9 and $22.7 \%$ for NAPHT-58 and NAPHT-59 respectively, relative to the initial amount of initiators. Considering that a 3 -fold reduction of the migratability was observed for the crosslinkable photoinitiators (NAPHT-56 and NAPHT-57), pertinence of the strategy was clearly evidenced. 
Following this work, Tang et al. examined the possibility to replace the amine-based linkage used in NAPHT-56 and NAPHT-57 by an ether group in NAPHT-60 and NAPHT-61 (See Scheme 14).[211] Choice of an ether group was motivated by the fact that this group was previously reported in the literature as having the potential to reduce the oxygen inhibition and improve the initiation efficiency.[212,213] Due to the distance between the ether group and the chromophore units, no influence on the absorption properties was expected and the UV-visible absorption spectra of NAPHT-60 and NAPHT-61 superimposed that of NAPHT-56NAPHT-59. Here again, photopolymerization experiments revealed that NAPHT-60 could serve as a one-component visible light photoinitiator with better initiating abilities than BAPO or the CQ/MDEA system in the presence or absence of air. However, the polymerization process remained slow compared to that reported for NAPHT-54 and NAPHT-55. Notably, it required an irradiation time increased by a factor 3 to furnish similar monomer conversions than that obtained with NAPHT-54 and NAPHT-55 for the polymerization of TMPTA while using the same light source (LED at $405 \mathrm{~nm}, 110 \mathrm{~mW} / \mathrm{cm}^{2}$ ).
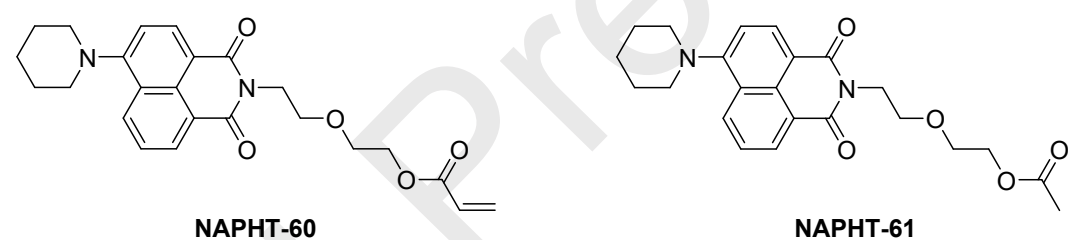

Scheme 14. Chemical structures of NAPHT-60 and NAPHT-61.

In the present case, comparison of the polymerization profiles obtained for NAPHT-60 and NAPHT-61 revealed that the presence of the methacryloyl group on NAPHT-60 did not influence the polymerization process as previously detected for NAPHT-56 and NAPHT-57. Comparison of the polymerization profiles of HDDA for NAPHT-56 and NAPHT-60 when used as a one-component system evidenced the higher photoinitiating ability of NAPHT-60. However, examination of the photophysical properties of NAPHT-56 and NAPHT-60 also revealed NAPHT-60 to possess a longer phosphorescence lifetime (19.6 ms vs. $14.2 \mathrm{~ms}$ ) so that the improvement of the polymerization rate can be assigned to its higher ability to create radicals and not to the presence of the ether linkage.[214-215] Comparison of the extractability of NAPHT-60 and NAPHT-61 confirmed the trend previously observed for NAPH56-NAPHT-59, with a 4-fold reduction of the extractability for the crosslinkable photoinitiator (6.2\% vs. $24.6 \%$ for NAPHT-60 and NAPHT-61 respectively). 
As final examples of crosslinkable photoinitiator is NAPHT-62 (See Scheme 15).[216] It has to be noticed that, in this last case, a macrophotoinitiator NAPHT-63, has been prepared by polymerizing 3-bis(trimethylsilyoxy)methylsiyl-propylmethacrylate with NAPHT-62.

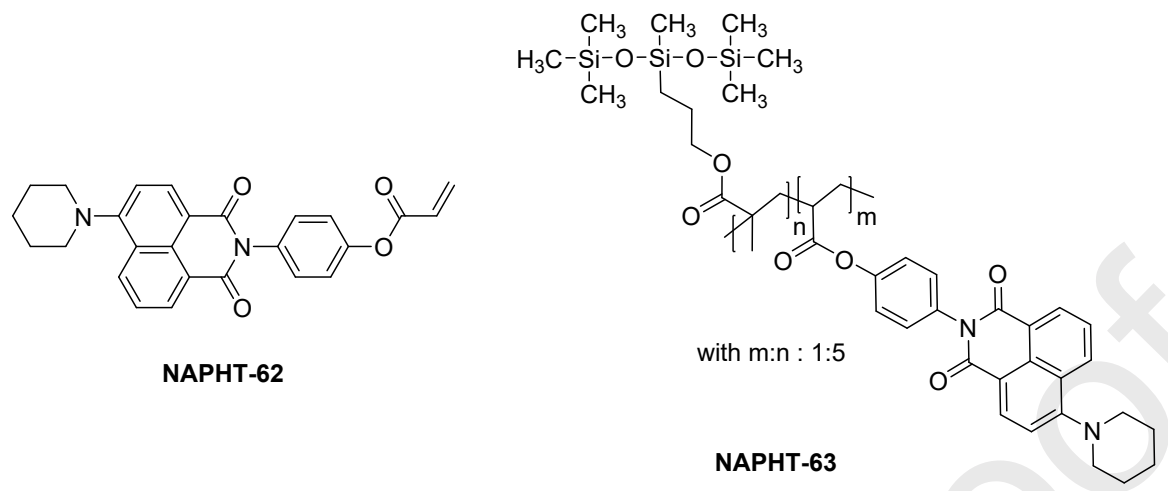

Scheme 15. Chemical structures of NAPHT-62 and NAPHT-63.

Among the most interesting results obtained with NAPHT-62 and NAPHT-63 used as one-component photoinitiating system, surface modification of a urethane diacrylate prepolymer (PUA) layer could be realized, what was demonstrated by contact angle measurements. It has to be noticed that modification of the surface properties of a polymer film by mean of the photoinitiator used to prepare the polymer is not new and a few examples of photoinitiators having this capacity have been reported prior to this study.[217-220] At similar photoinitiator content (1 wt\%), the hydrophilic surface obtained with NAPHT-62 (contact angle of $\left.70.1^{\circ}\right)$ could be converted as a hydrophobic one $\left(101.2^{\circ}\right)$ with NAPHT-63. By increasing the concentration of photoinitiator, hydrophobicity of the surface could be further improved, the contact angle increasing $105.1^{\circ}$ at $10 \mathrm{wt} \%$ and 110.3 at $15 \mathrm{wt} \%$. Resistance of the polymer films to water and ethanol was also examined and the water and ethanol absorption ratios of 4.4 and $8.9 \%$ determined for polymers formed with NAPHT-62 could be decreased to 2.1 and $4.3 \%$ with NAPHT-63 (1 wt\%). The resistance to water and ethanol could be further improved by increasing the photoinitiator content and ratios as low as 1.0 and 2.8 $\%$ could be obtained at 15 wt\% photoinitiator for water and ethanol. Finally, extractability of NAPHT-62 and NAPHT-63 from the HDDA polymer was examined. Here again, superiority of the silicone-based photoinitiator was confirmed, the amount of photoinitiator extracted from the polymer films decreasing from $32.2 \%$ for NAPHT-62 to $7.6 \%$ for the macrophotoinitiator NAPHT-63. 


\subsection{Panchromatic photoinitiators}

Panchromatic initiators are appealing candidates for photoinitiation as these molecules can be activated with a wide range of light sources without drastically affecting their photoinitiating efficiencies. Over the years, a few examples of such photoinitiators have been reported.[221-223] However, examples remain still scarce, justifying the search for new structures. In this field, the substitution pattern can drastically impact the absorption properties, what was demonstrated with the NAPHT-64-NAPHT-67 series (see Scheme 16).[224]

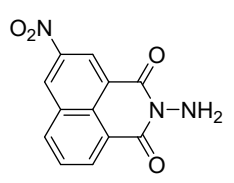

NAPHT-64

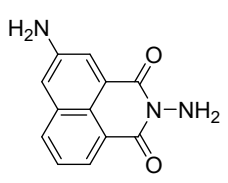

NAPHT-65

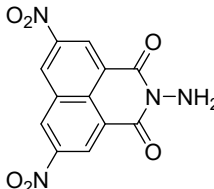

NAPHT-66

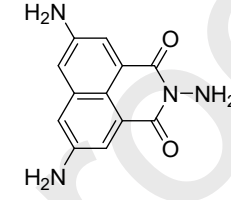

NAPHT-67

Scheme 16. Chemical structures of NAPHT-64-NAPHT-67.

Notably, for the nitro-based structures NAPHT-64 and NAPHT-66, an absorption strongly centered in the UV range (with absorption maxima at 329 and $317 \mathrm{~nm}$ respectively) was found but long tail extending until 500 and $700 \mathrm{~nm}$ were also detected for NAPHT-64 and NAPHT-66 respectively, so that their absorption spectra could overlap with the emission of numerous light sources (See Figure 14). Conversely, NAPHT-65 and NAPHT-67 substituted with amino groups showed an intense ICT band in the visible range with absorption maxima at 422 and $441 \mathrm{~nm}$, with long tails extending until 550 and $600 \mathrm{~nm}$ respectively. Considering the broadness of the absorptions, NAPHT-64-NAPHT-67 were tested in photoinitiating systems irradiated with LEDs at 405,455 and $470 \mathrm{~nm}$ but also with a halogen lamp. A comparison with the previous structures NAPHT-1-NAPHT-55 can also be established, NAPHT64-NAPHT-67 being tested in the same resins with the same additives and irradiated with the same light sources. A summary of the polymerization results is provided in the Table 9. 
Table 9. EPOX and TMPTA conversions obtained under air upon exposure to different visible light sources for $800 \mathrm{~s}$ for the EPOX resins (under air), for 400s for the TMPTA resins (in laminate) for NAPHT-64-NAPH-67 photoinitiating systems and reference systems.

\begin{tabular}{|c|c|c|c|c|c|c|c|c|}
\hline & \multicolumn{4}{|c|}{ EPOX } & \multicolumn{4}{|c|}{ TMPTA } \\
\hline & $\begin{array}{c}\text { Halogen } \\
\text { lamp }\end{array}$ & $\begin{array}{c}\text { LED } \\
(405 \mathrm{~nm})\end{array}$ & $\begin{array}{c}\text { LED } \\
(455 \mathrm{~nm})\end{array}$ & $\begin{array}{c}\text { LED } \\
(470 \mathrm{~nm})\end{array}$ & $\begin{array}{l}\text { Halogen } \\
\text { lamp }\end{array}$ & $\begin{array}{c}\text { LED } \\
(405 \mathrm{~nm})\end{array}$ & $\begin{array}{l}\text { LED } \\
(455 \mathrm{~nm})\end{array}$ & $\begin{array}{l}\text { LED } \\
(470 \mathrm{~nm})\end{array}$ \\
\hline NAPHT-64/lod $(0.5 \% / 2 \% \mathrm{w} / \mathrm{w})$ & & $n p^{a}$ & & & & & & \\
\hline NAPHT-65/lod $(0.5 \% / 2 \% \mathrm{w} / \mathrm{w})$ & & $59 \%$ & & & & $12 \%$ & & \\
\hline NAPHT-66/lod $(0.5 \% / 2 \% \mathrm{w} / \mathrm{w})$ & & $<5 \%$ & & & & & & \\
\hline NAPHT-67/lod $(0.5 \% / 2 \% \mathrm{w} / \mathrm{w})$ & & $55 \%$ & & & & $41 \%$ & & \\
\hline $\begin{array}{c}\text { NAPHT-64/lod/NVK } \\
(0.5 \% / 2 \% / 3 \%, w / w / w)\end{array}$ & & $51 \%$ & & & & & & \\
\hline $\begin{array}{l}\text { NAPHT-65/lod } / \mathrm{NVK} \\
(0.5 \% / 2 \% / 3 \% \mathrm{w} / \mathrm{w} / \mathrm{w})\end{array}$ & $41 \%$ & $62 \%, 66 \%^{\mathrm{b}}$ & $59 \%$ & $62 \%$ & & $50 \%$ & & \\
\hline $\begin{array}{l}\text { NAPHT-66/lod } / \text { NVK } \\
(0.5 \% / 2 \% / 3 \%, \mathrm{w} / \mathrm{w} / \mathrm{w})\end{array}$ & & $23 \%$ & & & & & & \\
\hline $\begin{array}{l}\text { NAPHT-67/lod/NVK } \\
(0.5 \% / 2 \% / 3 \%, w / w / w)\end{array}$ & $44 \%$ & $58 \%$ & $55 \%$ & $51 \%$ & $44 \%$ & $52 \%, 57 \%^{\mathrm{b}}$ & $48 \%$ & $49 \%$ \\
\hline $\begin{array}{c}\text { NAPHT-65/MDEA }(0.5 \% / 2 \% \\
\mathrm{w} / \mathrm{w})\end{array}$ & & & & & & $19 \%$ & & \\
\hline $\begin{array}{c}\text { NAPHT-67/MDEA }(0.5 \% / 2 \% \\
w / w)\end{array}$ & & & & & & $50 \%$ & & \\
\hline $\begin{array}{l}\text { NAPHT-65/MDEA/R-Cl } \\
(0.5 \% / 2 \% / 3 \%, \mathrm{w} / \mathrm{w} / \mathrm{w})\end{array}$ & & & & & & $6 \%$ & & \\
\hline $\begin{array}{l}\text { NAPHT-67/MDEA/R-Cl } \\
(0.5 \% / 2 \% / 3 \%, w / w / w)\end{array}$ & & & & & $49 \%$ & $61 \%, 61 \%^{b}$ & $57 \%$ & $56 \%$ \\
\hline
\end{tabular}

${ }^{a} \mathrm{np}$ : no polymerization ${ }^{\mathrm{b}}$ determined after one week of storage at room temperature. Light intensity of the different light sources: laser diode at $405 \mathrm{~nm}\left(110 \mathrm{~mW} / \mathrm{cm}^{2}\right)$, laser diode at $455 \mathrm{~nm}\left(80 \mathrm{~mW} / \mathrm{cm}^{2}\right)$, laser diode at $470 \mathrm{~nm}\left(70 \mathrm{~mW} / \mathrm{cm}^{2}\right)$, halogen lamp : 380-800 $\mathrm{nm}$ (12 $\left.\mathrm{mW} / \mathrm{cm}^{2}\right)$

Compared to their parent structures, NAPHT-3, NAPHT-5-7, a significant enhancement of the monomer conversions for EPOX and TMPTA can be clearly demonstrated with NAPHT64-NAPHT-67, irrespective of the photoinitiating systems (two or three-component system) and the light sources. To illustrate this, if a monomer conversion of $16 \%$ was obtained with the three-component system NAPHT-6/lod/NVK $(0.5 \% / 2 \% / 3 \%, w / w / w)$ for the polymerization of EPOX at $405 \mathrm{~nm}$, this latter could be increase up to 59\% with NAPHT-65 in the same conditions due to improved light absorption properties (See Tables 1 and 9). The same hold true while comparing NAPHT-7 and NAPHT-67. Notably, a 18\% increase of the TMPTA conversion can be observed for NAPHT-67 (52\%) while using the three-component system NAPHT-67/lod/NVK $(0.5 \% / 2 \% / 3 \%, \mathrm{w} / \mathrm{w} / \mathrm{w})$ whereas a final monomer conversion of only $34 \%$ could be obtained with NAPHT-7 in the same system upon irradiation at $405 \mathrm{~nm}$ (110 $\mathrm{mW} / \mathrm{cm}^{2}$ ). Remarkably, NAPHT-66 showed a panchromatic behavior in laminate and polymerization of TMPTA with LEDs emitting at $532 \mathrm{~nm}\left(100 \mathrm{~mW} / \mathrm{cm}^{2}\right)$ and $635 \mathrm{~nm}(100$ 
$\mathrm{mW} / \mathrm{cm}^{2}$ ) could still provide high conversions, 35 and $32 \%$ respectively with the NAPHT$66 / \mathrm{MDEA} / \mathrm{R}-\mathrm{Cl}(0.5 \% / 2 \% / 3 \%, \mathrm{w} / \mathrm{w} / \mathrm{w})$ system. These conversions are lower than those determined at $455 \mathrm{~nm}\left(80 \mathrm{~mW} / \mathrm{cm}^{2}, 45 \%\right)$ but the lower monomer conversions can be directly assigned to the molar extinction coefficients at the considered irradiation wavelengths. Finally, polymerization tests carried out with NAPHT-64 furnished low final monomer conversions at 532 and $635 \mathrm{~nm}(<20 \%)$ as a result of its poor absorptions at these wavelengths.

Following this work, the same authors developed new structures derived from NAPHT64-NAPHT-67, and NAPHT-68-NAPHT-70 could be obtained in high yields by reaction with naphthalic anhydrides NAPHT-65-NAPHT-67, as shown in the Scheme 17.[225]

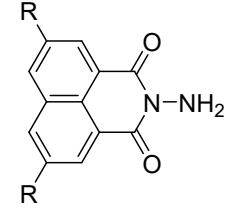

NAPHT-66 : $\mathrm{R}=\mathrm{NO}_{2}$ NAPHT-67 : $\mathrm{R}=\mathrm{NH}_{2}$

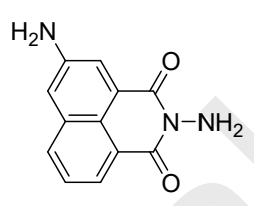

NAPHT -65

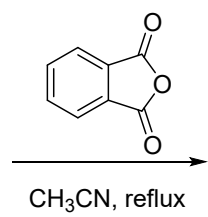

NAPHT-68 : $\mathrm{R}=\mathrm{NO}_{2}, 85 \%$ yield NAPHT-69: $\mathrm{R}=\mathrm{NH}_{2}, 86 \%$ yield

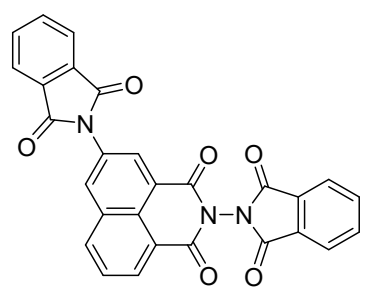

NAPHT-70

Scheme 17. Synthetic route to NAPHT-68-NAPHT-70.

Interestingly, broadness of the absorption of NAPHT-66 could be maintained in NAPHT-68 since an absorption extending between 300 and $600 \mathrm{~nm}$ could be still found for NAPHT-68. Conversely, a complete modification of the absorption spectra between NAPHT65 and NAPHT-70 could be found. Indeed, if NAPHT-65 was characterized by an intense ICT band in the visible range, no peak could be detected for NAPHT-70, consisting in a long tail extending until $600 \mathrm{~nm}$ (See Figure 14). 

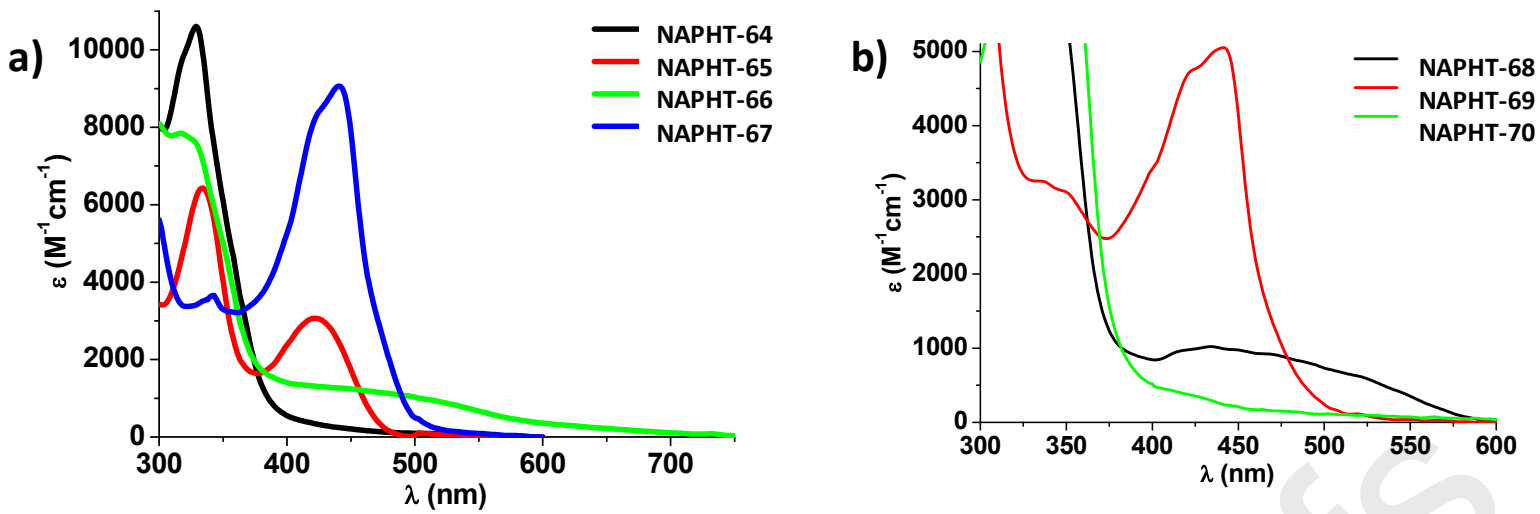

Figure 14. UV-visible absorption spectra of a) NAPHT-64-NAPHT-67 in acetonitrile b) NAPHT68-NAPHT-70 in toluene. Adapted from ref. [224] with permission from The Royal Society of Chemistry. Reprinted with permission from Xiao et al. [225] Copyright (c) 2015 John Wiley \& Sons, Inc

Finally, comparison of the final monomer conversions obtained for the CP of EPOX or the FRP of TMPTA revealed that almost similar monomer conversions could be obtained irrespective of the system or the irradiation wavelengths. Therefore, it can be concluded that the chemical modification of NAPHT-64-NAPHT-67 to convert them as NAPHT-68-NAPHT-70 was not justified as no modification of the monomer conversions could be clearly evidenced (See Tables 9 and 10). It has to be noticed that even if these last examples of photoinitiators (NAPHT-68-NAPH-70) are panchromatic on the basis of their absorption spectra, photopolymerization tests remained limited to irradiations between 405 and $455 \mathrm{~nm}$ and not at longer wavelengths as it would have been interesting to examine. 
Table 10. EPOX and TMPTA conversions obtained under air upon exposure to different visible light sources for $800 \mathrm{~s}$ for the EPOX resins (under air), for 400s for the TMPTA resins (in laminate) for NAPHT-68-NAPH-70 photoinitiating systems and reference systems.

\begin{tabular}{|c|c|c|c|c|}
\hline & & EPOX & & TMPTA \\
\hline & $\begin{array}{l}\text { Halogen } \\
\text { lamp }\end{array}$ & $\begin{array}{c}\text { LED } \\
(455 \mathrm{~nm})\end{array}$ & $\begin{array}{l}\text { Halogen } \\
\text { lamp }\end{array}$ & $\begin{array}{c}\text { LED } \\
(455 \mathrm{~nm})\end{array}$ \\
\hline NAPHT-68/lod $(0.5 \% / 2 \% \mathrm{w} / \mathrm{w})$ & $4 \%$ & - & & \\
\hline NAPHT-69/lod $(0.5 \% / 2 \% \mathrm{w} / \mathrm{w})$ & $55 \%$ & $57 \%$ & $35 \%$ & \\
\hline NAPHT-70/lod $(0.5 \% / 2 \% \mathrm{w} / \mathrm{w})$ & $n p^{a}$ & & & \\
\hline $\begin{array}{c}\text { NAPHT-68/lod/NVK } \\
(0.5 \% / 2 \% / 3 \%, \mathrm{w} / \mathrm{w} / \mathrm{w})\end{array}$ & $12 \%$ & $32 \%$ & & $28 \%$ \\
\hline $\begin{array}{c}\text { NAPHT-69/lod/NVK } \\
(0.5 \% / 2 \% / 3 \%, \mathrm{w} / \mathrm{w} / \mathrm{w})\end{array}$ & $63 \%$ & $65 \%, 58 \%^{b}$ & $55 \%$ & $58 \%, 55 \%^{\mathrm{b}}$ \\
\hline $\begin{array}{c}\text { NAPHT-70/lod/NVK } \\
(0.5 \% / 2 \% / 3 \%, w / w / w)\end{array}$ & $n p^{a}$ & $n p^{a}$ & & \\
\hline $\begin{array}{l}\text { NAPHT-69/MDEA } \\
(0.5 \% / 2 \%, w / w)\end{array}$ & & & $14 \%$ & $57 \%, 52 \%^{\mathrm{b}}$ \\
\hline $\begin{array}{l}\text { NAPHT-69/MDEA/R-Cl } \\
(0.5 \% / 2 \% / 3 \%, \mathrm{w} / \mathrm{w} / \mathrm{w})\end{array}$ & & & $45 \%$ & \\
\hline
\end{tabular}

a $n p:$ no polymerization ${ }^{b}$ determined after one week of storage at room temperature. Light intensity of the different light sources: laser diode at $455 \mathrm{~nm}\left(80 \mathrm{~mW} / \mathrm{cm}^{2}\right)$, halogen lamp: $380-800 \mathrm{~nm}\left(12 \mathrm{~mW} / \mathrm{cm}^{2}\right)$

\subsection{Naphthalimides with extended core}

To enhance the molar extinction coefficient of dyes, a well-known strategy consists in extending the aromaticity of molecules, what was done with NAPHT-71-NAPHT-76 (See Scheme 18) in which an additional aminothiazole group was introduced following the procedure previously detailed in this review.[226] Choice of this peripheral group for the design of NAPHT-71-NAPHT-76 was notably justified by the well-established photoassisted biological activity of these families of naphthalimides, ranging from DNA cleavage and anticancer applications.[227-231] 


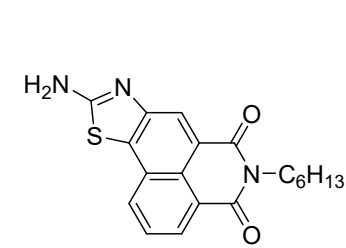

NAPHT-71

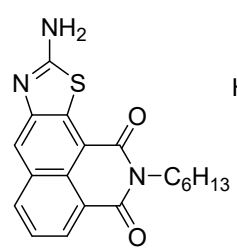

NAPHT-72

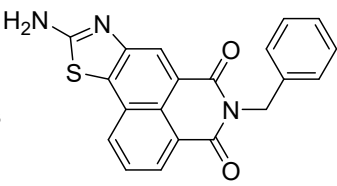

NAPHT-73

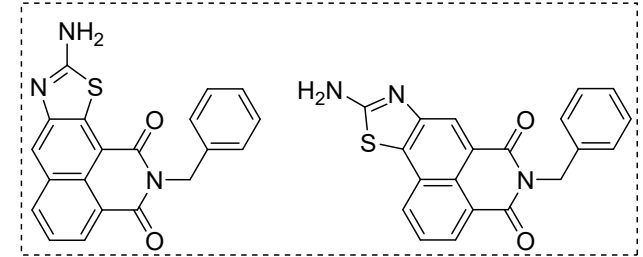

NAPHT-74

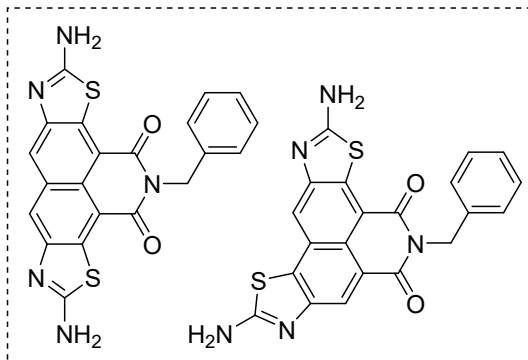

NAPHT-75

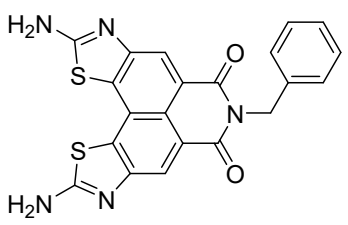

$\mathrm{H}_{2} \mathrm{~N}$

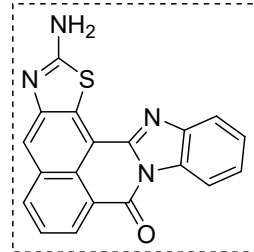

NAPHT-76

Scheme 18. Chemical structures of NAPHT-71-NAPHT-76.

Interestingly, if the formation of the aminothiazole ring is not selective and produce a mixture of isomers, some of them could be however separated by precipitation, as exemplified with NAPHT-71 and NAPHT-72 which could be totally separated by their differences of solubility. Conversely, NAPHT-73 could also be obtained in pure form by precipitation but not totally separated, NAPHT-74 remaining a mixture of isomers. By increasing the polyaromaticity in NAPHT-75 or NAPHT-76, their extremely low solubility in most of the common organic solvents impeded their separation by column chromatography or by precipitation. Notably, due to the low solubility of NAPHT-75 and NAPHT-76, absorption spectra should be recorded in $\mathrm{N}, \mathrm{N}$-dimethylformamide (DMF) contrarily to NAPHT-71-NAPHT74 for which the absorption spectra could be recorded in acetonitrile. An absorption maximum ranging between $395 \mathrm{~nm}$ for NAPHT-72 to $409 \mathrm{~nm}$ for NAPHT-74 were determined, therefore perfectly fitting with the emission of the LED@ $405 \mathrm{~nm}\left(110 \mathrm{~mW} / \mathrm{cm}^{2}\right)$. For NAPHT-75, an absorption located at $436 \mathrm{~nm}$ was found, assigned to the presence of two aminothiazole groups on the naphthalene core. Compared to the analogue structures NAPHT-16-NAPHT-18 which exhibit only a UV-centered absorption, benefits of this additional ring to red-shift the absorption is clearly evidenced. As anticipated from their absorption spectra, all dyes could efficiently initiate the CP of EPOX or the FRP of TMPTA at $405 \mathrm{~nm}$ (See Table 11). Besides, despites their remarkable absorption properties, NAPHT-75 and NAPHT-76 could only furnish 
final monomer conversions lower than $50 \%$ so that tacky polymers could only be obtained. This counter-performance can be directly assigned to their low solubility in resins. These two dyes were not tested for the FRP of acrylate. A deeper insight into the monomer conversions reported in the Table 11 also revealed that drastic differences can be found between NAPHT71-NAPHT-74 even if almost similar absorptions in terms of absorption maxima and molar extinction coefficients were determined. In fact, a deeper insight into the photochemical mechanism revealed the photoinitiating ability of NAPHT-61-NAPHT-74 not to be related to the position of the aminothiazole group but rather to the detrimental role of an uncontrollable back electron transfer between the photoinitiators and the additives, as mentioned in equations $r 31 b$ and $r 36 b$.

$$
\begin{aligned}
& \boldsymbol{N A P H T}-\boldsymbol{x} \rightarrow 1_{\mathrm{NAPHT}_{-x}}(h v) \text { and } 1_{\mathrm{NAPHT}_{-\boldsymbol{x}}} \rightarrow 3_{\mathrm{NAPHT}_{-x}}(r 30) \\
& \boldsymbol{N A P H T}-\boldsymbol{x} \rightarrow 1_{\text {NAPHT }_{-x}}(h v) \text { and } 1_{\text {NAPHT }_{-x}} \rightarrow 3_{\text {NAPHT }_{-x}}(\text { (r31a) } \\
& \boldsymbol{N A P H T}-\boldsymbol{x}^{\bullet+}+P h_{2} I^{\bullet} \rightarrow \boldsymbol{N A P H T}-\boldsymbol{x}+P h_{2} I^{+}(r 31 b) \\
& P h_{2} I^{\bullet} \rightarrow P h^{\bullet}+P h-I(r 32) \\
& P h^{\bullet}+N V K \rightarrow P h-N V K^{\bullet}(r 33) \\
& P h-N V K^{\bullet}+P h_{2} I^{\bullet} \rightarrow P h-N V K^{+}+P h^{\bullet}+P h-I(r 34) \\
& 1,3_{\text {NAPHT }-\boldsymbol{x}}+\mathrm{MDEA} \rightarrow \mathbf{N A P H T}-\boldsymbol{x}^{\bullet-}+\mathrm{MDEA}^{\bullet}+\mathbf{N A P H T}-\boldsymbol{x}-H^{\bullet} \\
& +\operatorname{MDEA}_{(-H)} \bullet(r 35 a) \\
& \boldsymbol{N A P H T}-\boldsymbol{x}^{\bullet-}+M D E A^{\bullet+} \rightarrow \mathbf{N A P H T}-\boldsymbol{x}+\operatorname{MDEA}(r 36) \\
& \boldsymbol{N A P H T}-\boldsymbol{x}^{\bullet-}+R^{\prime}-C l \rightarrow \mathbf{N A P H T}-\boldsymbol{x}+\left(R^{\prime}-C l\right)^{\bullet-}(r 37) \\
& 1,3_{N A P H T}-\boldsymbol{x}+R^{\prime}-C l \rightarrow \mathbf{N A P H T}-\boldsymbol{x}^{\bullet+}+\left(R^{\prime}-C l\right)^{\bullet}-(r 38) \\
& \text { NAPHT }-\boldsymbol{x}-H^{\bullet}+R^{\prime}-C l \rightarrow \mathbf{N A P H T}-\boldsymbol{x}+H^{+}+\left(R^{\prime}-C l\right)^{\bullet-}(r 39) \\
& \left(R^{\prime}-C l\right)^{\bullet-} \rightarrow R^{\prime \bullet}+C l^{-}(r 40)
\end{aligned}
$$


Table 11. EPOX and TMPTA conversions obtained under air upon exposure to different visible light sources for $800 \mathrm{~s}$ for the EPOX resins (under air), for 400s for the TMPTA resins (in laminate) for NAPHT-71-NAPH-76 photoinitiating systems and reference systems.

\begin{tabular}{|c|c|c|c|c|c|c|}
\hline & \multicolumn{3}{|c|}{ EPOX } & \multicolumn{3}{|c|}{ TMPTA } \\
\hline & $\begin{array}{c}\text { Halogen } \\
\text { lamp }\end{array}$ & $\begin{array}{l}\text { LED } \\
(405 \mathrm{~nm})\end{array}$ & $\begin{array}{l}\text { LED } \\
(455 \mathrm{~nm})\end{array}$ & $\begin{array}{c}\text { Halogen } \\
\text { lamp }\end{array}$ & $\begin{array}{c}\text { LED } \\
(405 \mathrm{~nm})\end{array}$ & $\begin{array}{c}\text { LED } \\
(455 \mathrm{~nm})\end{array}$ \\
\hline NAPHT-71/lod $(0.5 \% / 2 \% \mathrm{w} / \mathrm{w})$ & & $n p^{a}$ & & & $43 \%$ & \\
\hline NAPHT- $72 / \operatorname{lod}(0.5 \% / 2 \% \mathrm{w} / \mathrm{w})$ & & $57 \%$ & & & $29 \%$ & \\
\hline NAPHT-73/lod $(0.5 \% / 2 \% \mathrm{w} / \mathrm{w})$ & & $\mathrm{np}^{\mathrm{a}}$ & & & & \\
\hline NAPHT-74/lod $(0.5 \% / 2 \% \mathrm{w} / \mathrm{w})$ & & $55 \%$ & & & $40 \%$ & \\
\hline NAPHT-75/lod $(0.5 \% / 2 \% \mathrm{w} / \mathrm{w})$ & & $25 \%$ & & & & \\
\hline NAPHT-76/lod $(0.5 \% / 2 \% \mathrm{w} / \mathrm{w})$ & & $24 \%$ & & & & \\
\hline $\begin{array}{c}\text { NAPHT-71/lod/NVK } \\
(0.5 \% / 2 \% / 3 \%, \mathrm{w} / \mathrm{w} / \mathrm{w})\end{array}$ & $n p^{a}$ & $47 \%$ & $\mathrm{np}^{\mathrm{a}}$ & $40 \%$ & $56 \%$ & $49 \%$ \\
\hline $\begin{array}{l}\text { NAPHT-72/lod/NVK } \\
(0.5 \% / 2 \% / 3 \%, \mathrm{w} / \mathrm{w} / \mathrm{w})\end{array}$ & $29 \%$ & $56 \%, 62 \%^{b}$ & $54 \%$ & $23 \%$ & $58 \%, 54 \%{ }^{b}$ & $31 \%$ \\
\hline NAPHT-73/lod/NVK & & $41 \%$ & & & & \\
\hline $\begin{array}{l}\text { NAPHT-74/lod/NVK } \\
(0.5 \% / 2 \% / 3 \%, w / w / w)\end{array}$ & $23 \%$ & $57 \%$ & $55 \%$ & $41 \%$ & $58 \%$ & $50 \%$ \\
\hline $\begin{array}{l}\text { NAPHT-75/lod/NVK } \\
(0.5 \% / 2 \% / 3 \%, w / w / w)\end{array}$ & & $43 \%$ & & & & \\
\hline $\begin{array}{l}\text { NAPHT-76/lod/NVK } \\
(0.5 \% / 2 \% / 3 \%, w / w / w)\end{array}$ & & $50 \%$ & $39 \%$ & & & \\
\hline $\begin{array}{c}\text { NAPHT-71/MDEA }(0.5 \% / 2 \% \\
\mathrm{w} / \mathrm{w})\end{array}$ & & & & & $31 \%$ & \\
\hline $\begin{array}{l}\text { NAPHT-72/MDEA }(0.5 \% / 2 \% \\
\mathrm{w} / \mathrm{w})\end{array}$ & & & & & $37 \%$ & \\
\hline $\begin{array}{l}\text { NAPHT-71/MDEA/R-Cl } \\
(0.5 \% / 2 \% / 3 \%, \mathrm{w} / \mathrm{w} / \mathrm{w})\end{array}$ & & & & $36 \%$ & $49 \%$ & $50 \%$ \\
\hline $\begin{array}{l}\text { NAPHT-72/MDEA/R-Cl } \\
(0.5 \% / 2 \% / 3 \%, w / w / w)\end{array}$ & & & & $47 \%$ & $61 \%, 57 \%^{b}$ & $56 \%$ \\
\hline
\end{tabular}

a $\mathrm{np}$ : no polymerization ${ }^{\mathrm{b}}$ determined after one week of storage at room temperature. Light intensity of the different light sources: laser diode at $455 \mathrm{~nm}\left(80 \mathrm{~mW} / \mathrm{cm}^{2}\right)$, halogen lamp: $380-800 \mathrm{~nm}\left(12 \mathrm{~mW} / \mathrm{cm}^{2}\right)$

\subsection{Naphthalimide based iodonium salts}

lodonium salts are extensively studied in the literature to initiate the CP of epoxides. However, iodonium salts suffer from a lack of absorption in the visible range $[16,102,103,107,232-247]$ so that the use of a dye acting as a photosensitizer is often required to ensure light absorption and allow this cationic photoinitiator to be activated in the visible range. To extend the spectral response of iodonium salts to the visible range, an iodonium salt resulting from the covalent coupling between the naphthalimide chromophore and a diphenyliodonium salt was proposed in 2016 (See Scheme 19).[26] By mean of this covalent linkage, a red-shift of the absorption maximum by about $110 \mathrm{~nm}$ relative to that of the diphenyliodonium salt could be observed for NAPHT-77. Indeed, if the absorption maximum of diphenyliodonium salt is located at $230 \mathrm{~nm}$, absorption of NAPHT-77 was shifted to 340 
$\mathrm{nm}$, with a tail extending until $400 \mathrm{~nm}$. As the main advantages of this strategy, the covalent linkage of the two groups allowed to both simplify the formulation of the resins but also to increase the performance of the resulting system by inducing intramolecular processes instead of intermolecular reaction to generate the initiating species. Based on its absorption, NAPHT-77 could be activated with LEDs at $365 \mathrm{~nm}\left(500 \mathrm{~mW} / \mathrm{cm}^{2}\right), 385 \mathrm{~nm}\left(38 \mathrm{~mW} / \mathrm{cm}^{2}\right)$ and $395 \mathrm{~nm}\left(42 \mathrm{~mW} / \mathrm{cm}^{2}\right)$ without any additives. NAPHT-77 could notably initiate the CP of epoxides, divinyl ether or the concomitant polymerization of epoxides/divinyl ether blends, but also the free radical polymerization of methacrylates.

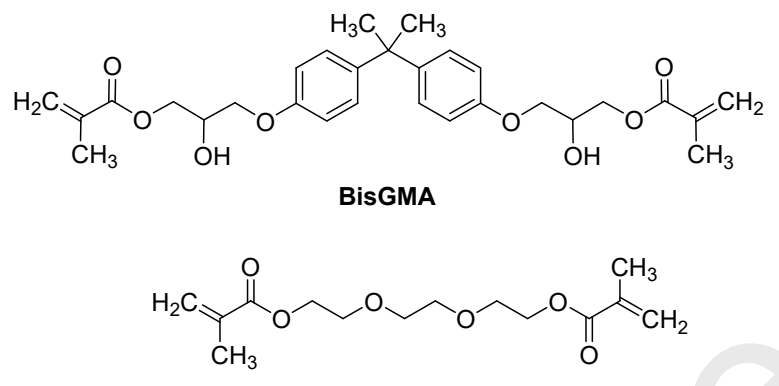

TEGDMA

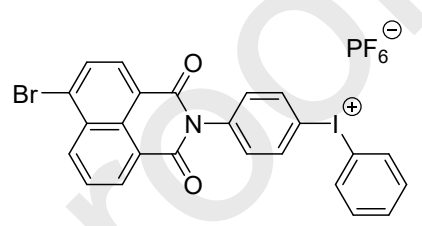

NAPHT-77<smiles>C=COCCOCCOCCOC=C</smiles>

DVE-3

Scheme 19. Chemical structure of NAPHT-77 and different monomers.

When tested as a single component for the CP of EPOX (1 or $2 \mathrm{wt} \%$ ), final conversion of 40 and $43 \%$ were respectively obtained after $800 \mathrm{~s}$ of irradiation under air at $365 \mathrm{~nm}$. In the same conditions, the thianthrenium salt which belongs to an important class of industrially used cationic photoinitiators [248] only furnished a final monomer conversion of $20 \%$, therefore demonstrating the high interest of this new structure. The CP of triethylene glycol divinyl ether (DVE-3) could also be easily achieved with high final monomer conversions : $90 \%$ upon irradiation with a LED emitting at $365 \mathrm{~nm}, 38 \%$ with a LED at $395 \mathrm{~nm}$, consistent with a reduction of the light absorption properties of NAPHT-77 at this wavelength. While examining the copolymerization of a DVE-3/EPOX blend (1:1), an almost complete monomer conversion could be obtained after only $200 \mathrm{~s}$ of irradiation at $365 \mathrm{~nm}$ under air, demonstrating the reactivity of this one-component system.

Tests of FRP were carried out with a dental resin composed a BisGMA/TEGDMA blend (70/30).[110,249] A final monomer conversion as high as $85 \%$ after $25 \mathrm{~s}$ in laminate and 43\% after $400 \mathrm{~s}$ under air could be determined, demonstrating that NAPHT-77 can efficiently overcome oxygen inhibition. In the same conditions, thianthrenium salt was ineffective to 
initiate a polymerization process. Examination of the chemical mechanism revealed the cleavage of the iodonium salt to occur on the phenyl side, what was confirmed by Electron spin resonance (ESR) spin trapping experiments, with the detection of the phenyl- $N$-tertbutylnitrone (PBN) adduct. Steady state photolysis experiments carried out in the presence of a $\mathrm{pH}$-indicator (methyl Red) also revealed the release of protons $\mathrm{H}^{+}$in the solution upon irradiation.[250] Based on laser flash photolysis experiments and fluorescence quenching experiments, a mechanism could be proposed to support the CP of epoxides and the FRP of methacrylates (See Scheme 20). Thus, upon irradiation, a decomposition of NAPHT-77 occurs, producing the highly reactive $\mathrm{Ph}^{\bullet}$, capable to initiate the FRP of (meth)acrylates. Parallel to this, an addition of $\mathrm{Ph}^{\bullet}$ on the iodobenzene derivative can also occur, producing a proton $\mathrm{H}^{+}$, capable to initiate the CP of epoxides.
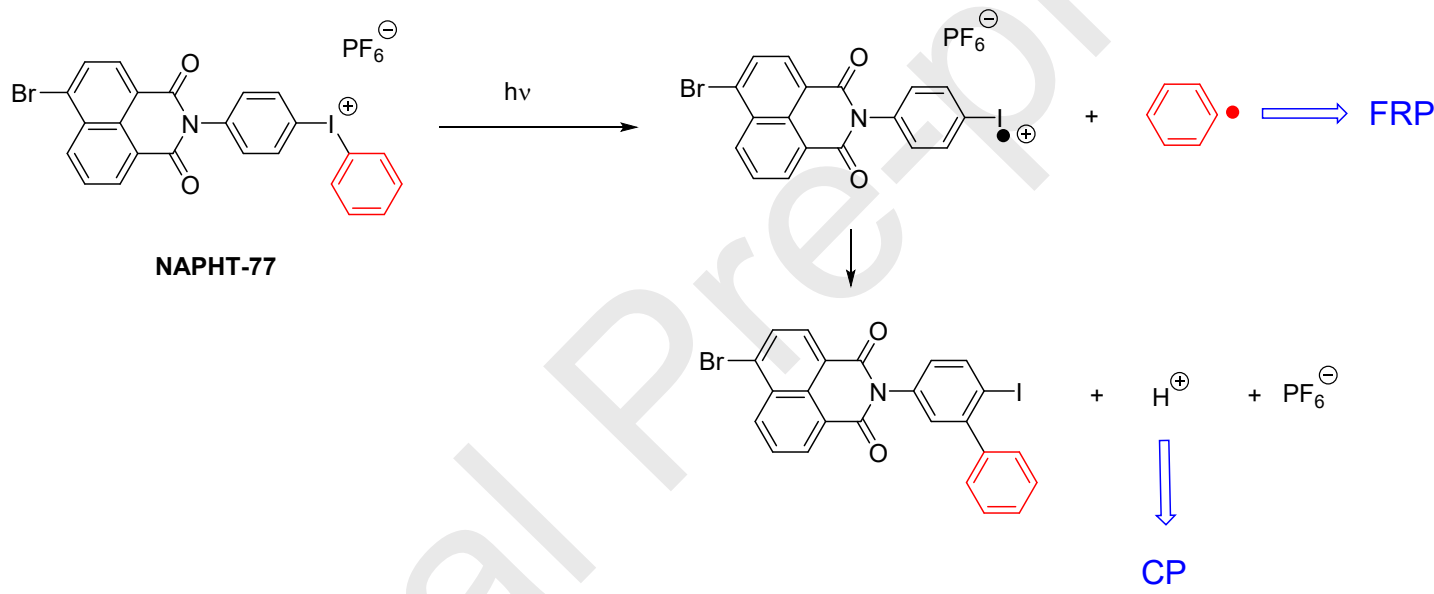

Scheme 20. Chemical mechanism involved in the CP of EPOX and the FRP of (meth)acrylates with NAPHT-77.

Finally, this year, the same group reported NAPHT-78 which is of similar structure than NAPHT-77 but this iodonium salt was proposed with five different counteranions (See Scheme 21).[25]

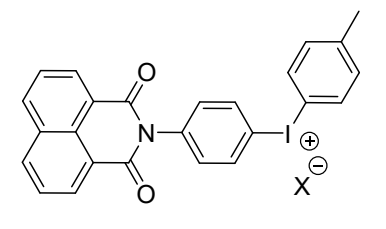

NAPHT-78

$$
\begin{aligned}
& \mathbf{a}: \mathrm{X}=\mathrm{TfO}^{-} \\
& \mathbf{b}: \mathrm{X}=\mathrm{PF}_{6}^{-} \\
& \mathbf{c}: \mathrm{X}=\mathrm{Cl}^{-} \\
& \mathbf{d}: \mathrm{X}=\mathrm{F}_{3} \mathrm{C}^{-} \mathrm{SO}^{-} \mathrm{O}^{-} \\
& \mathbf{e}: \mathrm{X}=\mathrm{SBF}_{6}^{-}
\end{aligned}
$$

Scheme 21. Chemical structure of NAPHT-78 and the different counter-anions. 
If the photophysical properties of NAPHT-78 were comparable to that of NAPHT-77, major differences in terms of final monomer conversions could be found between the different salts during the CP of EPOX under air and upon irradiation with a LED at $365 \mathrm{~nm}$. Notably, it is well-reported in the literature that the counteranions of low nucleophilicity $\left(\mathrm{SbF}_{6}{ }^{-}\right.$ , $\mathrm{PF}_{6}^{-}$, bis(trifluoromethane)sulfonamide) can preserve the cationic propagating center compared to counteranions of high nucleophilicity (Cl-; TfO-).[101,103,104] By a higher dissociation of the ion pair, the cationic initiating species is more easily accessible to react with the monomer, improving the polymerization efficiency (See Figure 15).

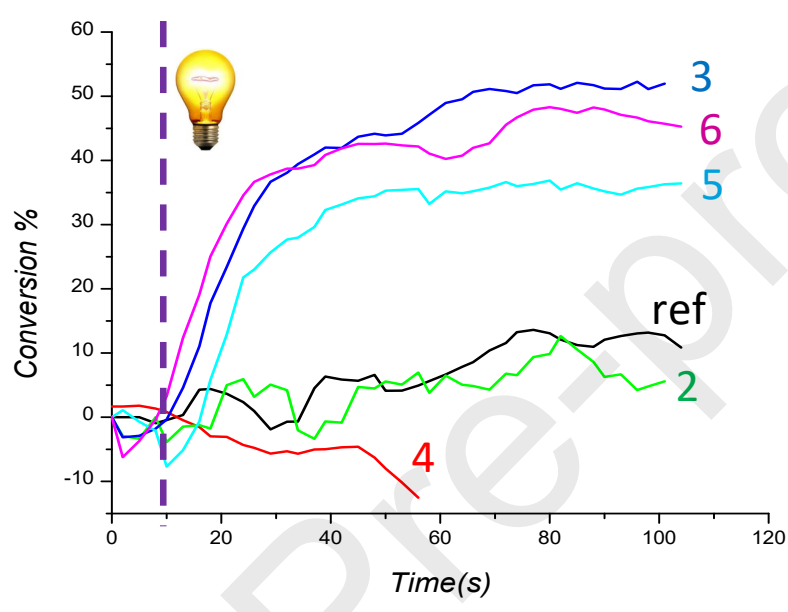

Figure 15. Polymerization profiles of EPOX while using NAPHT-78 as the photoinitiator upon irradiation under air with a LED emitting at $365 \mathrm{~nm}$. 1) NAPHT-78.OTf 2) NAPHT-78.PF 6 3) NAPHT-78.Cl 4) NAPHT-78.TFSI 5) NAPHT-78.SBF 6 Reprinted with permission from Villotte et al. [25] Copyright (C 2019 MDPI

Finally, one of the intriguing characteristics of NAPHT-78 was its ability to form a charge transfer complex with an amine i.e. trimethylaniline (TMA) so that this photoinitiator that do not exhibit any absorption in the visible range could initiate a polymerization of TMPTA at $405 \mathrm{~nm}$. The possibility to create a charge transfer between an electron-rich amine and an electrodeficient iodonium salt has recently been reported in the literature.[251] In the present case, to evidence the effectiveness of the strategy, a laser write experiment was carried out at $405 \mathrm{~nm}$ with the NAPHT-78.TFSI/TMA charge transfer complex and a 3D-structure could be printed by polymerizing TMPTA as the monomer (See Figure 16). 


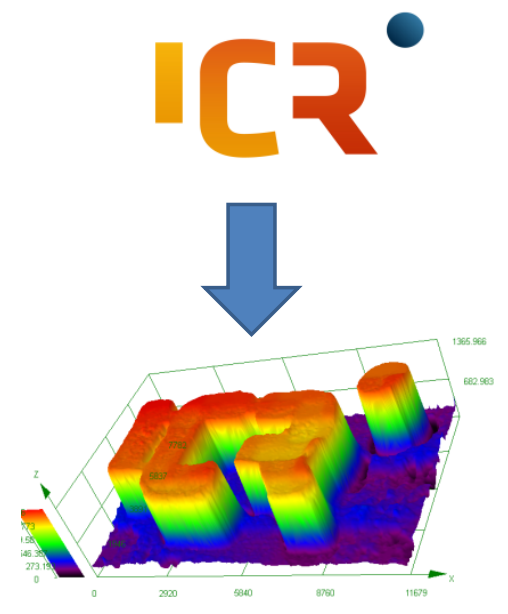

Figure 16. 3D structure obtained by laser write experiments with the NAPHT-78.TFSI/TMA charge transfer complex, upon irradiating at $405 \mathrm{~nm}$ a TMPTA resin with a LED. Reprinted with permission from Villotte et al. [25] Copyright (C) 2019 MDPI

\section{Conclusion}

In this review, a series of 78 naphthalimides reported in the literature have been presented and discussed. If naphthalic anhydrides have been investigated as photoinitiators, the limitations of this approach have rapidly been evidenced, the chemical modification being restrained to the naphthalene core. Following this initial approach, versatility of naphthalimides have rapidly been demonstrated since the extension of aromaticity, the covalent linkage of polymerizable groups, the functionalization of naphthalimides with iodonium salts or tertiary amines have been extensively studied. Considering that the ability of naphthalimides to initiate a polymerization process has now been clearly evidenced, the potential added value of these photoinitiators over traditional photoinitiators has still to be demonstrated. Indeed, even if a report has recently examined the water-resistance of a polymer film induced by the presence of the naphthalimide-based photoinitiator inside the polymer network, the biological activities of naphthalimides which are well-known in the literature have never been examined in polymer films. Notably, naphthalimides could give rise to polymers with antibacterial or antifungal properties. However, at present, this point has never been examined and it deserves to be investigated in the Future. 


\section{Acknowledgment}

This research was funded by Aix Marseille University and The Centre National de la Recherche (CNRS) for financial supports. This research was also funded by the Agence Nationale de la Recherche (ANR agency) through the PhD grants of Guillaume Noirbent (ANR-17-CE08-0054 VISICAT project).

\section{References}

[1] F. Jasinski, P.B. Zetterlund, A.M. Braun, A. Chemtob, Photopolymerization in dispersed systems, Prog. Polym. Sci. 84 (2018) 47-88.

[2] P. Garra, C. Dietlin, F. Morlet-Savary, F. Dumur, D. Gigmes, J.-P. Fouassier, J. Lalevée, Photopolymerization processes of thick films and in shadow areas: a review for the access to composites, Polym. Chem. 8 (2017) 7088-7101.

[3] G. Ng, J. Yeow, J. Xu, C. Boyer, Application of oxygen tolerant PET-RAFT to polymerization-induced self-assembly, Polym. Chem. 8 (2017) 2841-2851.

[4] X. Pan, M.A. Tasdelen, J. Laun, T. Junkers, Y. Yagci, K. Matyjaszewski, Photomediated controlled radical polymerization, Prog. Polym. Sci. 62 (2016) 73-125.

[5] J.-P. Fouassier, X. Allonas, D. Burget, Photopolymerization reactions under visible lights: principle, mechanisms and examples of applications, Prog. Org. Coat. 47 (2003) $16-36$.

[6] J.-T. Lin, D.-C. Cheng, K.-T. Chen, H.-W. Liu, Dual-wavelength (UV and blue) controlled photopolymerization confinement for 3D-printing: Modeling and analysis of measurements, Polymers 11 (2019) 1819.

[7] J. Lalevée, H. Mokbel, J.-P. Fouassier, Recent developments of versatile photoinitiating systems for cationic ring opening polymerization operating at any wavelengths and und.er low light intensity sources, Molecules 20 (2015) 7201-7221.

[8] M.-A. Tehfe, F. Louradour, J. Lalevée, J.-P. Fouassier, Photopolymerization reactions: On the way to a green and sustainable chemistry, Appl. Sci. 3 (2013) 490-514 
[9] L.K. Kostanski, Y.-M. Kim, J.F. Macgregor, A.E. Hamielec, Cationic polymerization using mixed cationic photoinitiator systems, Des. Monomers Polym. 10 (2007) 327-345.

[10] J.V. Crivello, E. Reichmanis, Photopolymer materials and processes for advanced technologies, Chem. Mater. 26 (2014) 533-548.

[11] S. Genty, P. Tingaut, M. Aufray, Fast polymerization at low temperature of an infrared radiation cured epoxy-amine adhesive, Thermochim. Acta 666 (2018) 27-35.

[12] Z. Zhang, N. Corrigan, A. Bagheri, J. Jin, C. Boyer, A versatile 3D and 4D printing system through photocontrolled raft polymerization, Angew. Chem. 131 (2019) 18122-18131.

[13] A.Y. Lee, J. An, C.K. Chua, Two-way 4D-printing: A review on the reversibility of 3dprinted shape memory materials, Engineering 3 (2017) 663-674.

[14] A. Bagheri, J. Jin, Photopolymerization in 3D Printing, ACS Appl. Polym. Mater. 1 (2019) 593-611.

[15] D.C. Aduba Jr., E.D. Margaretta, A.E.C. Marnot, K.V. Heifferon, W.R. Surbey, N.A. Chartrain, A.R. Whittington, T.E. Long, C.B. Williams, Vat photopolymerization 3D printing of acid-cleavable PEG-methacrylate networks for biomaterial applications, Mater. Today Commun. 19 (2019) 204-211.

[16] C. Dietlin, S. Schweizer, P. Xiao, J. Zhang, F. Morlet-Savary, B. Graff, J.-P. Fouassier, J. Lalevée, Photopolymerization upon LEDs: new photoinitiating systems and strategies, Polym.Chem. 6 (2015) 3895-3912.

[17] C. Schmitz, A. Halbhuber, D. Keil, B. Strehmel, NIR-Sensitized Photoinitiated Radical Polymerization and Proton Generation with Cyanines and LED Arrays, Prog. Org. Coat. 100 (2016) 32-46.

[18] T. Brömme, C. Schmitz, N. Moszner, P. Burtscher, N. Strehmel, B. Strehmel, Photochemical Oxidation of NIR Photosensitizers in the Presence of Radical Initiators and Their Prospective Use in Dental Applications, Chem. Select 1 (2016) 524-532.

[19] C. Schmitz, B. Strehmel, NIR LEDs and NIR lasers as feasible alternatives to replace oven processes for treatment of thermal-responsive coatings, J. Coat. Technol. Res. 16 (2019) 1527-1541. 
[20] A. Shiraishi, H. Kimura, D. Oprych, C. Schmitz, B. Strehmel, Comparison between NIR and UV-sensitized radical and cationic reactivity of iodonium salts comprising anions with different coordination behavior, J. Photopolym. Sci. Technol. 30 (2017) 633-638.

[21] B. Strehmel, C. Schmitz, T. Brömme, A. Halbhuber, D. Oprych, J. Gutmann, Advances of near infrared sensitized radical and cationic photopolymerization: from graphic industry to traditional coatings, J. Photopolym. Sci. Technol. 29 (2016) 111-121.

[22] A.H. Bonardi, F. Dumur, T.M. Grant, G. Noirbent, D. Gigmes, B.H. Lessard, J.-P. Fouassier, J. Lalevée, High performance near infrared (NIR) photoinitiating systems operating under low light intensity and in presence of oxygen, Macromolecules 51 (2018) 1314-1324.

[23] M.-A. Tehfe, F. Dumur, P. Xiao, M. Delgove, B. Graff, J.-P. Fouassier, D. Gigmes, J. Lalevée, Chalcone derivatives as highly versatile photoinitiators for radical, cationic, thiol-ene and IPN polymerization reactions upon visible lights, Polym. Chem. 5 (2014) 382-390.

[24] H. Mokbel, J. Toufaily, T. Hamieh, F. Dumur, D. Campolo, D. Gigmes, J.-P. Fouassier, J. Ortyl, J. Lalevee, Specific cationic photoinitiators for Near UV and visible LEDs: Iodonium vs. ferrocenium structures, J. Appl. Polym. Sci. 132 (2015) 42759.

[25] S. Villotte, D. Gigmes, F. Dumur, J. Lalevée, Design of Iodonium Salts for UV or Near-UV LEDs for Photoacid Generator and Polymerization Purposes, Molecules 25 (2020) 149.

[26] N. Zivic, M. Bouzrati-Zerrelli, S. Villotte, F. Morlet-Savary, C. Dietlin, F. Dumur, D. Gigmes, J.-P. Fouassier, J. Lalevée, A novel naphthalimide scaffold based iodonium salt as a one-component photoacid/photoinitiator for cationic and radical polymerization under LED exposure, Polym. Chem. 7 (2016) 5873-5879

[27] M.-A. Tehfe, F. Dumur, E. Contal, B. Graff, D. Gigmes, J.-P. Fouassier, J. Lalevée, Novel highly efficient organophotocatalysts: truxene-acridine-1,8-diones as photoinitiators of polymerization, Macromol. Chem. Phys. 214 (2013) 2189-2201.

[28] P. Xiao, F. Dumur, M.-A. Tehfe, B. Graff, D. Gigmes, J.-P. Fouassier, J. Lalevée, Acridinediones: effect of substituents on their photoinitiating abilities in radical and cationic photopolymerization, Macromol. Chem. Phys. 214 (2013) 2276-2282 
[29] A. Bonardi, F. Bonardi, G. Noirbent, F. Dumur, C. Dietlin, D. Gigmes, J.-P. Fouassier, J. Lalevée, Different NIR dye scaffolds for polymerization reactions under NIR light, Polym. Chem. 10 (2019) 6505-6514.

[30] A. Al Mousawi, C. Poriel, F. Dumur, J. Toufaily, T. Hamieh, J.-P. Fouassier, J. Lalevée, Zinc-tetraphenylporphyrin as high performance visible-light photoinitiator of cationic photosensitive resins for LED projector 3D printing applications, Macromolecules 50 (2017) 746-753

[31] P. Xiao, M. Frigoli, F. Dumur, B. Graff, D. Gigmes, J.-P. Fouassier, J. Lalevée, Julolidine or fluorenone based push-pull dyes for polymerization upon soft polychromatic visible light or green light, Macromolecules 47 (2014) 106-112.

[32] M.-A. Tehfe, F. Dumur, B. Graff, F. Morlet-Savary, J.-P. Fouassier, D. Gigmes, J. Lalevée, New push-pull dyes derived from Michler's ketone for polymerization reactions upon visible lights, Macromolecules 46 (2013) 3761-3770.

[33] H. Mokbel, F. Dumur, C.R. Mayer, F. Morlet-Savary, B. Graff, D. Gigmes, J. Toufaily, T. Hamieh, J.-P. Fouassier, J. Lalevée, End capped polyenic structures as visible light sensitive photoinitiators for polymerization of vinylethers, Dyes Pigm. 105 (2014) 121129.

[34] P. Garra, D. Brunel, G. Noirbent, B. Graff, F. Morlet-Savary, C. Dietlin, V.F. Sidorkin, F. Dumur, D. Duché, D. Gigmes, J.-P. Fouassier, J. Lalevée, Ferrocene-based (photo)redox polymerization under long wavelengths, Polym. Chem. 10 (2019) 1431-1441.

[35] M. Abdallah, T.-T. Bui, F. Goubard, D. Theodosopoulou, F. Dumur, A. Hijazi, J.-P. Fouassier, J. Lalevée, Phenothiazine derivatives as photoredox catalysts for cationic and radical photosensitive resins for 3D printing technology and photocomposites synthesis, Polym. Chem. 10 (2019) 6145-6156.

[36] S. Telitel, F. Dumur, T. Kavalli, B. Graff, F. Morlet-Savary, D. Gigmes, J.-P. Fouassier, J. Lalevée, The 1,3-bis(dicyanomethylidene)-indane skeleton as a (photo) initiator in thermal ring opening polymerization at RT and radical or cationic photopolymerization, RSC Adv. 4 (2014) 15930-15936. 
[37] H. Mokbel, F. Dumur, B. Graff, C.R. Mayer, D. Gigmes, J. Toufaily, T. Hamieh, J.-P. Fouassier, J. Lalevée, Michler's ketone as an interesting scaffold for the design of highperformance dyes in photoinitiating systems upon visible lights, Macromol. Chem. Phys. 215 (2014) 783-790.

[38] P. Xiao, F. Dumur, B. Graff, F. Morlet-Savary, L. Vidal, D. Gigmes, J.-P. Fouassier, J. Lalevée, Structural effects in the indanedione skeleton for the design of low intensity 300-500 nm light sensitive initiators, Macromolecules 47 (2014) 26-34.

[39] J. Zhang, J. Lalevée, J. Zhao, B. Graff, M.H. Stenzel, P. Xiao, Dihydroxyanthraquinone derivatives: natural dyes as blue-light-sensitive versatile photoinitiators of photopolymerization, Polym. Chem. 7 (2016) 7316-7324.

[40] M.-A. Tehfe, F. Dumur, P. Xiao, B. Graff, F. Morlet-Savary, J.-P. Fouassier, D. Gigmes, J. Lalevée, New chromone based photoinitiators for polymerization reactions upon visible lights, Polym. Chem. 4 (2013) 4234-4244.

[41] A. Al Mousawi, P. Garra, M. Schmitt, J. Toufaily, T. Hamieh, B. Graff, J.-P. Fouassier, F. Dumur, J. Lalevée, 3-Hydroxyflavone and N-phenyl-glycine in high performance photoinitiating systems for 3D printing and photocomposites synthesis, Macromolecules 51 (2018) 4633-4641.

[42] P. Xiao, F. Dumur, D. Thirion, S. Fagour, S. Vacher, X. Sallenave, F. Morlet-Savary, B. Graff, J.-P. Fouassier, D. Gigmes, J. Lalevée, Multicolor photoinitiators for radical and cationic polymerization: mono vs. poly functional thiophene derivatives, Macromolecules 46 (2013) 6786-6793

[43] M.-A. Tehfe, A. Zein-Fakih, J. Lalevée, F. Dumur, D. Gigmes, B. Graff, F. Morlet-Savary, T. Hamieh, J.-P. Fouassier, New pyridinium salts as versatile compounds for dye sensitized photo-polymerization, Eur. Polym. J. 49 (2013) 567-574

[44] J. Zhang, D. Campolo, F. Dumur, P. Xiao, D. Gigmes, J.-P. Fouassier, J. Lalevée, The carbazole-bound ferrocenium salt as a specific cationic photoinitiator upon near-UV and visible LEDs (365-405 nm), Polym. Bull. 73 (2016) 493-507. 
[45] A. Al Mousawi, F. Dumur, J. Toufaily, T. Hamieh, B. Graff, D. Gigmes, J.-P. Fouassier, J. Lalevée, Carbazole scaffold based photoinitiators/photoredox catalysts for new LED projector 3D printing resins, Macromolecules 50 (2017) 2747-2758.

[46] A. Al Mousawi, D. Magaldi Lara, G. Noirbent, F. Dumur, J. Toufaily, T. Hamieh, T.-T. Bui, F. Goubard, B. Graff, D. Gigmes, J.-P. Fouassier, J. Lalevée, Carbazole derivatives with thermally activated delayed fluorescence property as photoinitiators/photoredox catalysts for LED 3D printing technology, Macromolecules 50, 4913-4926 (2017).

[47] A. Al Mousawi, P. Garra, F. Dumur, T.-T. Bui, F. Goubard, J. Toufaily, T. Hamieh, B. Graff, D. Gigmes, J.-P. Fouassier, J. Lalevée, Novel Carbazole Skeleton-Based Photoinitiators for LED Polymerization and LED Projector 3D Printing, Molecules 22 (2018) 2143.

[48] A. Al Mousawi, A. Arar, M. Ibrahim-Ouali, S. Duval, F. Dumur, P. Garra, J. Toufaily, T. Hamieh, B. Graff, D. Gigmes, J.-P. Fouassier, J. Lalevée, Carbazole-based compounds as photoinitiators for free radical and cationic polymerization upon near visible light illumination, Photochem. Photobiol. Sci. 17 (2018) 578-585.

[49] M. Abdallah, D. Magaldi, A. Hijazi, B. Graff, F. Dumur, J.-P. Fouassier, T.-T. Bui, F. Goubard, J. Lalevée, Development of new high performance visible light photoinitiators based on carbazole scaffold and their applications in 3D printing and photocomposite synthesis, J. Polym. Sci. A Polym. Chem. 57 (2019) 2081-2092.

[50] A. Al Mousawi, F. Dumur, P. Garra, J. Toufaily, T. Hamieh, F. Goubard, T.-T. Bui, B. Graff, D. Gigmes, J.-P. Fouassier, J. Lalevée, Azahelicenes as visible light photoinitiators for cationic and radical polymerization: preparation of photo-luminescent polymers and use in high performance LED projector 3D printing resins, J. Polym. Sci. A Polym. Chem. 55 (2017) 1189-1199.

[51] A. Al Mousawi, M. Schmitt, F. Dumur, J. Ouyang, L. Favereaud, V. Dorcet, N. Vanthuyne, P. Garra, J. Toufaily, T. Hamieh, B. Graff, J.-P. Fouassier, D. Gigmes, J. Crassous, J. Lalevée, Visible light chiral photoinitiator for radical polymerization and synthesis of polymeric films with strong chiroptical activity, Macromolecules 51 (2018) 5628-5637

[52] M. Abdallah, H. Le, A. Hijazi, B. Graff, F. Dumur, T.-T. Bui, F. Goubard, J.-P. Fouassier, J. Lalevée, Acridone derivatives as high performance visible light photoinitiators for 
cationic and radical photosensitive resins for 3D printing technology and for low migration photopolymer property, Polymer 159 (2018) 47-58.

[53] J. Zhang, F. Dumur, M. Bouzrati, P. Xiao, C. Dietlin, F. Morlet-Savary, B. Graff, D. Gigmes, J.-P. Fouassier, J. Lalevée, Novel panchromatic photo-polymerizable matrices: N,N'dibutyl-quinacridone as an efficient and versatile photoinitiator, J. Polym. Sci. A Polym. Chem. 53 (2015) 1719-1727

[54] J. Li, X. Zhang, S. Ali, M.Y. Akram, J. Nie, X. Zhu, The effect of polyethylene glycoldiacrylate complexation on type II photoinitiator and promotion for visible light initiation system, J. Photochem. Photobiol. A: Chem. 384 (2019) 112037.

[55] J. Li, S. Li, Y. Li, R. Li, J. Nie, X. Zhu, In situ monitoring of photopolymerization by photoinitiator with luminescence characteristics, J. Photochem. Photobiol. A: Chem. $389(2020) 112225$.

[56] J. Li, Y. Hao, M. Zhong, L. Tang, J. Nie, X. Zhu, Synthesis of furan derivative as LED light photoinitiator: One-pot, low usage, photobleaching for light color 3D printing, Dyes Pigm. 165 (2019) 467-473

[57] E.A. Kamoun, A. Winkel, M. Eisenburger, H. Menzel, Carboxylated camphorquinone as visible-light photoinitiator for biomedical application: Synthesis, characterization, and application, Arab. J. Chem. 9 (2016) 745-754.

[58] A. Santini, I.T. Gallegos, C.M. Felix, Photoinitiators in dentistry: a review, Prim. Dent. J. 2 (2013) 30-33.

[59] B. Graff, J.E. Klee, C. Fik, M. Maier, J.-P. Fouassier, J. Lalevée, Development of novel photoinitiators as substitutes of camphorquinone for the led induced polymerization of methacrylates: a bis-silyl ketone, Macromol. Rapid Commun. 38 (2017) 160047.

[60] G. Ullrich, D. Herzog, R. Liska, P. Burtscher, N. Moszner, Photoinitiators with Functional Groups. VII. Covalently Bonded Camphorquinone-Amines, J. Polym. Sci. A Polym. Chem. 42 (2004) 4948-4963. 
[61] N. Karaca, N. Ocala, N. Arsua, S. Jockusch, Thioxanthone-benzothiophenes as photoinitiator for free radical polymerization, J. Photochem. Photobiol. A: Chem. 331 (2016) 22-28.

[62] Q. Wu, X. Wang, Y. Xiong, J. Yang, H. Tang, Thioxanthone based one-component polymerizable visible light photoinitiator for free radical polymerization, RSC Adv. 6 (2016) 66098-66107

[63] A. Al Mousawi, P. Garra, F. Dumur, B. Graff, J.-P. Fouassier, J. Lalevée, Flavones as natural photoinitiators for light mediated free radical polymerization via light emitting diodes, J. Polym. Sci. A Polym. Chem. 58 (2020) 254-262.

[64] P. Garra, D. Brunel, G. Noirbent, B. Graff, F. Morlet-Savary, C. Dietlin, V.F. Sidorkin, F. Dumur, D. Duché, D. Gigmes, J.-P. Fouassier, J. Lalevée, Ferrocene-based (photo)redox polymerization under long wavelengths, Polym. Chem. 10 (2019) 1431-1441.

[65] P. Xiao, F. Dumur, J. Zhang, J.-P. Fouassier, D. Gigmes, J. Lalevée, Copper complexes in radical photoinitiating systems: applications to free radical and cationic polymerization under visible lights, Macromolecules 47 (2014) 3837-3844.

[66] P. Xiao, F. Dumur, J. Zhang, D. Gigmes, J.-P. Fouassier, J. Lalevée, Copper complexes: the effect of ligands on their photoinitiation efficiencies in radical polymerization reactions under visible light, Polym. Chem. 5 (2014) 6350-6357.

[67] P. Xiao, J. Zhang, D. Campolo, F. Dumur, D. Gigmes, J.-P. Fouassier, J. Lalevée, Copper and iron complexes as visible-light-sensitive photoinitiators of polymerization, J. Polym. Sci. A Polym. Chem. 53 (2015) 2673-2684.

[68] A. Al Mousawi, A. Kermagoret, D.-L. Versace, J. Toufaily, T. Hamieh, B. Graff, F. Dumur, D. Gigmes, J.-P. Fouassier, J. Lalevée, Copper photoredox catalysts for polymerization upon near UV or visible light: structure/reactivity/ efficiency relationships and use in LED projector 3D printing resins, Polym. Chem. 8 (2017) 568-580.

[69] P. Garra, A. Kermagoret, A. Al Mousawi, F. Dumur, D. Gigmes, F. Morlet-Savary, C. Dietlin, J.-P. Fouassier, J. Lalevée, New copper(I) complex based initiating systems in redox polymerization and comparison with the amine/benzoyl peroxide reference, Polym. Chem. 8 (2017) 4088-4097. 
[70] P. Garra, F. Dumur, F. Morlet-Savary, C. Dietlin, D. Gigmes, J.-P. Fouassier, J. Lalevée, Mechanosynthesis of a copper complex for redox initiating systems with a unique near infrared light activation, J. Polym. Sci. A Polym. Chem. 55 (2017) 3646-3655.

[71] H. Mokbel, D. Anderson, R. Plenderleith, C. Dietlin, F. Morlet-Savary, F. Dumur, D. Gigmes, J.-P. Fouassier, J. Lalevée, Copper PhotoRedox Catalyst "G1": A New High Performance Photoinitiator for Near-UV and Visible LEDs, Polym. Chem. 8 (2017) 5580-5592.

[72] P. Garra, F. Dumur, A. Al Mousawi, B. Graff, D. Gigmes, F. Morlet-Savary, C. Dietlin, J.P. Fouassier, J. Lalevée, Mechanosynthesized Copper (I) complex based initiating systems for redox polymerization: towards upgraded oxidizing and reducing agents, Polym. Chem. 8 (2017) 5884-5896.

[73] P. Garra, M. Carré, F. Dumur, F. Morlet-Savary, C. Dietlin, D. Gigmes, J.-P. Fouassier, J. Lalevée, Copper-based (photo) redox initiating systems as highly efficient systems for interpenetrating polymer network preparation, Macromolecules 51 (2018) 679-688.

[74] P. Garra, F. Dumur, M. Nechab, F. Morlet-Savary, C. Dietlin, B. Graff, D. Gigmes, J.-P. Fouassier, J. Lalevée, Stable copper acetylacetonate-based oxidizing agents in redox (NIR photoactivated) polymerization: an opportunity for one pot grafting from approach and example on a 3D printed object, Polym. Chem. 9 (2018) 2173-2182.

[75] H. Mokbel, D. Anderson, R. Plenderleith, C. Dietlin, F. Morlet-Savary, F. Dumur, D. Gigmes, J.-P. Fouassier, J. Lalevée, Simultaneous initiation of radical and cationic polymerization reactions using the "G1" copper complex as photoRedox catalyst: Applications of free radical/cationic hybrid photo-polymerization in the composites and 3D printing fields, Prog. Org. Coat. 132 (2019) 50-61.

[76] J. Lalevée, M. Peter, F. Dumur, D. Gigmes, N. Blanchard, M.-A. Tehfe, F. Morlet-Savary, J.-P. Fouassier, Subtle ligand effects in oxidative photocatalysis with iridium complexes: application to photopolymerization, Chem. Eur. J., 17 (2011) 15027-15031.

[77] J. Lalevée, M.-A. Tehfe, F. Dumur, D. Gigmes, N. Blanchard, F. Morlet-Savary, J.-P. Fouassier, Iridium photocatalysts in free radical photopolymerization under visible lights, ACS Macro Lett. 1 (2012) 286-290. 
[78] J. Lalevée, F. Dumur, C.R. Mayer, D. Gigmes, G. Nasr, M.-A. Tehfe, S. Telitel, F. MorletSavary, B. Graff, J.-P. Fouassier, Photopolymerization of N-vinylcarbazole using visiblelight harvesting iridium complexes as photoinitiators, Macromolecules 45 (2012) 41344141.

[79] S. Telitel, F. Dumur, S. Telitel, O. Soppera, M. Lepeltier, Y. Guillaneuf, J. Poly, F. MorletSavary, P. Fioux, J.-P. Fouassier, D. Gigmes, J. Lalevée, Photoredox catalysis using a new iridium complex as an efficient toolbox for radical, cationic and controlled polymerizations under soft blue to green lights, Polym. Chem. 6 (2015) 613-624.

[80] S. Telitel, F. Dumur, M. Lepeltier, D. Gigmes, J.-P. Fouassier, J. Lalevée, Photoredox process induced polymerization reactions: iridium complexes for panchromatic photoinitiating systems, C.R. Chimie 19 (2016) 71-78.

[81] M.-A. Tehfe, M. Lepeltier, F. Dumur, D. Gigmes, J.-P. Fouassier, J. Lalevée, Structural effects in the iridium complex series: photoredox catalysis and photoinitiation of polymerization reactions under visible lights, Macromol. Chem. Phys. 218 (2017) 1700192.

[82] J. Zhang, D. Campolo, F. Dumur, P. Xiao, J.-P. Fouassier, D. Gigmes, J. Lalevée, Iron complexes as photoinitiators for radical and cationic polymerization through photoredox catalysis processes, J. Polym. Sci. A Polym. Chem. 53 (2015) 42-49.

[83] S.Telitel, F. Dumur, D. Campolo, J. Poly, D. Gigmes, J.-P. Fouassier, J. Lalevée, Iron complexes as potential photocatalysts for controlled radical photopolymerizations: A tool for modifications and patterning of surfaces, J. Polym. Sci. A Polym. Chem. 54 (2016) 702-713.

[84] J. Zhang, D. Campolo, F. Dumur, P. Xiao, J.-P. Fouassier, D. Gigmes, J. Lalevée, Visiblelight-sensitive photoredox catalysis by iron complexes: applications in cationic and radical polymerization reactions, J. Polym. Sci. A Polym. Chem. 54 (2016) 2247-2253.

[85] J. Zhang, D. Campolo, F. Dumur, P. Xiao, J.-P. Fouassier, D. Gigmes, J. Lalevée, Novel iron complexes in visible-light-sensitive photoredox catalysis: effect of ligands on their photoinitiation efficiencies, ChemCatChem 8 (2016) 2227-2233. 
[86] J. Zhang, F. Dumur, P. Horcajada, C. Livage, P. Xiao, J.-P. Fouassier, D. Gigmes, J. Lalevée, Iron-based metal-organic frameworks (MOF) as photocatalysts for radical and cationic polymerizations under near UV and visible LEDs (385 - 405 nm), Macromol. Chem. Phys. 217 (2016) 2534-2540.

[87] C. Mendes-Felipe, J. Oliveira, I. Etxebarria, J.L. Vilas-Vilela, S. Lanceros-Mendez, Stateof-the-Art and Future Challenges of UV Curable Polymer-Based Smart Materials for Printing Technologies, Adv. Mater. Technol. 4 (2019) 1800618.

[88] J. Shao, Y. Huang, Q. Fan, Visible light initiating systems for photopolymerization: status, development and challenges, Polym. Chem. 5 (2014) 4195-4210.

[89] H.K. Park, M. Shin, B. Kim, J.W. Park, H. Lee, A visible light-curable yet visible wavelength-transparent resin for stereolithography 3D printing, NPG Asia Mater. 10 (2018) 82-89.

[90] F. Yoshino, A. Yoshida, Effects of blue-light irradiation during dental treatment, Jpn Dent. Sci. Rev. 54 (2018) 160-168.

[91] S. Sanchez, A.Y.Y. Woo, T. Baumgartner, Electron-accepting $\pi$-conjugated species with 1,8-naphthalic anhydride or diketophosphanyl units, Mater. Chem. Front. 1 (2017) 2324-2334.

[92] Q. Xuhong, Z. Zhenghua, C. Kongchang, The synthesis, application and prediction of stokes shift in fluorescent dyes derived from 1,8-naphthalic anhydride, Dyes Pigm. 11 (1989) 13-20.

[93] M.S. Alexiou, V. Tychopoulos, S. Ghorbanian, J.H.P. Tyman, R.G. Brown, P.I. Brittain, J. Chem. Soc., Perkin Trans. 2 (1990) 837-842.

[94] A. Islam, C.-C. Cheng, S.-H. Chi, S. Jui Lee, P. Gayatri Hela,I-Chia Chen, Chien-Hong Cheng, Aminonaphthalic Anhydrides as red-emitting materials: Electroluminescence, crystal structure, and photophysical properties, J. Phys. Chem. B 109 (2005) 5509-5517

[95] H. Wei, G. Chen, L. Cao, Q. Zhang, Q. Yan, X. Fang, Enhanced hydrolytic stability of sulfonated polyimide ionomers using bis(naphthalic anhydrides) with low electron affinity, J. Mater. Chem. A 1 (2013) 10412-10421. 
[96] T. Anand, A. Kumar, S.K. Sahoo, A new $\mathrm{Al}^{3+}$ selective fluorescent turn-on sensor based on hydrazide-naphthalic anhydride conjugate and its application in live cells imaging, Spectrochim. Acta A 204 (2018) 105-112.

[97] P. Xiao, F. Dumur, B. Graff, D. Gigmes, J.-P. Fouassier, J. Lalevée, Blue light sensitive dyes for various photopolymerization reactions: Naphthalimide and naphthalic anhydride derivatives, Macromolecules 47 (2014) 601-608.

[98] B. Steyrer, P. Neubauer, R. Liska, J. Stampfl, Visible light photoinitiator for 3d-printing of tough methacrylate resins, Materials 10 (2017) 1445.

[99] H. Quan, T. Zhang, H. Xu, S. Luo, J. Nie, X. Zhu, Photo-curing 3D printing technique and its challenges, Bioact. Mater. 5 (2020) 110-115.

[100] H. Lai, D. Zhu, P. Xiao, Yellow triazine as an efficient photoinitiator for polymerization and 3D printing under LEDs, Macromol. Chem. Phys. 220 (2019) 1900315.

[101] J. Lalevée, M.-A. Tehfe, A. Zein-Fakih, B. Ball, S. Telitel, F. Morlet-Savary, B. Graff, J.-P. Fouassier, ACS Macro Lett. 1 (2012) 802-806.

[102] J.-P. Fouassier, J. Lalevée, Photoinitiators for Polymer Synthesis - Scope, Reactivity, and Efficiency, Wiley-VCH, Weinheim, Germany 2012.

[103] P. Xiao, J. Zhang, F. Dumur, M. A. Tehfe, F. Morlet-Savary, B. Graff, D. Gigmes, J.-P. Fouassier, J. Lalevée, Visible light sensitive photoinitiating systems: Recent progress in cationic and radical photopolymerization reactions under soft conditions, Prog. Polym. Sci. 41 (2015) 32-66.

[104] J.V. Crivello, Photoinitiators for free radical, cationic and anionic photopolymerization, 2nd ed., John Wiley \& Sons, Chichester, UK 1998

[105] J.-P. Fouassier, Photoinitiator, photopolymerization and photocuring: Fundamentals and applications, Hanser Publishers, Munich, Germany 1995

[106] S. Davidson, Exploring the Science, Technology and Application of UV and EB Curing, Sita Technology Ltd, London, UK 1999

[107] K. Dietliker, A compilation of photoinitiators commercially available for UV today, Sita Technology Ltd, Edinburgh, UK 2002. 
[108] H. Arikawa, H. Takahashi, T. Kanie, S. Ban, Effect of various visible light photoinitiators on the polymerization and color of light-activated resins, Dent. Mater. J. 28 (2009) 454460.

[109] W.F. Schroeder, S.V. Asmussen, M. Sangermano, C. Vallo, Visible light polymerization of epoxy monomers using an iodonium salt with camphorquinone/ethyl-4dimethylaminobenzoate, Polym. Int. 62 (2013) 1368-1376.

[110] L. Chen, Q. Yu, Y. Wang, H. Li, BisGMA/TEGDMA dental composite containing high aspect-ratio hydroxyapatite nanofibers, Dent. Mater. 27 (2011) 1187-1195.

[111] A. Amirouche-Korichi, M. Mouzali, D.C. Watts, Shrinkage strain - Rates study of dental composites based on (BisGMA/TEGDMA) monomers, Arab. J. Chem. 10 (2017) S190S195.

[112] L. Mello de Paiva Campos, L. Cidreira Boaro, H. Perez Ferreira, L.K. Gomes dos Santos, T. Ribeiro dos Santos, D. Fernandes Parra, Evaluation of polymerization shrinkage in dental restorative experimental composites based: BisGMA/TEGDMA, filled with MMT, J. Appl. Polym. Sci. 133 (2016) 43543.

[113] C. Belon, X. Allonas, C. Crouté-Barghorn, J. Lalevée, Overcoming the oxygen inhibition in the photopolymerization of acrylates: a study of the beneficial effect of triphenylphosphine, J. Polym. Sci. A: Polym. Chem. 48 (2010) 2462-2469.

[114] Y. Yagci, S. Jockusch, N.J. Turro, Photoinitiated polymerization: Advances, challenges, and opportunities, Macromolecules 43 (2010) 6245-6260.

[115] D. Karaca Balta, N. Arsu, Y. Yagci, S. Jockusch, N.J. Turro, Thioxanthone-anthracene: A new photoinitiator for free radical polymerization in the presence of oxygen, Macromolecules 40 (2007) 4138-4141.

[116] M. Höfer, N. Moszner, R. Liska, Oxygen scavengers and sensitizers for reduced oxygen inhibition in radical photopolymerization, J. Polym. Sci. A Polym. Chem. 46 (2008) 69166927. 
[117] P. Xiao, F. Dumur, M. Frigoli, M.-A. Tehfe, F. Morlet-Savary, B. Graff, J.-P. Fouassier, D. Gigmes, J. Lalevée, Naphthalimide based methacrylated photoinitiators in radical and cationic photopolymerization under visible light, Polym. Chem. 4 (2013) 5440-5448.

[118] P. Xiao, F. Dumur, M.A. Tehfe, B. Graff, D. Gigmes, J.-P. Fouassier, J. Lalevée, Difunctional acridinediones as photoinitiators of polymerization under UV and visible lights: Structural effects, Polymer 54 (2013) 3458-3466.

[119] P. Xiao, C. Simonnet-Jégat, F. Dumur, G. Schrodj, M.-A. Tehfe, J.-P. Fouassier, D. Gigmes, J. Lalevée, Photochemical in situ elaboration of polyoxometalate ( $\alpha$ $\left.\left[\mathrm{SiMo}_{12} \mathrm{O}_{40}\right]^{4-}\right) /$ polymer hybrid materials, Polym. Chem. 4 (2013) 4526-4530.

[120] P. Xiao, F. Dumur, J. Zhang, B. Graff, F. Morlet-Savary, J.-P. Fouassier, D. Gigmes, J. Lalevée, Naphthalic anhydride derivatives: Structural effects on their initiating abilities in radical and/or cationic photopolymerizations under visible light, J. Polym. Sci. A Polym. Chem. 53 (2015) 2860-2866.

[121] M.-A. Tehfe, F. Dumur, B. Graff, J.-L. Clément, D. Gigmes, F. Morlet-Savary, J.-P. Fouassier, J. Lalevée, New cleavable photoinitiator architecture with huge molar extinction coefficients for polymerization in the 340-450 nm range, Macromolecules 46 (2013) 736-746.

[122] M.-A. Tehfe, F. Dumur, B. Graff, F. Morlet-Savary, D. Gigmes, J.-P. Fouassier, J. Lalevée, Design of new Type I and Type II photoinitiators possessing highly coupled pyreneketone moieties, Polym. Chem. 4 (2013) 2313-2324.

[123] M.A. Lago, A. Rodríguez-Bernaldo de Quirós, R. Sendón, J. Bustos, M.T. Nieto, P. Paseir, Photoinitiators: A food safety review, Food Add. Contam. A 32 (2015) 779-798.

[124] T.K.H. Trinh, J.-P. Malval, F. Morlet-Savary, J. Pinaud, P. Lacroix Desmazes, C. Reibel, V. Héroguez, A. Chemtob, Mixture of azolium tetraphenylborate with isopropylthioxanthone: a new class of n-heterocyclic carbene (NHC) photogenerator for polyurethane, polyester, and ROMP polymers synthesis, Chem. Eur. J. 25 (2019) 9242-9252. 
[125] J. Zhang, P. Xiao, F. Morlet-Savary, B. Graff, J.-P. Fouassier, J. Lalevée, A known photoinitiator for a novel technology: 2-(4-methoxystyryl)-4,6-bis(trichloromethyl)1,3,5-triazine for near UV or visible LED, Polym. Chem. 5 (2014) 6019-6026.

[126] G. Pohlers, J.C. Scaiano, R. Sinta, R. Brainard, D. Pai, Mechanistic studies of photoacid generation from substituted 4,6-bis(trichloromethyl)-1,3,5-triazines, Chem. Mater.9 (1997) 1353-1361.

[127] K. Kawamura, K. Kato, Synthesis and evaluation as a visible-light polymerization photoinitiator of a new dye-linked bis(trichloromethyl)-1,3,5-triazine, Polym. Adv. Technol. 15 (2004) 324-328.

[128] P. Xiao, F. Dumur, J. Zhang, B. Graff, D. Gigmes, J.-P. Fouassier, J. Lalevée, Naphthalimide Derivatives: Substituent Effects on the Photoinitiating Ability in Polymerizations under Near UV, Purple, White and Blue LEDs $(385,395,405,455$, or 470 nm), Macromol. Chem. Phys. 216 (2015) 1782-1790.

[129] J. Zhang, F. Dumur, P. Xiao, B. Graff, D. Bardelang, D. Gigmes, J.-P. Fouassier, J. Lalevée, Structure design of naphthalimide derivatives: toward versatile photoinitiators for near-uv/visible leds, 3D printing, and water-soluble photoinitiating systems, Macromolecules 48 (2015) 2054-2063.

[130] L. Vetráková, V. Ladányi, J. Al Anshori, P. Dvořák, J. Wirzc, D. Heger, The absorption spectrum of cis-azobenzene, Photochem. Photobiol. Sci. 16 (2017) 1749-1756.

[131] E.N. Cho, D. Zhitomirsky, G.G.D. Han, Y. Liu, J.C. Grossman, Molecularly engineered azobenzene derivatives for high energy density solid-state solar thermal fuels, ACS Appl. Mater. Interf. 9 (2017) 8679-8687.

[132] Z. Ahmed, A. Siiskonen, M. Virkkiand A. Priimagi, Controlling azobenzene photoswitching through combined ortho-fluorination and -amination, Chem.Commun. 53 (2017) 12520-12523.

[133] G. Cabré, A. Garrido-Charles, M. Moreno, M. Bosch, M. Porta-de-la-Riva, M. Krieg, M. Gascón-Moya, N. Camarero, R. Gelabert, J.M. Lluch, F. Busqué, J. Hernando, P. Gorostiza, R. Alibés, Rationally designed azobenzene photoswitches forefficient twophoton neuronal excitation, Nature Commun. 10 ((2019) 907. 
[134] M.-A. Tehfe, F. Dumur, E. Contal, B. Graff, D. Gigmes, F. Morlet-Savary, J.-P. Fouassier, J. Lalevée, New insights in radical and cationic polymerizations upon visible light exposure: role of novel photoinitiator systems based on the pyrene chromophore, Polym. Chem. 4 (2013) 1625-1634.

[135] S. Telitel, F. Dumur, T. Faury, B. Graff, M.-A. Tehfe, D. Gigmes, J.-P. Fouassier, J. Lalevée, New core-pyrene $\pi$-structure organophotocatalysts usable as highly efficient photoinitiators, Beilstein J. Org. Chem. 9 (2013) 877-890.

[136] F. Dumur, Recent advances on pyrene-based photoinitiators of polymerization, Eur. Polym. J. 126 (2020) 109564.

[137] N. Uchida, H. Nakano, T. Igarashi, T. Sakurai, nonsalt 1-(arylmethyloxy)pyrene photoinitiators capable of initiating cationic polymerization, J. Appl. Polym. Sci. 131 (2014) 40510.

[138] A. Mishra, S. Daswal, 1-(Bromoacetyl)pyrene, a novel photoinitiator for the copolymerization of styrene and methylmethacrylate, Rad. Phys. Chem. 75 (2006) 1093-1100.

[139] J. Zhang, J. Lalevée, N.S. Hill, X. Peng, D. Zhu, J. Kiehl, F. Morlet-Savary, M.H. Stenzel, M.L. Coote, P. Xiao, Photoinitiation mechanism and ability of monoamino-substituted anthraquinone derivatives as cationic photoinitiators of polymerization under LEDs, Macromol. Rapid Commun. 40 (2019) 1900234.

[140] J. Zhang, J. Lalevée, F. Morlet-Savary, B. Graff, P. Xiao, Photopolymerization under various monochromatic UV/visible LEDs and IR lamp: Diamino-anthraquinone derivatives as versatile multicolor photoinitiators, Eur. Polym. J. 112 (2019) 591-600.

[141] P. Xiao, F. Dumur, B. Graff, D. Gigmes, J.-P. Fouassier, J. Lalevée, Variations on the benzophenone skeleton: novel high-performance blue light sensitive photoinitiating systems, Macromolecules 46 (2013) 7661-7667.

[142] J. Zhang, N. Zivic, F. Dumur, P. Xiao, B. Graff, D. Gigmes, J.-P. Fouassier, J. Lalevée, A benzophenone-naphthalimide derivative as versatile photoinitiator for near UV and visible lights, J. Polym. Sci. A Polym. Chem. 53 (2015) 445-451. 
[143] K. Wang, Y. Lu, P. Chen, J. Shi, H. Wang, Q. Yu, Novel one-component polymeric benzophenone photoinitiator containing poly (ethylene glycol) as hydrogen donor, Mater. Chem. Phys. 143 (2014) 1391-1395.

[144] G. Temel, B. Enginol, M. Aydin, D. Karaca Balta, N. Arsu, Photopolymerization and photophysical properties of amine linked benzophenone photoinitiator for free radical polymerization, J. Photochem. Photobiol. A: Chem. 219 (2011) 26-31.

[145] A. Allushi, C. Kutahya, C. Aydogan, J. Kreutzer, G. Yilmaz, Y. Yagci, Conventional Type II photoinitiators as activators for photoinduced metal-free atom transfer radical polymerization, Polym.Chem. 8 (2017) 1972-1977.

[146] G. Hou, S. Shi, S. Liu, J. Nie, Synthesis and evaluation of 4-benzophenone methoxyl methacrylate as a polymerizable photoinitiator, Polymer 40 (2008) 228-232.

[147] G.K. Pullen, N.S. Allen, M. Edge, I. Weddell, R. Swart, F. Catalina, S. Navaratnam, Anthraquinone photoinitiators for free radical polymerisation: Structure dependence on photopolymerisation activity, Eur. Polym. J. 32 (1996) 943-955.

[148] L. Breloy, V. Brezová, A. Blacha-Grzechnik, M. Presset, M.S. Yildirim, I. Yilmaz, Y. Yagci, D.-L. Versace, Visible light anthraquinone functional phthalocyanine photoinitiator for free-radical and cationic polymerizations, Macromolecules 53 (2020) 112-124.

[149] M. Tozuka, T. Garashi, T. Sakurai, 1-(Arylmethyloxy)-9,10-anthraquinones: photoinitiators for radical and cationic polymerizations, Polymer J. 41 (2009) 709-714.

[150] J.-P. Fouassier, F. Morlet-Savary, J. Lalevée, X. Allonas, C. Ley, Dyes as photoinitiators or photosensitizers of polymerization reactions, Materials 3 (2010) 5130-5142.

[151] J. Zhang, N.S. Hill, J. Lalevée, J.-P. Fouassier, J. Zhao, B. Graff, T.W. Schmidt, S.H. Kable, M.H. Stenzel, M.L. Coote, P. Xiao, Multihydroxy-anthraquinone derivatives as free radical and cationic photoinitiators of various photopolymerizations under green LED, Macromol. Rapid Commun.39 (2018) 1800172.

[152] D. Tunc, Y. Yagci, Thioxanthone-ethylcarbazole as a soluble visible light photoinitiator for free radical and free radical promoted cationic polymerizations, Polym. Chem. 2 (2011) 2557-2563. 
[153] S. Jauk, R. Liska, Photoinitiators with functional groups, Macromol. Rapid Commun. 26 (2005) 1687-1692.

[154] J. Wei, H. Wang, X. Jiang, J. Yin, Effect on photopolymerization of the structure of amine coinitiators contained in novel polymeric benzophenone photoinitiators, Macromol. Chem. Phys. 207 (2006) 1752-1763.

[155] N.S. Allen, Photoinitiators for UV and visible curing of coatings: mechanisms and properties, J. Photochem. Photobiol. A Chem. 100 (1996) 101-107.

[156] M. Haas, J. Radebner, A. Eibel, G. Gescheidt, H. Stueger, Recent advances in germanium-based photoinitiator chemistry, Chem. Eur. J. 24 (2018) 8258-8267.

[157] J.L. Aparicio, M. Elizalde, Migration of photoinitiators in food packaging: A Review, Packag. Technol. Sci. 28 (2015) 181-203.

[158] A.L. Dawidowicz, R. Typek, M.P. Dybowski, P. Nowakowski, Does the increase of radiation energy really reduce the risk of photoinitiator migration from polygraphic varnish to packed product? The influence of UV radiation dose on the migration of 4phenylbenzophenone from polyacrylate varnish in food packaging, Food Packag. Shelf Life 20 (2019) 100308.

[159] E.A. Kandirmaz, E.N. Gençoğlu, N.K. Apohan, The synthesis of new type ii polymeric photoinitiator (thioxantone) via atom transfer radical polymerization and their curing and migration studies, Macromol. Res. 27 (2019) 756-763.

[160] M.A. Lago, R. Sendón, J. Bustos, M.T. Nieto, P.P. Losada, A. Rodríguez-Bernaldo de Quirós, Migration Studies of Two Common Components of UV-curing Inks into Food Simulants, Molecules 24 (2019) 3607.

[161] J. Zhang, N. Zivic, F. Dumur, P. Xiao, B. Graff, J.-P. Fouassier, D. Gigmes, J. Lalevée, UVviolet-blue LED induced polymerizations: Specific photoinitiating systems at 365,385 , 395 and 405 nm, Polymer 55 (2014) 6641-6648.

[162] N. Zivic, J. Zhang, D. Bardelang, F. Dumur, P. Xiao, T. Jet, D.-L. Versace, C. Dietlin, F. Morlet-Savary, B. Graff, J.-P. Fouassier, D. Gigmes, J. Lalevée, Novel naphthalimideamine based photoinitiators operating under violet and blue LEDs and usable for 
various polymerization reactions and synthesis of hydrogels, Polym. Chem. 7 (2016) 418-429.

[163] J. Zhang, N. Zivic, F. Dumur, P. Xiao, B. Graff, J.-P. Fouassier, D. Gigmes, J. Lalevée, N[2-(Dimethylamino)ethyl]-1,8-naphthalimide derivatives as photoinitiators under LEDs, Polym. Chem. 9 (2018) 994-1003.

[164] J. Zhang, N. Zivic, F. Dumur, P. Xiao, B. Graff, J.-P. Fouassier, D. Gigmes, J. Lalevée, Naphthalimide-tertiary amine derivatives as blue-light-sensitive photoinitiators, ChemPhotoChem 2 (2018) 481-489.

[165] A.-H. Bonardi, S. Zahouily, C. Dietlin, B. Graff, F. Morlet-Savary, M. Ibrahim-Ouali, D. Gigmes, N. Hoffmann, F. Dumur, J. Lalevée, New 1,8-naphthalimide derivatives as photoinitiators for free-radical polymerization upon visible light, Catalysts 9 (2019) 637.

[166] T.G. Ribelli, D. Konkolewicz, X. Pan, K. Matyjaszewski, Contribution of photochemistry to activator regeneration in ATRP, Macromolecules 47 (2014) 6316-6321.

[167] A.-H. Bonardi, F. Bonardi, G. Noirbent, F. Dumur, D. Gigmes, C. Dietlin, J. Lalevée, Freeradical polymerization upon near-infrared light irradiation, merging photochemical and photothermal initiating methods, J Polym. Sci. 58 (2020) 300-308.

[168] A.-H. Bonardi, F. Bonardi, F. Morlet-Savary, C. Dietlin, G. Noirbent, T.M. Grant, J.-P. Fouassier, F. Dumur, B.H. Lessard, D. Gigmes, J. Lalevée, Photoinduced thermal polymerization reactions, Macromolecules 51 (2018) 8808-8820.

[169] S.C. Ligon, B. Husár, H. Wutzel, R. Holman, R. Liska, strategies to reduce oxygen inhibition in photoinduced polymerization, Chem. Rev. 114 (2014) 557-589.

[170] J. Kirschner, J.-M. Becht, J.E. Klee, J. Lalevée, A new phosphine for efficient free radical polymerization under air, Macromol. Rapid Commun. (2020) https://doi.org/10.1002/marc.202000053

[171] F. Morlet-Savary, J.E. Klee, P. Pfefferkorn, J.-P. Fouassier, J. Lalevée, The camphorquinone/amine and camphorquinone/amine/phosphine oxide derivative 
photoinitiating systems: Overview, mechanistic approach, and role of the excitation light source, Macromol. Chem. Phys. 216 (2015) 2161-2170.

[172] W.D. Cook, photopolymerization kinetics of dimethacrylates using the camphorquinone/amine initiator system, Polymer 33 (1992) 600-609.

[173] D.K. Balta, G.Temel, M. Aydin, N. Arsu, Thioxanthone based water-soluble photoinitiators for acrylamide photopolymerization, Eur. Polym. J. 46 (2010) 13741379.

[174] X. Huang, X. Wang, Y. Zhao, Study on a series of water-soluble photoinitiators for fabrication of hydrogels by two-photon polymerization, Dyes Pigm. 141 (2017) 413419.

[175] J. Wang, S. Stanic, A.A. Altun, M. Schwentenwein, K. Dietliker, L. Jin, J. Stampfl, S. Baudis, R. Liska, H. Grützmacher, A highly efficient waterborne photoinitiator for visible-light-induced three-dimensional printing of hydrogels, Chem. Commun. 54 (2018) 920-923.

[176] S. Dadashi-Silab, C. Aydogana, Y. Yagci, Shining a light on an adaptable photoinitiator: advances in photopolymerizations initiated by thioxanthones, Polym. Chem. 6 (2015) 6595-6615.

[177] J. Xing, J. Liu, T. Zhang, L. Zhang, M. Zheng, X. Duan, A water soluble initiator prepared through host-guest chemical interaction for microfabrication of 3D hydrogels via twophoton polymerization, J. Mater. Chem. B 2 (2014) 4318-4323.

[178] J. Zhang, P. Xiao, S. Shi, J. Nie, Preparation and characterization of a water soluble methylated $\beta$-cyclodextrin/camphorquinone complex, Polym. Adv. Technol. 20 (2009) 723-728.

[179] S. Li, F. Wu, E. Wang, A water-soluble supramolecular structured photosensitive initiation system: Me- $\beta-C D$ complex of xanthene dye/aryliodonium salt, Polymer 50 (2009) 3932-3937.

[180] G. Temel, T. Parali, M. Tulu, N. Arsu, Photopolymerization of acrylamide with benzophenone/methylated- $\beta$-cyclodextrin inclusion complex in the presence of 
jeffamine based dendrimers as coinitiators in aqueous media, J. Photochem. Photobiol. A 213 (2010) 46-51.

[181] S. Li, L. Li, F. Wu, E. Wang, A water-soluble two-photon photopolymerization initiation system: Methylated- $\beta$-cyclodextrin complex of xanthene dye/aryliodonium salt, J. Photochem. Photobiol. A 203 (2009) 211-215.

[182] I.C. Alupei, V. Alupei, H. Ritter, Cyclodextrins in Polymer Synthesis: Photoinitiated Free-Radical Polymerization of $\mathrm{N}$-Isopropylacrylamide in Water Initiated by a Methylated $\beta$-Cyclodextrin/2-Hydroxy-2-methyl-1-phenylpropan-1-one Host/Guest Complex, Macromol. Rapid Commun. 23 (2002) 55-58.

[183] L. Ingrassia, F. Lefranc, R. Kiss, T. Mijatovic, Naphthalimides and azonafides as promising anti-cancer agents, Curr. Med. Chem. 16 (2009) 1192-1213.

[184] E.E. Langdon-Jones, A.B. Jones, C.F. Williams, A.J. Hayes, D. Lloyd, H.J. Mottram, S.J.A. Pope, Anticancer, azonafide-inspired fluorescent ligands and their rhenium(i) complexes for cellular imaging, Eur. J. Inorg. Chem. 3 (2017) 759-766.

[185] S. Banerjee, E.B. Veale, C.M. Phelan, S.A. Murphy, G.M. Tocci, L.J. Gillespie, D.O. Frimannsson, J.M. Kelly, T. Gunnlaugsson, Recent advances in the development of1,8naphthalimide based DNA targeting binders, anticancer and fluorescent cellular imaging agents, Chem. Soc. Rev. 42 (2013) 1601-1618.

[186] J.T. Norton, M.A. Witschi, L. Luong, A. Kawamura, S. Ghosh, M. Sharon Stack, E. Sim, M.J. Avram, D.H. Appella, S. Huang, Synthesis and anticancer activities of 6aminoamonafide derivatives, AntiCancer Drugs 19 (2008) 23-36.

[187] G. Gellerman, Recent developments in the synthesis and applications of anticancer amonafide derivatives. a mini review, Lett. Drug Des. Discov. 13 (2016) 47-63.

[188] V.J. Stella, Q. He, Cyclodextrins, Toxicol. Pathol. 36 (2008) 30-42.

[189] R.S. Davidson, Polymeric and polymerisable free radical photoinitiators, J. Photochem. Photobiol. A: Chem. 69 (1993) 263-275.

[190] R.S. Davidson, A.A. Dias, D.R. Illsley, Type II polymeric photoinitiators (polyetherimides) with built-in amine synergist, J. Photochem. Photobiol. A Chem. 91 (1995) 153-163. 
[191] M.-A. Tehfe, F. Dumur, B. Graff, F. Morlet-Savary, J.-P. Fouassier, D. Gigmes, J. Lalevée, Trifunctional photoinitiators based on a triazine skeleton for visible light source and UV led induced polymerizations, Macromolecules 45 (2012) 8639-8647.

[192] J.-P. Fouassier, Photoinitiation, Photopolymerization, Photocuring; Hanser: Münich, 1995.

[193] R. Liska, Photoinitiators with functional groups. V. New water-soluble photoinitiators containing carbohydrate residues and copolymerizable derivatives thereof, J. Polym. Sci. A: Polym. Chem. 40 (2002) 1504-1518.

[194] J.-P. Fouassier, D.J. Lougnot, G. Li Bassi, C. Nicora, Reactivity and excited state processes in a polymeric photoinitiator, Polym. Commun. 1989, 30, 245-248.

[195] A. Rosspeintner, M. Griesser, N. Pucher, K. Iskra, R. Liska, G. Gescheidt, Toward the photoinduced reactivity of 1,5-diphenylpenta-1,4-diyn-3-one (dpd): real-time investigations by magnetic resonance, Macromolecules 42 (2009) 8034-8038.

[196] J. Lalevée, N. Blanchard, C. Fries, M.-A. Tehfe, F. Morlet-Savary, J.-P. Fouassier, New thioxanthone and xanthone photoinitiators based on silyl radical chemistry, Polym. Chem. 2 (2011) 1077-1084.

[197] Y. Chen, J. Loccufier, L. Vanmaele, H. Frey, Novel multifunctional hyperbranched polymeric photoinitiators with built-in amine coinitiators for UV curing, J. Mater. Chem. 17 (2007) 3389-3392.

[198] X. Jiang, J. Luo, J. Yin, A novel amphipathic polymeric thioxanthone photoinitiator, Polymer 50 (2009) 37-41.

[199] G. Yilmaz, B. Aydogan, G. Temel, N. Arsu, N. Moszner, Y. Yagci, Thioxanthonefluorenes as visible light photoinitiators for free radical polymerization, Macromolecules 43 (2010) 4520-4526.

[200] G. Yilmaz, A. Tuzun, Y. Yagci, Thioxanthone-carbazole as a visible light photoinitiator for free radical polymerization, J. Polym. Sci., Part A: Polym. Chem. 48 (2010) 51205125. 
[201] T. Corrales, F. Catalina, C. Peinado, N.S. Allen, Free radical macrophotoinitiators: An overview on recent advances, J. Photochem. Photobiol. A. 159 (2003) 103-109.

[202] L. Angiolini, D. Caretti, C. Carlini, E. Corelli, E. Salatelli, Polymeric photoinitiators having benzoin methylether moieties connected to the main chain through the benzyl aromatic ring and their activity for ultraviolet-curable coatings, Polymer 40 (1999) 7197-7202.

[203] X. Allonas, C. Grotzinger, J. Lalevée, J.-P. Fouassier, M. Visconti, Structure/properties relationships in photoinitiators of polymerization 12. A novel bifunctional compound, Eur. Polym. J. 37 (2001) 897-902.

[204] L. Pouliquen, X. Coqueret, F. Morlet Savary, J.-P. Fouassier, Functionalized polysiloxanes with thioxanthone side groups: a study of their reactivity as radical polymerization macroinitiators, Macromolecules 28 (1995) 8028-8035.

[205] C. Dietlin, J. Lalevée, X. Allonas, J.-P. Fouassier, M. Visconti, G. Li Bassi, G. Norcini, Reactivity and efficiency of difunctional radical photoinitiators, J. App. Polym. Sci. 107 (2008) 246-252.

[206] Z. Raad, E. Ay, O. Dautel, F. Dumur, G. Wantz, D. Gigmes, J.-P. Fouassier, J. Lalevée, Oligomeric photocatalysts in photoredox catalysis: towards high performance and low migration polymerization photoinitiating systems, Macromolecules 49 (2016) 21242134.

[207] M.-A. Tehfe, J. Lalevée, S. Telitel, E. Contal, F. Dumur, D. Gigmes, D. Bertin, M. Nechab, B. Graff, F. Morlet-Savary, J.-P. Fouassier, Polyaromatic chromophores as organophotoinitiator catalysts for efficient visible light induced dual radical/cationic photopolymerization and Interpenetrated Polymer Networks formation, Macromolecules 45 (2012) 4454-4460.

[208] P. Xiao, W. Hong, Y. Li, F. Dumur, B. Graff, J.-P. Fouassier, D. Gigmes, J. Lalevée, Green light sensitive diketopyrrolopyrrole derivatives used in versatile photoinitiating systems for photopolymerizations, Polym. Chem. 5 (2014) 2293-2300.

[209] F. Dumur, Recent advances on carbazole-based photoinitiators of polymerization, Eur. Polym. J. 125 (2020) 109503. 
[210] J. Yang, W. Liao, Y. Xiong, Q. Wu, X. Wang, Z. Li, H. Tang, Naphthalimide dyes: Polymerizable one-component visible light initiators, Dyes Pigm. 148 (2018) 16-24.

[211] J. Yang, Can Xu, Ying Xiong Xiaoling Wang, Yujun Xie, Zhen Li, Hongding Tang, A green and highly efficient naphthalimide visible photoinitiator with an ability initiating free radical polymerization under air, Macromol. Chem. Phys. 219 (2018) 1800256.

[212] T. Lee, C. Guymon, E. S. Jönsson, C. E. Hoyle, The effect of monomer structure on oxygen inhibition of (meth)acrylates photopolymerization, Polymer 45 (2004) 61556162.

[213] K. Sakayori, Y. Shibasaki, M. Ueda, Synthesis of a novel high sensitive photo-radical initiator with good thermal stability based on naphthalic-1,8-N-alkylimide derivatives, J. Polym. Sci. Part A: Polym. Chem. 43 (2005) 5571-5580.

[214] N.S. Allen, T. Corrales, M. Edge, F. Catalina, M. Blanco-Pina, A. Green, Photochemistry and photopolymerization activities of novel phenylthiobenzophenone and diphenylthiophene photoinitiators, Polymer 39 (1998) 903-909.

[215] N. Allen, F. Catalina, P. Green, W. Green, Photochemistry of carbonyl photoinitiators. Photopolymerisation, flash photolysis and spectroscopic study, Eur. Polym. J. 22 (1986) 49-56.

[216] J. Yang, W. Liao, Y. Xiong, X. Wang, Z. Li, H. Tang, A multifunctionalized macromolecular silicone-naphthalimide visible photoinitiator for free radical polymerization, Progress in Organic Coatings 115 (2018) 151-158.

[217] J. Wang, G. Siqueira, G. Müller, D. Rentsch, A. Huch, P. Tingaut, J. LevaloisGrützmacher, H. Grützmacher, Synthesis of new bis (acyl) phosphane oxide photoinitiators for the surface functionalization of cellulose nanocrystals, Chem. Commun. 52 (2016) 2823-2826.

[218] F. Sun, Y. Li, N. Zhang, J. Nie, Initiating gradient photopolymerization and migration of a novel polymerizable polysiloxane (-hydroxy alkylphenones photoinitiator, Polymer 55 (2014) 3656-3665. 
[219] Y. Qi, L. Li, Z. Fang, J. Zhong, Q. Dong, Effects of small molecular weight silicon containing acrylate on kinetics, morphologies, and properties of free-radical/cationic hybrid UV-cured coatings, J. Appl. Polym. Sci. 131 (2014) 40655.

[220] J. Cheng, S. Jiang, Y. Gao, J. Wang, F. Sun, H. Du, Hydrosoluble hybrid and multifunctional polysiloxane-based photoinitiators for initiating gradient photopolymerization of acrylamide aqueous solution, RSC Adv. 4 (2014) 21410-21418.

[221] P. Xiao, F. Dumur, T.- Tuan Bui, F. Goubard, B. Graff, F. Morlet-Savary, J.-P. Fouassier, D. Gigmes, J. Lalevée, Panchromatic photopolymerizable cationic films using indoline andsquaraine dye based photoinitiating systems, ACS Macro Lett. 2 (2013) 736-740.

[222] J. Zhang, F. Dumur, M. Bouzrati, P. Xiao, C. Dietlin, F. Morlet-Savary, B. Graff, D. Gigmes, J.-P. Fouassier, J. Lalevée, Novel panchromatic photopolymerizable matrices: N,N'Dibutylquinacridone as an efficient and versatile photoinitiator, J. Polym. Sci. A Polym. Chem. 53 (2015) 1719-1727.

[223] J. Zhang, N. Zivic, F. Dumur, C. Guo, Y. Li, P. Xiao, B. Graff, D. Gigmes, J.-P. Fouassier, J. Lalevée, Panchromatic photoinitiators for radical, cationic and thiol-ene polymerization reactions: A search in the diketopyrrolopyrrole or indigo dye series, Materials Today Communications 4 (2015) 101-108.

[224] P. Xiao, F. Dumur, J. Zhang, B. Graff, D. Gigmes, J.-P. Fouassier, J. Lalevée, Amino and nitro substituted 2-amino-1H-benzo-[de]isoquinoline-1,3(2H)-diones: as versatile photoinitiators of polymerization from violet-blue LED absorption to a panchromatic behavior, Polym. Chem. 6 (2015) 1171-1179.

[225] P. Xiao, F. Dumur, J. Zhang, B. Graff, D. Gigmes, J.-P. Fouassier, J. Lalevée, Naphthalimide-phthalimide derivative based photoinitiating systems for polymerization reactions under blue lights, J Polym. Sci. A Polym. Chem. 53 (2015) 665674.

[226] P. Xiao, F. Dumur, J. Zhang, B. Graff, D. Gigmes, J.-P. Fouassier, J. Lalevée, New role of aminothiazo-naphthalimide derivatives: outstanding photoinitiators for cationic and radical photopolymerizations under visible LEDs, RSC Adv. 6 (2016) 48684-48693. 
[227] Z. Li, Q. Yang, X. Qian, Novel 2-aminothiazonaphthalimides as visible light activatable photonucleases: effects of intercalation, heterocyclic-fused area and side chains, Bioorg. Med. Chem. Lett. 15 (2005) 1769-1772.

[228] X. Liang, K. Xu, Y. Xu, J. Liu, X. Qian, B1-induced caspase-independent apoptosis in MCF7 cells is mediated by down-regulation of $\mathrm{Bcl}-2$ via p53 binding to P2 promoter TATA box, Toxicol. Appl. Pharmacol. 256 (2011) 52-61.

[229] X. Liang, Y. Xu, K. Xu, J. Liu and X. Qian, B1, a Novel Amonafide Analogue, Overcomes the Resistance Conferred by $\mathrm{Bcl}-2$ in Human Promyelocytic Leukemia HL60 Cells, Mol. Cancer Res. 8 (2010) 1619-1632.

[230] X. Qian, Z. Li, Q. Yang, Highly efficient antitumor agents of heterocycles containing sulfur atom: Linear and angular thiazonaphthalimides against human lung cancer cell in vitro, Bioorg. Med. Chem. 15 (2007) 6846-6851.

[231] X. Liang, A. Wu, Y. Xu, K. Xu, J. Liu, X. Qian, B1, a novel naphthalimide-based DNA intercalator, induces cell cycle arrest and apoptosis in HeLa cells via p53 activation, Invest. New Drugs 29 (2011) 646-658.

[232] Y. Yagci, Photoinitiated cationic polymerization of unconventional monomers, Macromol. Symp. 240 (2006) 93-101.

[233] M.U. Kahveci, A.G. Gilmaz, Y. Yagci, in Photochemistry and Photophysics of Polymer Materials, ed. N.S. Allen, Wiley, USA, 2010, pp. 421-478.

[234] Y. Yagci, S. Jockusch, N.J. Turro, Photoinitiated polymerization: Advances, challenges, and opportunities, Macromolecules 43 (2010) 624-639.

[235] J.V. Crivello, in Dyes and Chromophores in Polymer Science, ed. J. Lalevée, J.-P. Fouassier, ISTE Wiley, London, 2015.

[236] M. Sangermano, N. Razza, J. V. Crivello, Cationic UV-curing: Technology and applications, Macromol. Mater. Eng. 299 (2014) 775-793.

[237] J.V. Crivello, Ring-opening polymerization and special polymerization processes, in Polymer Science: A Comprehensive Reference, ed. K. Matyjaszewski, M. Möller, Elsevier, 2012, vol. 4, pp. 919-955. 
[238] S.P. Pappas, J.H. Jilek, Photoinitiated Cationic Polymerization by Photosensitization of Onium Salts, Photogr. Sci. Eng., 1979, 23, 140-143.

[239] J.L. Dektar, N.P. Hacker, Photochemistry of triarylsulfonium salts, J. Am. Chem. Soc. 112 (1990) 6004-6015.

[240] Y. Yagci, A. Kornowski, W. Schnabel, N-alkoxy-pyridinium and N-alkoxy-quinolinium salts as initiators for cationic photopolymerizations, J. Polym. Sci. Part A: Polym. Chem. 30 (1992) 1987-1991.

[241] S. Denizligil, Y. Yagci, C. McArdle, Photochemically and thermally induced radical promoted cationic polymerization using an allylic sulfonium salt, Polymer 36 (1995) 3093-3098.

[242] J.V. Crivello, S.Q. Kong, Synthesis and characterization of second-generation dialkylphenacylsulfonium salt photoinitiators, Macromolecules 33 (2000) 825-832.

[243] Y.Y. Durmaz, N. Moszner, Y. Yagci, visible light initiated free radical promoted cationic polymerization using acylgermane based photoinitiator in the presence of onium salts, Macromolecules 41 (2008) 6714-6718.

[244] J.V. Crivello, Radical-Promoted Visible Light Photoinitiated Cationic Polymerization of Epoxides, J. Macromol. Sci. Part A Pure Appl. Chem. 46 (2009) 474-483.

[245] U. Bulut, G.E. Gunbas, L. Toppare, A quinoxaline derivative as a long wavelength photosensitizer for diaryliodonium salts, J. Polym. Sci., Part A: Polym. Chem. 48 (2010) 209-213.

[246] G. Liu, X. Zhu, B. Xu, X. Qian, G. Song, J. Nie, Cationic photopolymerization of bisphenol A diglycidyl ether epoxy under 385 nm, J. Appl. Polym. Sci. 130 (2013) 3698-3703.

[247] O.S. Taskin, I. Erel-Goktepe, M. Alyaan, A. Khan, S. Pispas, Y. Yagci, Polystyrene-bpoly(2-vinyl phenacyl pyridinium) salts as photoinitiators for free radical and cationic polymerizations and their photoinduced molecular associations, J. Photochem. Photobiol. A 285 (2014) 30-36.

[248] J.V. Crivello, J. Ma, F. Jiang, Synthesis and photoactivity of novel 5-arylthianthrenium salt cationic photoinitiators, J. Polym. Sci., Part A: Polym. Chem. 40 (2002) 3465-3480. 
[249] W. Teshima, Y. Nomura, A. Ikeda, T. Kawahara, M. Okazaki, Y. Nahara, Thermal degradation of photo-polymerized BisGMA/TEGDMA-based dental resins, Polym. Degrad. Stab. 84 (2004) 167-172.

[250] J.H. Zhang, Q. C. Liu, Y.-M. Chen, Z.-Q. Liu, C. W. Xu, Determination of acid dissociation constant of methyl red by multi-peaks Gaussian fitting method based on UV-visible absorption spectrum, Acta Phys.-Chim. Sin. 28 (2012) 1030-1036.

[251] P. Garra, B. Graff, F. Morlet-Savary, C. Dietlin, J.-M. Becht, J.-P. Fouassier, J. Lalevée, Charge transfer complexes as pan-scaled photoinitiating systems: from $50 \mu \mathrm{m} 3 \mathrm{~d}$ printed polymers at $405 \mathrm{~nm}$ to extremely deep photopolymerization $(31 \mathrm{~cm})$. Macromolecules 51 (2018) 57-70.

\section{Conflicts of interest}

The authors declare no conflict of interest.

\section{High-performance Visible light photoinitiators}

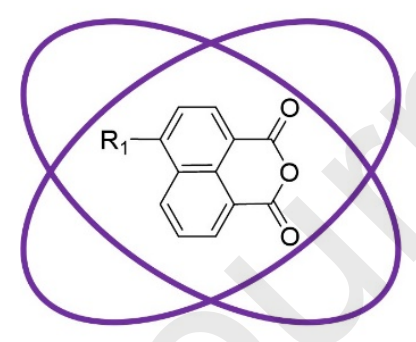

Naphtalic anhydrides
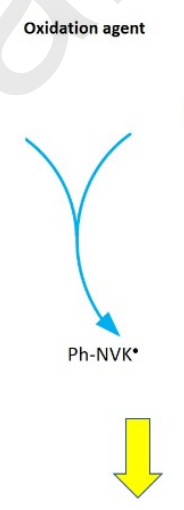

FRP

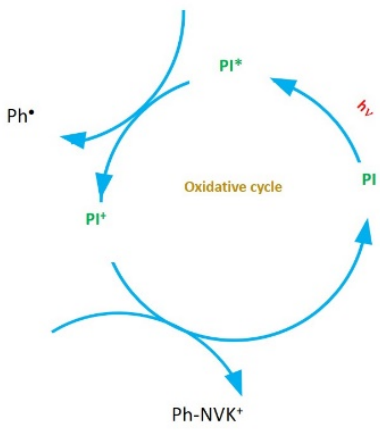

Ph-NVK+

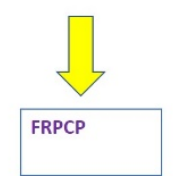

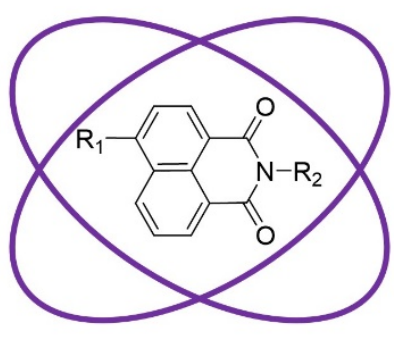

1,8-Naphtalimides 